NOTE TO USERS

This reproduction is the best copy available.

UMI 



\title{
Aboriginal Mental Health or \\ The Good Mind Model Ka'nikonhrì:io \\ From a Haudenosaunee point of view
}

\author{
By \\ Holly "Karennenha:wi" Brant \\ HBA Laurentian University
}

A Thesis Submitted to the Faculty of Graduate Studies and Research

in partial fulfillment of the requirements for the degree of

Master of Social Work

\author{
School of Social Work \\ Carleton University \\ Ottawa, Ontario
}

(c) Copyright

2009 , Holly Brant 
Library and Archives

Canada

Published Heritage Branch

395 Wellington Street

Ottawa ON K1A ON4

Canada
Bibliotheqque et

Archives Canada

Direction du

Patrimoine de l'édition

395 , rue Wellington

Ottawa ON K1A ON4

Canada
Your file Votre référence

ISBN: 978-0-494-60243-0

Our file Notre reférence

ISBN: 978-0-494-60243-0
NOTICE:

The author has granted a nonexclusive license allowing Library and Archives Canada to reproduce, publish, archive, preserve, conserve, communicate to the public by telecommunication or on the Internet, loan, distribute and sell theses worldwide, for commercial or noncommercial purposes, in microform, paper, electronic and/or any other formats.

The author retains copyright ownership and moral rights in this thesis. Neither the thesis nor substantial extracts from it may be printed or otherwise reproduced without the author's permission.
AVIS:

L'auteur a accordé une licence non exclusive permettant à la Bibliothéque et Archives Canada de reproduire, publier, archiver, sauvegarder, conserver, transmettre au public par télécommunication ou par l'Internet, prêter, distribuer et vendre des thèses partout dans le monde, à des fins commerciales ou autres, sur support microforme, papier, électronique et/ou autres formats.

L'auteur conserve la propriété du droit d'auteur et des droits moraux qui protège cette thèse. $\mathrm{Ni}$ la thèse ni des extraits substantiels de celle-ci ne doivent être imprimés ou autrement reproduits sans son autorisation.
In compliance with the Canadian Privacy Act some supporting forms may have been removed from this thesis.

While these forms may be included in the document page count, their removal does not represent any loss of content from the thesis.
Conformément à la loi canadienne sur la protection de la vie privée, quelques formulaires secondaires ont été enlevés de cette thèse.

Bien que ces formulaires aient inclus dans la pagination, il n'y aura aucun contenu manquant. 
The undersigned recommend to the Faculty of Graduate Studies

And Research acceptance of the thesis

\title{
" Aboriginal Mental Health or
}

The Good Mind Model Ka'nikonhrì:io

From a Haudenosaunee point of view"

\author{
submitted by Holly Brant \\ in partial fulfillment of the requirements for \\ the degree of Master of Social Work
}

Adje van de Sande

Cynthia Wesley-Esquimaux

Thesis Supervisor

Thesis Supervisor

Hugh Shewell

\author{
Director, School of Social Work \\ Carleton University
}

September 2009

Date 
This is dedicated to my daughter Shannon. 


\begin{abstract}
Ka'nikonhrì:io or The Good Mind Model

The Haudenosaunee (Mohawk) Good Mind Model is a mental health model that originated hundreds of years ago as a way to balance the emotional, spiritual and mental needs of the Long House People. Historically, the Haudenosaunee had many different types of techniques to heal from loss, grief, and trauma because knowledgeable people and elders were available to pass on traditions, ceremonies, language, culture, customs, values, governance systems, and healing practices. In the past five hundred years, oppressive legislation, aggressive assimilation practices and colonialism have thwarted traditional practices. This paper speaks to why it is important to return to traditional healing modalities in our communities. It also suggested that a thoughtful blend of 'wise practices' as outlined by the Mohawk people themselves, and a blending of traditional modalities can contribute to a flexible model that can have utility for many people. The "Good Mind" model has demonstrated utility and practicality and is currently being practiced effectively on the Tyendinaga Mohawk Territory, Ontario.
\end{abstract}


Acknowledgements

I would like to thank Cynthia Wesley Esquimaux, a professor at the University of Toronto, without whose help this paper would not have been possible. She never knew me at all and when I reached out for help, she was there. She provided encouragement, laughter, patience, precious time, expertise in the academic world and references to help me along with this journey. She stood beside me never wavering and always sought options that fit for me. She clearly went out of her way to help and advise even in her already busy world. For that I will be always be grateful.

Nine years ago if you asked me I would be doing my graduate work I would have laughed out loud. Without the encouragement from Mac Saulis a professor at Sir Wilfred Laurier he believed in me even though he never knew me either. He squared my shoulders and gently pushed me to pursue graduate work; he knew then what I was not sure of and stood beside me when the tough got going. When the tough got going and it did he reminded me of who I am and reminded me to use my voice, he reminded me about strength and always offered options. For that I will be always be grateful.

Many years ago was the first time I heard Jan Longboat talk. She provided Haudenosaunee teachings and I was always mesmerized about her gentle approach and stories. She is a rich source of information. I was able to reach out to her when I was unclear about translating our ideas into a mainstream paradigm and she provided guidance, clarity, support, genuine caring, laughter and helpful advice. She offered her guidance and support and when I was not sure she cleared fog away and reminded me about resilience and being a Haudenosaunee woman. For that I will be always be grateful.

Much of my research has focused on healing and I turned to the Aboriginal Healing Foundation for sources and references. I found the information to be extremely helpful on my academic journey. With Cynthia's help she was able to recruit Mike DeGagne who works at the Aboriginal Healing Foundation to be my Third Reader for my thesis. I was thrilled that he accepted, once more a gentleman who did not know me, but was willing to help out just because. I can not express how excited that I am to have these people help me with this project, their input, guidance, support and advice really made this paper.

To Chief and Council of the Tyendinaga Mohawk Territory for believing in me. Nine years ago, I did not think they thought I could do it, but they were willing to give me a try. I proved them right in their decision. I have been funded by our Band and am extremely grateful; I will, if allowed continue to give back to my community.

Lastly to my boyfriend; Ky Maracle, my daughter Shannon Butcher and my family. They supported me when I was down, up, sideways, busy and cranky. I had very little time in the last 2 years for them but they have been supportive and loving and put their needs second. I will always remember that, their sacrifice for supporting me and the unconditional love.

In peace and gratefulness,

Holly Karennenha:wi Brant 
Ka'nikonhrì:io or The Good Mind Model Introduction

p. 1

Research Question

p. 2

Historic Trauma

p. 2

Historical Trauma

p. 7

Contact and Colonialism

p. 8

Physical Impact

p. 8

Economic Impact

*p. 9

Social Impact

p. 14

The Indian Act

p. 15

The Legacy of the Residential Schools

p. 15

The Sixties Scoop

p. 18

Residential Students, the Apology and Aboriginal Child Welfare

p. 19

Psychological /Cultural Trauma

p. 22

Spiritual Impact

p. 24

The Good Mind Model

p. 25

Cultural / Environmental / Personal Safety

p. 26

Environmental Safety

p. 27

Personal Safety

p. 27

Sweat Lodge Ceremony

p. 28

Fasting

p. 28

Circles

p. 29

Unburdening

p. 33

Spirituality

p. 34

Spiritual forces-spiritual energy-medicines, Medicine People

p. 35

Spiritual Rituals

p. 36

Ceremonies

p. 38

The Condolence Ceremony

p. 39

Using Traditional Medicines

p. 40

Physical Relaxation Process

p. 41

The Inclusion of Family

p. 42

Healing With A Type of Psychoanalytic Theory

p. 43

Trauma \& Memory

p. 44

Complex Post Traumatic Stress Disorder

p. 46

Residential School Syndrome

p. 47

Attachment Theory

p. 48

Trauma or Bereavement

p. 49

Treatment

p. 50

The Good Mind

p. 51

A Crooked Mind/Not A Good Mind

p. 56

Legends as Example of the Good Mind and the Crooked Mind

p. 60

Literature Review

p. 63

The Mohawk Creation Story

p. 65

The Analysis of the Creation Story

p. 70

Women and Men: The Different Genders

p. 71 
Thanksgiving Address/Opening Address or Ohen:ton The words that came before all else p. 73 The Legend of Deganawidah: The Peace Maker

p. 75 The Four Sacred Beings

p. 75

The Legend of Deganawidah: The Peace Maker continues

p. 77

Hiawatha

The Analysis of Deganawidah's Legend

p. 80

The Code of Handsome Lake

p. 84

The Great Law of Peace or The Constitution of the Five Nations

p. 87

The Elders Voices

p. 88

Moving Forward: Closing the gap of Knowledge

p. 96

Methodologies

p. 99

Method for Secondary Data

p. 100

Results

p. 104

Responses about Mental Health Pie Chart

p. 105

Goals and Expectations Pie Chart

p. 107

What was most helpful of your healing journey? Pie Chart

p. 109

What new skills did you learn? Pie Chart

p. 110

Analysis

p. 111

Conclusion

p. 111

p. 112 


\section{Glossary of Terms}

Atotárho was placed the Head of Chiefs of all the five Nations of the League. He was twisted and he was crooked in his mind. It is said he was so wicked that he had a twisted body, his mind looked for trouble and he even had snakes in his hair. He looked to fight and continued to eat the flesh of humans. After his transformation he became became Spiritual Leader of the Grand Council of the Haudenosaunee

Ayowenta (Hiawatha) "man who eats humans"

Client means Participant

Handsome Lake or Skanyatarí:yo

Haudenosaunee is a Cayuga word, Mohawks originally said Rotinonhysón:ni or could be spelled Rotinonhson:ni but Haudenosaunee is recognized across Turtle Island, means they build a house which is the explanation of People of the long house.

He-Earthholder and his other names were Hoda'he', He Has a Standing Tree, or Keeper of the Standing Tree.

Helper means counsellor

Iroquoian or the people of the Longhouse or Mohawk, Iroquois

ka'nikonhrìio means Good Mind more than aboriginal mental health

Native people means First Nations, Aboriginal, Indigenous, Indians in the Americas, Native Americans

Original People or Onkwehon:we, Mohawks of the Bay of Quinte or Kanyen'heha:ka (People of the Flint or Keepers of the Eastern Door), Mohawk

Seth Newhouse or Dayodekane

Shonkwaya'tíhson (Creator) He who Created Us, Great Spirit Shonkwaya'tíhson

sken:nen, peace, tranquility

Thanksgiving Address/ Opening Address or Ohen:ton, The words that come before all else Ohento Kariwentehkwen'

Tharonhyawá:kon "He Embraces the Sky" and Shawískara "Mischievous One" with obvious connotations to their personalities. 


\section{Glossary of Terms}

Tharonhyawá:kon made beautiful things like the rose, Shawískara would put thorns on the stem.

The Great Law, Kayanerekowa is the same as Kayanere'kó:wa.

The Great Law of Peace or The Constitution of the Five Nations

The Iroquois Confederacy "Rotinonhsyon:ni" we are; Mohawk, Oneida, Onondaga, Cayuga, Seneca Nations and the Tuscarora who joined later in 1710 to form the Six Nations Confederacy or the Haudenosaunee Confederacy (Wallace, 1994). Or our ancestors, Iroquois nations

Three Sisters is corn, beans and squash

Tsikónhsase (pronounced Jigonsashe). Was also known as the Head League Clan Mother or the Mother of All Nations 


\section{Ka'nikonhrì:io or The Good Mind Model}

This thesis will describe an aboriginal mental health model that is currently being used on Tyendinaga Mohawk Territory, Ontario. It will describe the Good Mind Model and illustrate how it functions as a framework for mental health treatment and care. It will demonstrate the genesis and traditional underpinnings for the Good Mind and how historically this concept has evolved. The thesis will provide an overview of how forces in historical and modern native life have moved many native people away from a state of good mind. The research and questionnaire analysis demonstrates that the Mohawks of the Bay of Quinte still see mental health within the good mind framework, and consequently they value treatment which supports the renewal of the good mind model. This is a living, practical way of approaching native mental health.

This good mind concept is centuries old and has been used by First Nations people since the beginning of time. It will explicate and define an Iroquoian concept and framework for healing; a concept our people refer to as "good mind" (Parker, 1916). The concept of good mind constitutes a mental health and healing model that falls under the rubric of "wise practices" in Aboriginal traditional knowledge (Thoms, 2007, p. 9). It will discuss where various forms of mental distress plaguing contemporary Haudenosaunee people originated from and how today we are healing and revitalizing our culture by returning to our teachings (Porter, 2006; Longboat, Aug. 2008). This paper will delineate the pathways of contemporary mental/psychological, psychogenic dis-ease in the Iroquois community at large, and will explain each treatment modality utilized to instill a "good mind" in more detail. We believe that a revitalization and use of traditional treatment techniques are necessary for addressing the present healing needs of the 
Haudenosaunee ka'nikonhrìio. In this light, the basis of this thesis looks at what becomes a possibly controversial, yet natural conclusion:

\section{Research Question: Can the Haudenosaunee historical paradigm of the "Good Mind"} healing model be resurrected and reconstituted, to reflect a valid mental health healing and treatment model that revitalizes Haudenosaunee health and provides utility today?

This thesis will challenge the ideology that deems anything outside of the western medical model as inconsequential or invalid. It will explicate the many ways that Indigenous wise practices and healing modalities have utility and value for cross cultural understanding and helping models. The Haudenosaunee believe in the efficacy of their healing practices and continue to grow stronger in putting forth their culturally based healing methods as valid and legitimate. After all, the Haudenosaunee continue to flourish and raise their children with their own culture. They are becoming increasingly confident that they can share their healing methods because they are transferable and useful to others when given due consideration.

The Mohawk people have many different names. The Haudenosaunee (the people of the Longhouse) or Onkwehón:we "the original people" (Butcher, 2007), and the Iroquois or more specifically the Kanyen'heha:ka (People of the Flint or Keepers of the Eastern Door) (Wallace,1946). Within the Onkwehón:we are other Nations, but specifically within the Iroquois Confederacy "Rotinonhsyon:ni" we are; Mohawk, Oneida, Onondaga, Cayuga, Seneca Nations and the Tuscarora who joined later in 1710 to form the Six Nations Confederacy or the Haudenosaunee Confederacy (Wallace, 1994).

\section{Historic trauma}

Historic trauma or what are regarded as non medical health determinants or perhaps even more simply put; the root causes of pain for the Haudenosaunee will be explored throughout the 
text and historic narratives. The Haudenosaunee have had to endure many types of trauma throughout their existence. We are increasingly aware that trauma that is not dealt with will layer itself like an onion and have the ultimate effect of mental and emotional poison which will contribute to imbalance in all four quadrants of peoples lives (Out of the shadows, 2006). Unfortunately the suppression of extreme sorrow or rage can lead to illness. To mask feelings, suppress anger or attempt to hide genuine feelings can cause incongruence and conflict in self and can erupt on its own or under the influence of alcohol. The eruption can lead to violence to unsuspecting individuals and misdirected anger (Brant, 1990). The strong characteristic of the abuse of alcohol is to dull feelings or to stultify the bad feelings for the life of the high. The problem is the feelings return when the intoxication is gone and the psychological pain returns along with anew feelings of guilt and decreased self efficacy (Saunders \& Houghton, 1996). Interestingly Norman et al wanted to know the characteristics of relapse in their study with people who have a history of trauma but who did not exactly fit the criterion in the DSM for PTSD and have "substance use disorders" (2007, p. 89). It was already mentioned that alcohol can have a numbing effect; it is often used as a coping mechanism, to self medicate (Walton, et at. 2000; Norman et al, 2007). Therefore, the magnetism to escape from their pain of loss and to dull any psychological pain through alcohol can appear quite enticing. With the history of trauma some Indigenous people did not exactly fit the criterion for PTSD as noted earlier in this thesis. Norman et al. (2007) found that people who do present with a history of trauma and substance use disorders should be taken under consideration for future addiction relapse clinical consideration. This type of information is significant for future health considerations. 
What has been referred to as "an attempt of cultural genocide" (Morrissette, 1994, p. 381) of First Nations people has been North America's most "embarrassing and suppressed subject" (ibid, p, 381). Unresolved trauma can have devastating effects on the mind and body (Diamond, 2004; Stamm, et al, 2003) and the Haudenosaunee people, like many others, have had to deal with the effects of; colonialism, the Indian Act, the legacy of the residential school system, the sixties (adoption) scoop, made and broken treaties, and inter-generational domestic trauma (Kirmayer, Simpson \& Cargo, 2003). The struggle of the people to resist oppression and the exploitation of their land is a part of the history of all First Nation's people in the country that is now called Canada.

Over the last several generations the Haudenosaunee have been able to pick out root causes of historic trauma and pain from past events. My thesis will examine the effects that have compounded and become embedded in our culture as a result of intergenerational trauma. We are aware at our shelter that alcoholism, drug dependence, gambling and the inability to deal with emotional pain in a healthy way has been thwarting healing and wellness (Johnson \& Camerson, 2001). When the old healing ways through ceremony and teachings were taken or legislated away by the Canadian government, the Haudenosaunee no longer had effective or accessible healing methods. The people were forced to languish in pain because many of the old ceremonies went underground to preserve them (Hodgson, 1990) and were not readily available anymore to the larger common population. Many of the old responsibilities were taken away from the people due to these laws, roles that entailed caring for Mother Earth as well as themselves and their families; and as a result the Haudenosaunee people now believe they have failed to protect the earth or each other. Another example of historic and unresolved hurt occurred when children were taken away from homes and communities and placed in residential 
schools (Kirmayer, et al, 2003; AHF, 2002); the parents believed they failed to protect their most precious bundles, their children, from harm (Stamm, et al, 2003; Hodgson, 1990).

Perceived failure compounded with real failure has resulted in what has been termed complex post traumatic stress disorder (Herman, 1997), where an entire cultural community, rather than solely individuals are deeply damaged by; fear, helplessness and horror. All of which are components of what was experienced during painful historic and as yet unresolved events (Wesley-Esquimaux, 2004). Some of the very same criterion is recognized in the Diagnostic and Statistical Manual IV. One component that is missing is the forced silence that was inflicted on children at the residential schools (Corrado \& Cohen, 2003). The children were threatened with abuse if they talked, laughed or tried to speak in their own language (AHF- A healing journey, 2006). We have elders that had those personal experiences and they note that, "when our voices were taken away, we really began to get sick" (Longboat, Aug. 2008). That deeply embedded fear of expression began with children as young as six years old in some places (ibid) and continued in adults into very late ages affecting their ability to communicate in intimate relationships or raise children in a loving and expressive home.

Traditional practitioners understand the need to listen to the people, learn the history, to be compassionate, to acknowledge spirituality, and remain flexible enough to work with families and communities. In the good mind model, these relatively simple steps encompass the tried and true treatment and healing modalities that work well with Aboriginal people. One question on the minds of many people is whether the good mind model, once fully revitalized and reconstituted, will work as well as it did historically for the Haudenosaunee. Can this model provide an avenue to healing and promoting a good "mental health model" in our communities today? We say yes to both questions. 
Utilizing our traditional teachings on "Good Mind" has already started to shift the entire treatment orientation of our shelter, our community, and the revitalization process has already begun. Therefore, I am able to state with clarity the mechanisms and evidence based "wise practices" (Thoms, 2007, p. 9) that have been carried forward by the healers in our Iroquois nations, and that inform the development and maintenance of a good mind state, (Porter, 2008). I can demonstrate how recognition and implementation of the good mind model of treatment is essential to the future health and well-being of our people. None of the ideas presented in this paper will be new; rather this discussion reveals a revitalization of our past healing methods coupled with and enhanced by evolving knowledge and treatment practices.

These techniques can include; sweats (as an example the term 'sweats' refer to what is known as a sweat lodge ceremony, cleansing through heat and steam in a sweat lodge), fasting (voluntary giving up of food), and circles (people sitting together equally and sharing), both healing and educational, ceremonies (spiritual rituals), using traditional medicines (plant and herbal concoctions), unburdening (naming and feeling pain and experience), cleansing (through sweat or bathing with cedar boughs), and a physical relaxation process (meditation and healthy sleep cycles). The inclusion of the family and community as directed by the person seeking the healing is equally important. Each one of these techniques or methods has been used throughout time to holistically address the physical, mental, emotional and spiritual aspects of the people and ensure the presence of what we know to be a good mind (Brant, 2004). Traditional ceremonies are a way to use reflection and introspection as healing tools. The expression of honesty and genuineness is considered paramount and becomes a prerequisite for participation. Sometimes the season plays a role, but always the reason or the readiness of the individual in the moment is respected. Full knowledge of relevant teachings by the counselor is necessary to 
properly employ each technique, and each treatment step is a prelude to participating in an overall healing experience in which all participation is considered voluntary.

\section{Historical Trauma}

Dr. Cynthia Wesley-Esquimaux (2004) has written that historical trauma and intergenerational grief has impacted Indigenous people in six specific areas; physical, economic, social/cultural, psychological, and perhaps most importantly, spiritually. The first stage of impact was contact with the European people and the beginning of infectious diseases which decimated Indigenous populations across the entire continent. People were also economically devastated by their forced removal from the land they cultivated and hunted on. The second stage was prompted through the cultural and "religious transformation" imposed by missionaries that led Aboriginal people away from traditional practices and knowledge bases. The social and cultural effects were caused by the displacement of and silence of "knowledgeable" Aboriginal peoples and the introduction of unknown and alien social structures and societal norms. All of these changes inadvertently damaged individuals and families. The third stage was marked by psychological/cultural oppression and marginalization. People experienced a massive loss of personal control and self-efficacy to the colonizers. Finally, and perhaps most devastating was the fourth stage of impact on spiritual practice and knowledge which changed the entire internal structure of Native praxis and mental health. Wesley-Esquimaux writes that the present spiritual stage contains the movement to wellness, reclamation of traditional values, and a reassessment of the truth and legitimacy of the original teachings of the people, by the people, just as Rupert Ross wrote about in his book, Returning to the Teachings (Ross, 1996). 


\section{Contact and Colonialism:}

In order to explain historical trauma it is important to establish some time frames within which to contextualize the material. Chronological order would appear the best approach to explaining the written history that flowed from the lived experience of Indigenous populations on this continent. What will be challenged will be the interpretation of that written history. More specifically, the challenge will not be that the events took place, but rather that the analysis of the event and the outcomes have been skewed over time to validate the subsequent marginalization of Native peoples. This particular section will discuss the discourse that establishes a chronological order of events that occurred to Indigenous people, and that collectively caused overt destruction with rippling effects to the Mohawks of the Bay of Quinte; in essence, the direct experience of historical trauma.

\section{Physical Impact}

In Sale's book entitled The conquest of paradise, Christopher and the Colombian legacy, (1990) he contended that Christopher Columbus brought suffering and devastation to the Indigenous people. Diamond writes that not only were Native Americans killed by the conquests of Columbus but also most devastatingly the "murderous Spanish microbes" that brought smallpox, flu, plague and tuberculosis would forever change the number of Native Americans $(1999$, p.197). When Columbus 'discovered' Indigenous people over 500 years ago in 1492 he erroneously named them "Indians". Prior to Columbus 'discovering those Indians' in the Americas Indigenous people were alive and inhabiting Mother Earth on what we referred to as Turtle Island (Porter And Grandma Said, 2008).

According to Stamm et al. (2003) and Rogers (2001) First Nations had advanced social and political governance, a well advanced culture, languages, spiritual traditions and stability in 
their health, until Europeans came to the North American continent. This does not mean that there were no illnesses experienced by Indigenous people; what is known is that Indigenous people knew their climate, knew the seasons, knew how to grow food, knew how to make medicines from the plants that grew around them when they did fall ill and they could survive a variety of illnesses (Porter, 2004; Porter, 2006; Isaacs, 1976).

After Columbus a flurry of Europeans came to the North American continent. The British Explorer James Cook brought along with him ideas foreign to Indigenous people such as capitalism, but more destructively, he brought new diseases never before witnessed by Indigenous people (Trask, 1993). Unfortunately, they were ill equipped to deal with these new diseases, and this timeframe became a marker for the physical trauma of infectious diseases on the chronological chart.

\section{Economic Impact}

With the influx of European people from Dutch, British or French colonies, the ideas of colonialism, imperialism, and capitalism flourished. The variety of people only mattered when they were able to wrest control of a particular region from the Indigenous population and establish political reign. It can be argued that imperialism "started in the fifteenth century" (Tuhiwai Smith, 2000 p. 21) although the earlier "economic expansion of Europe" really became the primary tool to subjugate Indigenous people (ibid, p, 21). Along with the economic expansion of Europe came ideas of a new form of capitalism, forced and inexpensive labour, land acquisition and the piling up of money. In England and in France up until the time of the Great Revolution in 1789 land ownership was a social privilege (Polanyi, 1957). These ideas were foreign to the Indigenous people of this continent; they believed that Mother Earth was not something to be owned or held privately and accessed only by the privileged. Neither owning 
"land" nor the "privileged" concepts made sense to the Indigenous people. "Land was sacred," and no one could own it or remove it from collective use. The Haudenosaunee understood women to be the heirs of Mother Earth and that women were the caretakers of it. The Earth was seen as sacred; it also held deep spiritual significance to the Haudenosaunee (Mann, 1997, Kayanerekowa). There was no such concept as the "privileged" in their longhouses either, as everything and everyone on the Mother Earth were equal. To the Haudenosaunee there were to be no class systems or hierarchies to separate the people from the richness of the land and her many resources (RCAP v.3, 1996).

Mohawk Valley near Albany New York was the homeland of the Mohawks when the American Revolution began. On the chronological map the mid 1700's mark the time when the Haudenosaunee had to flee their ancestral homeland (Porter, 2006). The Mohawks of the Bay of Quinte stayed loyal to the British Crown and it also marked the start of our economic devastation, and the removal and sale of our lands. Sir William Johnson was one of the most successful Indian Agents in North America. He stayed close to the Mohawks and even married Molly Brant, sister of Joseph Brant, a pro-British supporter, and leader of the Mohawks (Porter, 2006; Mohawk, 1993). Not surprisingly at the time of his death Sir William Johnson was to have amassed one hundred thousand acres; more acreage than the entire Simcoe Deed of 1793 that was given to the Mohawks of the Bay of Quinte (Mohawk, 1993; Indian Treaties and Surrenders Vol. 1, 1891). At the end of the American Revolution, some Mohawks followed Joseph Brant to present day Hamilton and other Mohawks joined their brethren in Akwesasne where a community has been established in 1755; Captain John Deserontyon lead his followers to Tyendinaga in May of 1784 (Mohawk, 1993; MBQ www.mbq-tmt.org 2009; Porter, 2006). 
Present day Mohawks of the Bay of Quinte still do a re-enactment of the Landing of the Mohawks in May as a way to celebrate our heritage and coming to these lands.

Although the Haudenosaunee knew no one could own land, they were living in a world where they quickly learned they could be kicked off their homeland or killed if they stayed on land that was not deemed 'theirs'. Our ancestors did understand the concept of survival. As a result of staying loyal to the British Crown and as compensation, our ancestors were offered land in Canada. Under Treaty Three and one half, known as the Simcoe Deed we were promised a tract of land that measured approximately ninety two thousand seven hundred acres, of those lands there are approximately eighteen thousand acres remaining in our hands (Indian Treaties, 1891; Maracle, 2009). At present day 2009 we are in a land dispute over a specific tract of land called the Culbertson tract. We contend we own it, and that it was taken away illegally. The Mohawks of Tyendinaga are one of many First Nations in these present day land disputes across Canada (MBQ Research Dept, www.mbq-tmt.org 2009). Our land has been taken and eroded away with little regard to the treaties; this is yet another marker of our economic downturn. We fled our homeland in the mid 1700's and people who do not understand the history and what happened behind the scenes say, "you lost, that was a long time ago, get over it", but in fact the losses continue into the present day, so how can we forget it? As many Indigenous scholars are now stating unequivocally, "coming to know the past has been part of the critical pedagogy of decolonization" (Tuliwai Smith, 2000, p. 34), and learning to fight for what is right.

For the Haudenosaunee there is no difference between land and the environment. The Haudenosaunee got their medicines, food and trade from the land (RCAP v.3, 1996). The land was seen as sacred because our very sustenance depended on it. When the market trade came to North America and precious resources were raped from Mother Earth, for example the clear 
cutting of trees; the rupture between the spirituality of the land and the people started, the people began to lose that familiar tie that once held the fabric of the community/nation together (ibid). This loss had been prophesized earlier by Haudenosaunee, it is said that when we forget to give thanks, when we do not to treat Mother Earth with respect, when we stop listening to the natural guidance of the animals, Mother Earth will stop providing what she had been instructed to do (Porter, 2008). “...to the Haudenosaunee, the Good Mind and land are inseparable for neither is possible without the other" (Sheridan \& Longboat, 2006, p. 378).

When the Haudenosaunee were given the Thanksgiving Address, we were taught to be respectful of everything on Mother Earth, we were taught to give thanks and to send greetings to everything on Mother Earth. We were taught that everyone was equal and no one should have complete reign over another culture. This is most aptly demonstrated by the Two Row Wampum Belt between the Haudenosaunee and the Dutch of 1613 (FNTI, 2008). It was one of the first treaties (Gaswëhta') the Haudenosaunee made on record. Tehanetorens wrote that before glass beads were introduced by the "white people" $(1972$, p. 3$)$ that wampum belts were made with porcupine quills or the round clam shells from Atlantic coastal waters. The Two Row Wampum was made of beads and the background was white to symbolize the purity of the agreement with two parallel horizontal purple lines that ran from one side to the other. The purple lines represented each culture and each understood that while they were of different cultures they were equal brothers and that neither side would interfere with the other's laws. One purple line represented the Dutch in their ship and the other purple line represented the Haudenosaunee in their canoe. Collectively with the three white lines the wampum belt was the agreement that signified both cultures will live side by side in peace, equality and respect (Tehanetorens, 1972). This belt was about relationships, which is significant, because it expressed the ability of Good 
Minds to come together. Wampum was also used for official and sacred ceremonies, to seal a pledge, or make a contract or agreement; it could also show title, for example the female in the family had the right to bestow the chieftain title (Kayanerekowa). The Two Row Wampum Belt was assembled after contact to record the event.

Shortly after the Two Row Wampum belt was constructed the first missionary school opened near Quebec City in 1620 - 1629 (AHF Research Series, 2008). The struggle to remain autonomous and the struggle to live together in harmony was the dichotomy that set the stage for the unfolding of history. Wampum was a way to record history, history was not written down by the Haudenosaunee, but if the wampum belt was held by its keeper, it was a way to validate any event it was meant to record. The Great Law was not written down originally; it was in the wampum, it was observed as sacred. According to Rick Hill every Nation had a wampum keeper and the Haudenosaunee's was the Onondagas, Keepers of the Fire, or People of the Hills (FNTI, 2008).

The other significant wampum belt arrived via the Covenant Chain or Friendship Belt in 1677; it was to signify a peaceful relationship between the English and the Haudenosaunee (Muller, 2007). Tehanetorens however has written that the Friendship Belt was between the Ojibway and the Iroquois (Tehanetorens, 1972). Regardless of the nations involved, the belt symbolized peace between the parties. On the left side of the belt was a Haudenosaunee who was dropping the war club as a sign of peace, connected by a horizontal line on the right hand side of the belt, the English person had both hands down but was still clinging to the horizontal line that connected to the Haudenosaunee. Originally it was a silver chain that connected the two peoples which also required that they gather together to renew and shine the chain and as a way to be bound together with good minds. 
"It is provided thus: Any Chief of the League of the Five Nations may construct shell strings or wampum belts of any size or length as pledges or records of matters of national or international importance" (Tehanetorens, 1972, p. 21). At the time the good will translated to sovereignty for each nation. As time marched on in the chronological order of events this expression would be laid by the way side.

\section{Social Impact}

While John Mohawk notes that most of the Mohawks that had fled from the Mohawk Valley were primarily Anglican in the mid 1700's (1993, p. 176); present day teachings from Jan Longboat from Six Nations in 2008 in the conference entitled Recognizing our successes; Building on our strengths and in Tom Porter's book entitled And Grandma Said from Akwesasne respectively recall different stories from their elders about Haudenosaunee teachings (2008). In addition it was Mr. Ike Hill of Tyendinaga that brought his version of the Great Law of Peace which had been transcribed from a hand written copy to Kanhiote Tyendinaga Territory Public Library (Kayanerekowa). Notwithstanding, a generation later, children on Tyendinaga are still taught the story of Deganawidah and his accomplishments as a Peacemaker.

It is noteworthy that because the Mohawks of the Bay of Quinte stayed loyal to the British Crown by way of a gift to the Mohawks, England's Queen Ann bestowed an eight piece silver Chalice Set in 1712 to be used by the Mohawks for the Mohawk Chapel. The set was buried during the American Revolution to keep it safe but one piece became lost. The set today is split between the Mohawks of the Bay of Quinte and the Mohawks at Six Nations (MBQ, Queen Ann Silver, 2009; Christ Church-microfilm archive.). Even as these gifts were being bestowed by the Monarchy on the Mohawks, the government and the Churches had begun the legacy of residential schools and aggressive assimilation practices. The government had begun 
what they saw as the act of 'civilizing' the Indigenous people, but what this actually meant was aggressive assimilation. The Mohawk Indian Residential School opened in 1831 in Brantford, Ontario (AHF Research Series, 2008). The Mohawk people were not exempt from the ever changing landscape of colonialism; this phase of history, that of the residential school, is the marker for the cultural and religious transformation and the struggle for retention of traditional practices and knowledge bases that had been practiced since time immemorial (Wesley Esquimaux \& Smolewski, 2004).

\section{The Indian Act:}

The passage of the Indian Act in 1876 heralded legislation with a very large impact, because it governed virtually every aspect of Indian life and made Indians wards of the state (Indian Act: Office Consolidation 1985). The new legislative powers defined who an Indian was and who was not, right down to subjugating entire communities in the name of the colonial power called Canada (Kirmayer et al., 2003). Their lives, liberties, and who they were along with any remaining ownership of land was legislated away (Tuhiwai Smith, 1999). With the making of reserves, land bases set aside for Indian use, often in areas that no one had any use for, continued the displacement of Indigenous peoples across Canada. The social devastation to the Indigenous people via imposed alien social structures left the Indigenous people diminished and impoverished. They no longer knew who they were, what they had been, or where they were going. The aggressive assimilation of the Indigenous people began in earnest in the country, which had once been the source of their happiness and freedom.

\section{The Legacy of the Residential Schools}

Close on the heels of the opening of the Mohawk Indian Residential School in 1831 came the Bagot Commission Report of 1844 (Leslie, 1982; Kirmayer et al., 2003). The Government 
recognized that Indigenous people existed, but the Government also believed that the Indians were uncivilized and began to move away from implementing treaties and protecting Indians rights, to imposing various forms of assimilation. The Davin Report or more formally the Report on Industrial schools for Indians and half-breeds of 1879 reaffirmed the new approach toward Indians on reserves (Davin, 1879). It launched the policies of the government to assimilation, to take the children away from their Indigenous families and homes and to place the children in schools to be educated just like British Canadians (Kirmayer et al. 2003).

In Indigenous worldviews everything is interconnected. The circular view of connection places everything; people, environment, animals and the cosmos all within that circular context (Nabigon \& Mawhiney, 1996). According to Mohawk tradition children learn everything they need to know from the time they are born. It is up to the adults to protect the children and discipline them. Discipline is not to be given harshly, but always with kind words and only in very extreme cases. If a child has repeatedly not paid heed to advice given, consequences with a red willow whip are given, but always with an explanation, never in anger, and very sparingly (Porter, 2008). The children are considered equal and important. According to John Mohawk, the Skyholder gave the Iroquois four rituals and in one specific ritual, the Peachstone Game, he gave instructions; "It will be the duty of all people that they will possess the power to be happy, and they will be in the habit of giving thanks when they see that all my work continues to please the minds of the children, even to the least, and that you all have an equal right to it" (1993, p. 128). The over riding view of Indigenous peoples was that extended family or other adults who lived in the village could care for the children; that is why they were metaphorically in the nucleus of the circle. The Elders embraced the children on the outside of the children's circle and all the women in the next circle embracing the Elders and the men on the outside circle 
protecting everyone within the circles. All connected, all equal all important to the nation and survival.

When the assimilation policies came into force, the government may or may not have known that to take the children away from the parents, grand parents and community would be the most devastating blow they could deliver to the entire nation (AHF A Healing Journey, 2006). It crippled Indigenous people, because children were to be protected and treated as their most precious bundles. "In 1920, Duncan Campbell Scott, the bureaucrat in charge of Canada's Indian Policy, revised the Indian Act to make attendance at residential school mandatory for all children up to age 15" (AHF A healing journey, 2006, p. 10). It was legislated at that time that any parent or grandparent that resisted could be jailed for not giving their children/grandchildren up. The children were abducted and taken from their homes, the parents fought or were jailed and the children were taken anyway (Hodgson, 1990), and the family life the Indigenous person had once enjoyed was devastated. Unfortunately, the children saw only that the parents could/would not stop their abduction. It was confusing and scary because the children could not speak the British Canadian language or understand what was going on and the parents felt like they had failed deeply at protecting their children (Fournier \& Crey, 1997).

When the children were taken away it was with the intent, in the words of Duncan Campbell Scott to "kill the Indian in the child" (AHF a healing journey, 2006 p. 11). Children were taught to be ashamed of their Indigenous culture and language and the children were punished when they spoke their own language at the schools (ibid). Corporal punishment was dispensed to the point that children were dying in the schools either from disease, malnutrition, over crowding or trying to escape to get back home (Fournier \& Crey, 1996; Porter Oct., 2008). 
Children were not taught at school for a full day, often schooling meant attending classes only half day, with the girls learned sewing and cooking and the boys learned farm work and doing chores, sometimes menial chores to fill in the time (Morrissette, 1994). The loss of identity, culture, and the shame and induced silence would become indelible markers for trauma and intergenerational grief that has been extremely difficult to resolve (Morrissette, 1994; Kiramayer et al., 2003; Stamm et al., 2004; Corrado \& Cohen, 2003). "Between 1831 and 1998, 130 industrial, boarding and residential schools would operate" (AHF A healing journey, 2006, p. 10). The mental and emotional health consequences are still being followed and documented by the Aboriginal Healing Foundation today. In 1991 the Royal Commission on Aboriginal Peoples held hearings to uncover the widespread abuse that happened in the residential schools (Kiramyer et al., 2003; Chansonneuve, 2005). Today we are undertaking the Truth and Reconciliation Process in Canada to help Canadians at large understand how Aboriginal peoples came to be so disenfranchised in their own country. Generations later, Indigenous people are still learning to cope and heal from the trauma of losing not only their lands, livelihoods, and homes, but their most precious resource; their children.

\section{The Sixties Scoop}

For the Indigenous children that eluded the residential schools, the escape was not long lasting. Government child welfare policy in Canada was based on dominant mainstream nonnative middle class values and mores; this meant that the basis of the interpretation of what was deemed "proper care" of children (Fournier \& Crey, 1997, p. 30) came out of a standard that was very different from Aboriginal people's interpretation of healthy child care. The term sixties scoop was coined by Patrick Johnson in 1985 when he examined the history of the exorbitant number of Aboriginal children who were apprehended by child welfare agencies. He saw that 
apprehension was mostly due to poverty and children were placed in foster homes only to be adopted into to non-aboriginal families (Johnson, 1983). Complaints arose from the Indigenous and Métis community and a public inquiry was held in Manitoba. The conclusion was that child welfare practices were greatly flawed (AHF Research Series, 2008) and discriminatory. The abuse is documented in Stolen from our embrace by Fournier and Crey's where a direct account of living and experiencing placement in foster homes in the sixties is given by those who were forced to grow up in that system.

\section{Residential Students, the Apology and Aboriginal Child Welfare}

The literature clearly demonstrates that the residential school experience has had a devastating effect on many generations of Indigenous people. It has taken insight from the Indigenous people themselves to begin their healing, but it must also include partnership with a government that recognizes the ability of people to develop, implement and evaluate their own healing and wellness methods (Jones, 2008). This partnership must recognize and respect each other's roles. The government must abide by their fiduciary responsibilities and both parties must be transparent and accountable at all times. In addition, while the government policies change over the years policy must reflect and be tied to the political will of the government in power at the time (Mercredi, 2008). If the political will does not reflect the genuine honest transformation it claims to support, all the apologies in the world will be worthless. If a tragedy happened one hundred years ago to a people and if society sees that it is still happening and does little or nothing to rectify it, where is the justice, where is the transformation?

In relation to the residential schools, in 1998 The Honourable Jane Steward said, "The Government of Canada acknowledges the role it played in the development and administration of these schools. Particularly to those individuals who experienced the tragedy of sexual and 
physical abuse at residential schools, and who have carried this burden believing that in some way they must be responsible, we wish to emphasize that what you experienced was not your fault and should never have happened. To those of you who suffered this tragedy at residential schools, we are deeply sorry" (Chansonneuve, 2005, p.4). This chilling statement was the first apology made by a government official publically to former residential school students. It would later serve as a preamble to the official apology to the former residential school students from Prime Minister Stephen Harper on June 11, 2008 (Hansard, 2008).

The Prime Minister of Canada, Stephen Harper offered his apology to the residential school students for the multiple abuses and the tragedy of how the students were treated when the schools were in operation. He offered his apology to former students and said publically on behalf of Canada that the assimilation policy of the government was wrong. In my work over the past ten years, and speaking with survivors and their families, some people hailed the apology as a victory and feel that now the healing and reconciliation can move forward with them and the rest of Canada. Others who have heard the apology are not as positive, while others are waiting for something, anything to come of it. From the negotiations made between Canada and the Anglican, Presbyterian, United Churches of Canada and the Roman Catholic Entities and the Assembly of First Nations and Inuit Representatives and Counsel, a Residential School Settlement Agreement was born (Indian Residential Schools Settlement, 2009). The Government of Canada and the Churches acknowledge abuses did happen at residential schools and that there would be compensation to the residential school residents, or the heirs of their estates and healing and reconciliation would be offered (ibid). While there are many facets of the Agreement these two areas in particular would offer a glimpse into the abuses that happened while attending the residential schools and the types of healing needed. 
The official apology from Prime Minister Stephen Harper happened on June, 112008. The present day First Nation child welfare policies do not reflect the sincerity of the official apology. In 2000 the Assembly of First Nations and Indian and Northern Affairs Canada under took a review of the federal child welfare formula and found that "First Nations children on reserve received approximately $22 \%$ less child welfare funding than other children in Canada" (AHF Research Series, 2008, p. 168). Despite several attempts from First Nation politicians and advocates to sway the Government to act; the Wen:de Report composed of three different articles detailed the funding formula, the inadequate funding at all levels and viable solutions that could emerge, still there was inaction by the government (ibid., p.169). In February 2007 the Assembly of First Nations and the First Nations Child and Family Caring Society filed a complaint with the Canadian Human Rights Commission. Their complaint was vis-à-vis the inadequate funding and services from the Canadian Government for First Nations Children and the care for the First Nations child and family service agencies (AFN, 2008). A Communique to First Nations Communities dated October 16, 2008 by then National Chief Phil Fontaine and First Nations Child and Family Caring Society Executive Director Cindy Blackstock commended the decision by the Canadian Human Right's Commission to allow a tribunal to hear the complaint (AFN, 2008). The decision of the Commission was viewed as a victory to First Nations Child Welfare because the Assembly of First Nation's 2006 Leadership Action Plan on First Nations child welfare has been ignored by the Government despite criticism from the Auditor General of Canada in May 2008 (RSCPA, March 2009). The tribunal is set to begin on September 14, 2009 (FNCFCSC, 2009).

Inaction can be deadly. Take the case of a toddler named Jordan who was of the Cree Nation in Manitoba. His community was Norway House and he was born with a complex 
medical disorder and the only way his parents could make sure he got the medical care he needed was to place him with a child welfare agency. Jordon was in the hospital for two years. In that time his medical condition stabilized enough for him to leave the hospital, it should have been a jubilant time, but due to jurisdictional disputes between the Federal and the Manitoba Government over who would pay for the cost of his care. Sadly, he died in 2005 before he got to go home (AHF Research Series, 2008). Since that time a private member's bill has been tabled and passed affirming "That, in the opinion of the House, the government should immediately adopt a "child first" principle. Jordan's Principle was designed to resolve jurisdictional disputes involving the care of First Nations children (ibid., p. 172). All federal parties gave unanimous approval to the motion and it appears that positive steps have been taken out of the tragedy of Jordan losing his life before he was able to return home to his parents. Approving a motion versus tabling and passing a bill in the Provinces and in the Territories are very different acts. Ontario is one of the provinces that adopted Jordan's Principle in April 2009 (OMAA, 2009).

\section{Psychological/Cultural Trauma}

Any locus of control (ability to make decisions) Indigenous people had before contact was quickly erased under the pressures of colonization and displacement. The Indian Act was a powerful way to ensure the Canadian government had control of Native people at least until the assimilation process was completed. The loss of psychological, emotional and social controls would become markers in the continuing onslaught of historic trauma on Indigenous peoples across Canada. The oppression, marginalization and loss of control were accomplished by psychological and cultural trauma as outlined by (Wesley-Esquimaux \& Smolewski, 2004) the five areas of impact and contemporary Indigenous scholars. 
While there were many pieces of legislation written by the government and treaties signed by the Government of Canada and the Indigenous people, the largest piece of legislation and the two treaties and that directly relate to this paper are; the Indian Act, Treaty Number Six and Treaty Three and One half or it is also known, the Simcoe Deed. The Indian Act and Treaty Three and one half have already been mentioned. The treaties had significant impacts in a myriad of ways because they addressed different issues. The piece of legislation named the Indian Act dealt with Indigenous people on every level and was discussed earlier. Treaty Number Six dealt with health care and the other treaty, the Simcoe Deed dealt with a specific land tract. Treaty Number Six was between Her Majesty the Queen and the Plain and Wood Cree Indians and Other Tribes of Indians at Fort Carlton, Fort Pitt and Battle River (Duxamel, 1964). It was originally signed in 1876 and contains the Medicine Chest Clause of Treaty Number Six (ibid, p.4). It said that, "a medicine chest shall be kept at the house of each Indian Agent for the use and benefit of the Indians at the direction of such agent" (Duxamel, 1964, p, 4). This clause was interpreted by Indigenous people to mean that the government would provide an entire or wholistic framework of health care or even frees health care to the Indigenous people; however the government today denies this interpretation.

With healing ceremonies outlawed (Hodgson, 1990), "identities legislated" (Tuhiwau Smith, 1999, p. 22), treaties continuing to be broken (Duxamel, 1964; Indian Treaties and Surrenders 1891), relationships marred, continuing erosion of land bases (RCAP v.3, 1996; Mohawk, 1993) along with poor assimilation policies and rampant abuse; every policy has manifested into a framework of; loss of identity, loss of language, abject shame, horror, helplessness, a learned welfare state and unrelenting "cultural stress" (Isaccs, 1976, p. 276). 


\section{Spiritual Impact}

The final stage addresses the impact on spirituality and spiritual practice. All of the stages are significant because they represent different areas that have been negatively affected, but each stage is not entirely distinctive on its own. There tends to be a little blurring of each stage into another. The spiritual impact is closely related to the phase of cultural oppression. When the Government outlawed healing ceremonies, they legislated against the source of the tools and techniques Indigenous people would use to heal themselves. In order to heal, Indigenous people would need to go back to the spirituality of the teachings or as Rupert Ross (1996) noted, they would have to ultimately, Return(ing) to the Teachings and find their original strengths.

The legacy of the residential schools has manifested as a negative impact on spirituality, and spiritual practice. Indigenous children could not practice their ceremonies or learn their own history because another religion was forced upon them. Religion also took away the children's Indigenous languages and their inner strength and resources (AHF A healing journey, 2006). One of the most fundamental spiritual aspects an Indigenous person can possess is their own language because it connects the person to their identity, ancestors, environment and their place in the world. The language is descriptive and distinctive to the way of life, culture and world view, it connects the person with the rest of the circle of life. John Mohawk was quoted as saying "There is no English word that appropriately defines the entities which bind human societies to the land, the past, the future and, ultimately to the universe" (Sheridan \& Longboat, 2006, p. 380). The Indigenous people were oral, sacred teachings came via Elders and ceremonies, and they had to be memorized and lived (Parker, 1968; Friesen, 1999; Longboat, J. Aug. 19, 2008; Porter And Grandma Said, 2008). What was learned went from generation to 
generation through a beautiful oral tradition. The Mohawk people did not have anything written until the reported wampum belt was used by Hiawatha for condolence (Tehanetorens, 1972). Even so, there were no written words on them, symbols represented the event or what it was used for, and it epitomized validity (Kayanerekowa).

Many people would not understand why language is spiritual but as Jan Longboat so eloquently explained through the Good Mind, "medicine means more than love, we have been waiting for you and we will give our medicine, your voice is your medicine, there's many ways to use your medicine, speaking, crying, hollering and singing" (Aug. 19, 2008). The legacy of the residential school experience induced silence, forbade speaking any language other than English and ignored crying, all of which undermined the Haudenosaunee's Good Mind. The residential school erased equality, and doled out corporal punishment, leaving in its wake, a stripped, lonely, frightened, confused, isolated, suppressed and angry individual (AHF v. 1, 2006).

The historical trauma we are discussing here may have begun many years ago, but the inter-generational trauma and grief is still being felt by Indigenous families across Canada. The loss was never completely resolved, maybe because Indigenous people are still affected today by the effects of colonialism, imperialism and Euro centrism.

\section{The Good Mind Model}

This model uses cultural, environmental and personal safety as the beginning steps when rapport is being built. It encompasses the need to listen deeply to people and be aware of their history. It acknowledges and embraces spirituality, but is flexible with individual beliefs. It teaches about ceremony and is always respectful of each person. The participant will outline the "best" type of ceremony that $\mathrm{s} / \mathrm{he}$ is most comfortable with after the teachings. The traditional 
medicines, physical relaxation and the inclusion of the family are encouraged but always guided by the needs of the participant. Indigenous treatment uses healing with a type of psychoanalytic theory focusing on trauma and in empowering the survivor. The historical underpinning of the Haudenosaunee peoples are included as part of the healing. The voice is an important part of medicine for the Haudenosaunee.

\section{Cultural / Environmental/Personal Safety}

In working with people who have been traumatized the most important aspect at the start of the healing relationship is the safety of the individual and family. In looking at other techniques used in the Good Mind Model there is an element of safety built into each of them. It is important to name the differences in the healing relationship with the traumatized individual and the helper(s). When people seek help it is because there is or has been turmoil, either external or internal in their lives and there is unease, anxiety or dissatisfaction present in their lives. The term "cultural safety" was coined by a Maori nurse, I. Ramsden in 1992 when she was talking about the basic treatment of patients and said there should be "no assault on a person's identity" (Williams, 1998). Service delivery should include an appreciation of cultural diversity and if it is truly embraced by the service delivery agent; the agency will be able to provide a genuine non discriminatory, anti-racist approach that will enhance personal empowerment, self determination and social justice. It is also increasingly felt that, "The people most able or equipped to provide a culturally safe atmosphere are people from the same culture" (Williams, 1998, p. 3). The participants need to know their helper understands and embraces similar cultural norms so the participant is not viewed as the "Other" (Tuhiwai Smith, 1999, p. 21; Walker, 2006, p. 332) or as an“outsider" (Wesley, Esquimaux, 2007, p. 63). If the person feels like $s / h e$ is the "other" s/he might feel they need to educate the helper first for the helper to 
properly understand the context and issue. All too often the participant is too weary or does not have the energy needed to start from a "pre" beginning with every caregiver. It is easier for the participant to seek help with someone who already has an understanding, empathy and knowledge of the beginning and context of requested care (culture, value, norms) so the participant can promptly venture to where the $\mathrm{h} /$ she wants to go in healing.

\section{Environmental Safety}

The place of healing should also be taken into account. If participants need to go out on the land they should not have to travel for great lengths of time to get there, because usually there are feasts that follow and access to proper facilities is required. There should be plenty of land to do what is necessary at their disposal for on-the-land activities such as fasts or sweats. For example, unburdening work is intense and in order for it to happen optimally it should be undertaken in a sound proof room for maximum privacy and confidentiality. If this is not possible, the level of unburdening may not be as intense as it may need to be. The pictures on the walls and the general ambiance of a building should reflect characteristics of the services offered as well. Soothing, calming colours, comfortable inviting rooms, and cultural elements necessary to carry out the activity of the day are positive indicators of a thoughtful and responsive healing environment. In some healing work, a private room with a tub large enough for a cedar bath, a fire place or a wood stove to represent the fire, or a fountain in the house to represent water all contributes to a patient's state of mind and comfort level.

\section{Personal Safety}

Closely relates to the safe construction of the actual building and the thoughtful presentation of the facilities and staff. As mention before, people who have been traumatized have had their trust in a parent/guardian/ loved one/ person of power/entity demolished. That 
trauma may have happened over time by the same person or by different people. The degrees of trauma may vary, but the end result is the loss of trust in other people. People who have been traumatized find it very difficult to trust, therefore those who have been traumatized need to know that the helper will stay with them during their painful journey. They even need to be reassured that their pain is not so intense that people will leave them, and be assured that once their pain comes out, they will still have the person helping them there listening and present. Sweat Lodge Ceremony (cleansing through sweat or bathing with cedar boughs),

A sweat lodge ceremony or a sweat is cleansing through heat and steam in a sweat lodge. For example, in a sweat lodge ceremony, a fire keeper, usually a male, but if not available a grandmother, tends to a very hot fire where a certain kind of rock referred to as 'grandfathers' are heated to a red hot temperature (they do not break open) before they are placed in a fire pit inside the lodge. The lodge is usually constructed in a secluded area and is completely covered over with hides or tarps. One person can enter or many depending on the size of the lodge, and generally, the participants are of the same gender. The sweat lodge ceremony is used for cleansing of the body and of the mind, and to help people reach clarity around personal issues through cleansing and prayer. People are encouraged to speak out, sing and share emotions throughout the ceremony, but it is never forced. Like the circles, sweat lodge ceremonies vary and can have different reasons why people participate in them, the Good Mind Model primarily uses these ceremonies for healing.

\section{Fasting}

The voluntary giving up of food is a way to get toxins out of the body. It should only be done seasonally and usually twice a year. Fasting can start out and last for one day and as people get better at it a person can go as long as four days. This is always done with supervision. The 
intent to get closer to the Creator and it is considered a very spiritual practice. Fasting in the Good Mind Model is done as an on-the-land activity. It invites the participants to be a part of something that is bigger than them alone. It is done in harmony with the land as a way to focus. While five or six people can be put out on the land at one time, they are never put together; they each have their own spot. "Going out on the land also represents, strengthens, and reaffirms connections to the past and to the ancestors. It bridges the traditional with the modern, strengthens connections, and supports factors influencing resilience" (Fletcher \& Denham, 2008, p. 120).

\section{Circles}

It would be difficult to name specifically when this type of technique came into being. It is not like "Freudian" "Gestalt" "Jung" or "Rogerian" therapy (KAHR, 2006, p. 62) because "no one' specifically can legitimately say they were the first to come up with this concept (Hart, 2002). Indigenous people have a circular world view and feel that all entities are interconnected. Specifically the Haudenosaunee have sat in circles for centuries (Kayanerekowa, The Great Law). It was to symbolize that all in the circle were equal and there was no hierarchy in the circle; no one was the boss, what was said in the circle was given due consideration from the group. Historically everyone got to speak if that was their wish, but no one was forced to do so. Once words came out or ideas came from a person in a circle it was no longer that person's, it belonged to the group. Consensus was the decision maker and people who came into the circle were to do so with a good mind. That meant there should be no anger and everyone was to come to a decision that was best for the community and nation.

Circles helped the group to make decisions, but there are other types of circles, some are sharing, educational and healing. The Good Mind Model uses them all depending on the 
situation and what is required. According to Hart (2002) there are many commonalities in Indigenous circles. The circle size for instance can really be of anywhere up to sixty people or as small as three people. Usually the larger the size the longer the circle will last because everyone can talk in the circle if $\mathrm{s} /$ he chooses. The ideal size would be no more than fifteen people. The smaller the size the more people usually will disclose, as they may feel more comfortable talking openly, but not necessarily so. The smaller the circle would also give the participants the feeling that they could talk longer and not take up someone else's time. If inside, the room must be large enough to accommodate all participants comfortably so each person can sit facing the centre of the circle, and facing each other. It could be outside or around a fire, but it should be quiet enough for all to hear the words being spoken from the quietest person. There is a conductor of the circle, someone who participates, shares and learns with the group. The conductor is someone who is kind and non judgmental. The conductor can be a strong but silent gentle "referee". There is no boss or teacher of the circle unless there is an Elder there for teachings, but specifically during a sharing circle there are certain rules that should be explained. The first is that confidentiality is a must, what is said in the circle stays in the circle. There is absolutely no gossiping or speaking disrespectfully, harshly or critically about a person outside or inside the circle. Participants are told they can speak if they wish but are not forced to do so. Everyone's words are to be respected. No one is to interrupt while a person is speaking, even if it means pregnant pauses or if there is emotion, and in the circle patience is considered a virtue. In addition it is in compliance with the ethic of non interference (Brant, 1990). It is considered extremely rude if one person interrupts another even if they do not agree, in the circle; the person who disagrees should be thinking about how s/he is feeling and where those feelings are coming 
from and try to share that during their turn. All feelings are valid and if anything normalized. All participants are expected to speak with honesty when it comes to their turn.

Some circles are set up with a candle in the centre to represent fire and some have water in a glass to represent cleanliness and life. In some circles the conductor or the elder may have sacred bundles which can contain articles that are sacred to that person. Traditional medicines, rocks, feathers, blankets, drums, rattles or shells could be part of the bundle. Some circles have a smudge ceremony first; although people can opt out if they wish. The smudging is for clearing the minds of any negative thoughts and is symbolically cleaning the room. The participant takes the smudge (medicine) while burning and is washing it over their face or taking the smoke and putting it close to their ears so they may hear what is really being said and makes washing motions on their head and body to cleanse themselves for the circle.

It is believed that women are very strong while on their moon time. Moon time means while a woman is in her menses' cycle; it means that she is already cleansing her body and is thought of as already in ceremony. In some circles women on their moon time are considered too strong in the circle, although there are female medicines that are allowed to be used while a woman is on her moon time. For example, usually sage can be used even if a woman is on her moon time (Ntum, 1998).

In some circles people have an object to hold on, because some people like the stability of something in their hand. In some circles there is a rock or a feather or another object that is passed to the speaker, the idea is that no one else can talk until they come in possession of the object. The direction of the circle is not important to all conductors, however, the Haudenosaunee believe that circles should go in a counter clock wise direction (Porter, 2008). 
This circle direction is usually only changed to a clock wise direction if there has been a death, for example a loved ones' ten day feast will be served in a clock wise direction.

With the logistics taken care of, the next step is the content of the circle. Usually all the participants are there for a reason, they all may have some issue in common and each is encouraged to speak in the circle. The circles must be in a non judgmental, safe environment for participants to share their feelings and experiences. No one will be interrupted, ridiculed, mocked, belittled or judged. The atmosphere is one where the participant can come and say what they are feeling and be supported and validated by all of the participants.

Healing circles differ from sharing circles in that the level of sharing is deeper and usually the participants are in the circle for the same reason; whether it is trauma, loss, grief or an 'at loss issue'. Healing circles usually have more than one gathering with the same participants over time so there is a building up of trust. Usually there is a great amount of emotion in healing circles, and this is preferred. People are encouraged to speak their mind, to be honest with their own emotions and release their feelings safely. The conductor is a person who has honed their skills and keeps the person, group and atmosphere safe. But healing circles can also include laughter and healthy releases; laughter and joy are a requirement as well, feelings that are timed correctly.

That is usually the only "timing" that goes on in circles. Time for aboriginal people is not the same as it is for non native people. In circles, no one is timed; people speak for as long as they feel they need to without interruption. When a participant starts talking is not as important as that the person is talking (Janca, 2003).

The strength is in the circle. The closeness, the genuineness, the honesty and the connection with everyone else in the circle, therefore, people should not leave the circle once it 
starts. It can be done if the participant is so overwhelmed that they have to break but it is important to come back to the group. The closing of the group can come in the form of an Elder saying a prayer or a final check in with the participants. Or the participants can all stand and all hold hands and with their hands down ward bring their hand up with a yelp to release energy. Participants have stood in the circle and hugged each person or shook hands at the end; it depends on the type of circle and the intenseness of the group. In healing circles that I have been a part of I can attest that they are exhilarating, draining and satisfying all within the same experience.

\section{Unburdening}

Newer concepts, such as unburdening were introduced to us by Diane Hill from Six Nations many years ago and have been incorporated into the good mind model. Unburdening can also be linked to the sweat lodge experience. According to an article entitled Traditional Healing: Helping our people lift their burdens by Bob Antone and Diane Hill (1990), there is a lot of importance to naming the emotions that have caused the original hurt in people. It is important for people to release those emotions that create negative thoughts and emotions because people can continue to be hurt by past events. Keeping silent about early hurts only fosters more pain, and finding the original hurt, facing it, naming it and letting it go, releases the burdens being carried and lets the darkness pass. Antone and Hill (1990) noted that once this process is done the person can feel love, be re-connected to others and experience positive energy in their lives again.

Unburdening sessions can be very powerful; the ability to name an emotion correctly and deal with the behavior associated with it, is a way to face the original hurt and let it go. Through the historical traumas that Indigenous people have faced there still remains unresolved pain. 
That is why this particular technique is used in the Good Mind model, it is a safe effective way to deal with and eliminate the original hurt (burden) the person is carrying around.

The unburdening sessions can be co-facilitated and this is actually preferable. Ground rules are that confidentiality is a must, building solid rapport is necessary and a completely safe environment is essential. Unburdening invites the participant to go back in time to try to identify feelings and to explore within their lifetimes where, when and how the feeling originated. It can be from a time the person was young, and taking the person there and dealing with the pain in a healthy strong way is necessary. It may take more than one session to deal with the pain, as the pain may be too intense or the participant too fearful at that time. The healing is dictated by the participant and will come with effort. Grounding is also necessary to ensure the participant is not actually back in the original place of the trauma but dealing with it in the 'here and now' and is perfectly safe. The plan is to deal with the situation so the participant is able to correct the situation and 'save' him/herself or deal effectively with the situation and give a good safe outcome, in other words, re-write the end of the trauma in a satisfactory and safe way.

\section{Spirituality}

There is a compelling place for spirituality practice in social work (Graham et al, 2007). Most practitioners are often afraid to tread in a field where they are not completely comfortable. They may not have worked out personal beliefs or issues around spiritual practices of their own and would not want to pursue the need to try and understand the spiritual practices of Aboriginal peoples (Elijah, 2008). We believe that self awareness and insight is of utmost importance to working in the healing relationship. In the exploration of self awareness for the practitioner, the client's cues for healing should not be ignored. The Haudenosaunee believe that to ignore spirituality in healing would be to ignore the essence of the person, the identity of an individual, 
and the client's perceived connection with their own life force, as well as the environment and the Creator. There is a union between spirituality and having a good mind, something that has great utility across cultures and mental wellness treatment modalities.

Acceptance of spiritual forces and spiritual energy is a fundamental and important part of Haudenosaunee personal and worldview (Porter, 2006). There has always been a deep sense of spirituality within the Haudenosaunee culture. The ceremonies are one way we use to stay balanced; they provide many connections to the true self and having a good mind as well as a connection to the Creator. For example, when a person talks with the spirits (prays) and has a good mind, the spirits will come and if the person stays quiet, the person will hear their message. However, if the person does not have a good mind and is hurting the peace of the people or even themselves, the spirits will stay away and there will be no connection made.

\section{Spiritual forces-spiritual energy-medicines, Medicine People}

Health is seen as a gift from the Creator, but it is also understood that the people are responsible to take care of their own wellness. Traditional oral teachings tell us everyone has a gift and place in the world. It may take years to reach that enlightened state where the person has achieved inner peace and is practiced at their art. Those people that are working with their spiritual gifts carry their spiritual healing with them, and share it with others everywhere.

There are times when the Haudenosaunee need the help of some of their people who possess a special kind of gift or medicine power. For example some helpers are called Seers, they can communicate with energy forms, and work with the energy forms to see into the future, past and present. Other helpers make medicine from roots, twigs, bark and various natural elements and those people are called Medicine People; those people still exist today for the Haudenosaunee. The third helper is the person that may not have developed their full spiritual 
knowledge, but understands the interconnectedness of spiritual energies and the use of medicines (Antone \& Hill, 1990) (see using traditional medicines, plant and herbal concoctions).

Medicines that the Haudenosaunee utilize are known to have specific energies and are considered to be of a spiritual nature. Good medicines are not only plant and herbal medicines that are found external to the Haudenosaunee people themselves. There are different healing helpers that the Medicine people and the Seers promote that are internal to human beings; laughter, tears, and kind words (Shestowsky, 1992; Longboat Aug., 2008). The body itself is also observed as a place of healing where feet; voice, hands and face are known to release pain and tension (Hodgson, 1990). Therefore we are taught that the emotional and mental aspects of a person are directly connected to the physical and spiritual elements.

\section{Spiritual Rituals}

Teachings and rituals are different. We receive teachings from the Creator. Tom Porter stated at a conference entitled Celebration of Life that "the first teaching was the Thanksgiving Address the second teaching was the Clan System and the third teaching was about ceremonies. The Four Sacred Beings taught the four sacred rituals, but only after the first three are restored can the Great Law [exist] be restored amongst us (2004). The Haudenosaunee people had/have strayed so far away from the teachings that the Creator sent down a Spiritual Being to teach and correct their behavior with renewed teachings.

The Haudenosaunee have been given four specific rituals to keep ourselves well. These rituals continue to be celebrated, albeit they are not as accessible to the entire population, and they have been passed down from generation to generation. According to both Porter (And Grandma Said, 2008) and Mohawk (1993) these four rites have been given to the people to keep 
them well, because through them they will remember to be grateful and to always give thanks and send greetings.

The first ritual is the Great Feather dance, a turtle rattle is used and it represents the shaking up of Mother Earth to loosen it up so great things can grow; it is to restore life and to stir and reawaken life. The turtle represents the importance of going back to our Creation story and being reminded of how important that story is to the people. The dance is to give thanks and respect to Mother Earth for all that she has given. During this dance a kahstówa (hat) is worn, a "feather hat" (Porter And Grandma Said, 2008, p. 171). Mohawks would wear the hat with different symbols on the bottom of it to represent our culture and three feathers were placed on the top on spindles so they can move freely, other Iroquois people wear a different number of feathers to represent their brotherhood, for example, the Seneca would wear one feather, the Oneida another number of feathers, and so on through the confederacy.

The second ritual is the Drum Dance; the Drum Dance uses a water drum and is much like the Thanksgiving Address, except it is sung. It can be quite lengthy and there is very specific protocol that must be followed. This song is still sung in Longhouses to this day. The Drum Dance requires two people to walk from east to west as they follow path of the sun, "it is a spiritual history of who we are" (ibid, p.181), it is similar to the feather dance, except that a drum is used and not the turtle rattle. Both very clearly relate back to the Haudenosaunee Creation story.

The third ritual is the Thanksgiving Song. It is really for the men to perform because the women are already seen as very strong and the song was given to provide the men a little more strength and to allow them a ceremony that creates balance with the women. 
The fourth ritual is the Peach Stone Game, and this ritual was given to remind the people to have fun. It is really just a game with a wooden bowl and peach pits tossed into the bowl much like dice, there is a burnt side that is black and a white side. All four rituals continue to be performed in Longhouse to this day. Teachings and protocol are provided by our medicine people and when you attend Longhouse ceremonies those teachings are given at that time.

\section{Ceremonies}

Ceremonies have been given to the Indigenous people to help keep them connected to the Creator. It is the regular performance of that spiritual connection that reminds each of us to be grateful for what we have and what we have been given. Ceremonies create and define a way to live life, they give teachings for the way people might best conduct their behaviour everyday and to keep well and balanced. They are a reminder that people are not alone and that the Creator is always listening. Sometimes the season plays a role, like the Mid Winter Ceremony but always the reason or the readiness of the individual in the moment is respected. Full knowledge of any relevant teachings for healing purposes is necessary to properly employ each technique, and participation is always considered voluntary.

There are other ceremonies that are used on Tyendinaga today in the Good mind model. The Moon ceremony is done monthly for the females of Tyendinaga. Teachings are given at the beginning of the ceremony, out of respect for their femininity, participants are told to bring water and wear a dress or skirt. The connection to Mother Earth, Grand Mother Moon, water and females is emphasized in these monthly ceremonies; it is a recreation of the sacred connection to the Creator, and a reminder of a woman's duties and responsibilities to the land and waters. 


\section{The condolence ceremony}

The condolence ceremony is used when people are dealing with grief issues. The ceremony is incorporated into the Good Mind model. Iroquois people have always been fascinated with the state of death, and what is means to the spiritual health of the culture. There was and continues to be a healthy respect for the dead, partially because it was believed that the dead were very strong spiritually and needed to be respected. If they were not respected it was thought the dead would invoke bad events on to the living (Shimony, 1994; Porter, 2008). Some Iroquois still believe that being dead is similar to being a part of the living, only they are now invisible, and are hovering above or dancing with the living during a feast. In the condolence of Hiawatha he makes wampum for the death of his loved ones. The wampum is made, put in a bundle and hung outside his lodge between two sticks. It is reported by Tehanetorens (1972) that each wampum string would represent a specific ceremony that would be performed for each of the losses of the grieving person.

According to Shimony (1994) the condolence ceremony was conducted when a Chief died and the loved ones had to grieve his loss, and it prepared a way for the women to appoint another Chief in his place. It is used now for the passing of any loved one. All Iroquois Nations considered themselves brethren to each other, they were divided by older and younger brethren, for example the Mohawk, Onondaga and Seneca were considered the older brothers, so if a Chief of one of these Nations died, it was up to the younger brethren to console the older ones, the Cayuga, Oneida and Tuscarora and visa versa if a younger brethren died (ibid).

Wampum is stung together with sinew and the clam shells or beads are strung together by the sinew to form strings. The strings do not have to be sewn together but if they are, they would make a belt. Each string could be read and each wampum belt would have a different bead count 
(Tehanetorens, 1972). The strings of the wampum follow the condolence ceremony, elder Jake Swamp (2007) recited, "we wipe away the tears so you may see, wipe the fuzz from your ears so you may hear, remove the sorrow from your throat so you may talk and give you liquid so you may cleanse the ache in your stomach". It is a strong ceremony; it is to bring condolence and healing to the minds and bodies of the loved ones and help resolve their loss.

The ceremonies are a way to stay connected to the Creator and to stay grateful. They are a wonderful way to remember our history and ancestors and instill the presence of a good mind. Using traditional medicines (plant and herbal concoctions)

Medicines for the Haudenosaunee have been known to have specific energies and are considered to be of a spiritual nature (see Spiritual forces-spiritual energy-medicines, Medicine People). Mr. Porter stated that, "they can disturb you when you use them, so place tobacco down to quiet them" (Porter, 2004). Certain medicines such as tobacco, cedar, sage, and sweet grass are considered sacred to all Natives peoples across Canada (Mohawk, 1993). "Any time you are walking the earth, that you need some kind special attention, that you need a hand, or simply want to say thank you, you will have this tobacco" (Porter - And Grandma Said, 2008, p. $319 \&$ 320). But "Indian tobacco" is not like tobacco bought in the stores of today; it is home grown and is thought to have sprouted from Sky Woman's daughter, from where she was buried, as told in our Creation story (ibid. p. 317).

Medicines can fix or alleviate problems; properly prepared sweet flag prevents colds and corn silk is used for treating acid reflux. People drink the liquid from the distilled corn silk and it is also good for lowering bad cholesterol (Porter, 2004). It is said that medicines have to be shown proper respect. This means taking only the amount that is needed in the moment and only harvesting when the season and time is right. Each time natural medicines are picked there is an 
expectation that the person harvesting them will put tobacco down on the ground where the medicines have been picked as a gesture of thanksgiving. If the medicines are not respected in this way, it is said that people will not be able to find the medicines, and this invisibility is not seen to be out of coincidence. We are told clearly and unequivocally that, "If you can't clear your mind the medicines will hide on you" (Longboat, January, 2008). The relationship is said to be reciprocal; we show the plants respect and they will be available to us to help do what is best for treating and healing the people.

It is noteworthy that Isaacs' paper entitled Iroquois Herbalism: The past 100 years (1976) notes a comparative study carried out on the use of Iroquois medicines in 1915 and 1971. The orally transmitted information may have dated back as early as 1875 , the earlier data came from Arthur C. Parker who was part Seneca. What is of interest in this report is that the kind of medicines used from yesteryear to 1971 and the volume of specific medicines suggests an increase in psychotherapeutic medicines due to "cultural stresses" (Ibid. p. 276). Physical relaxation process (meditation and healthy sleep cycles).

Our Elders have repeatedly told us that we have the ability to heal within ourselves. We have the tools and the Creator gave us what we need to continue to be healthy. It is considered vital that we include a physical relaxation process. A physical routine for healing and health should be incorporated into our activities every day, preferably one that is fun or enjoyable like rest, dreams, visions, exercise, walking and breath elimination (Longboat, "Circle of Life").

Throughout the years Indigenous people have had to live with other cultures but have a retained their belief in best "wise" practices for health and healing amongst themselves (Thoms, 2007, p. ii). The Aboriginal Healing Foundation has offered the term "promising practices" to imply that not all survivors of residential school want to use one particular technique, what is 
important is the technique feels right to the person, their families, and the community at large (2006 v. 1, p. 113). It also implies that healing is considered as movement in a journey. If a model can have transferability, it should be widely considered; if any technique is applicable to other models, then it should be considered of use. It is of little value to narrowly define or be explicit about ownership of a technique of healing and people should consider a possibility it if it has been demonstrated to work (Waldram, 2008). That is the ethos of the Good mind model and why we use the sweat and smudge today in it.

\section{The inclusion of family}

Personal agency is paramount in both the journey of healing and non interference in the belief system of the Haudenosaunee (Shestowsky, 1991-1992; Brant, 1990). The healing journey is one where relationships are built, especially around trust and truth. It is not a journey that can be forced; it must be completely accepted by the person doing and receiving the healing work (Waldram, 2008). The individual must be afforded autonomy and make the decision to begin the work. In a study conducted regarding family involvement, over half of the "Users" wanted their family to be involved, but fewer than forty percent had been asked (Carpenter \& et al, 2004, p. 326). The importance of the family in working with Indigenous people must be respected (Rogers, 2001). When requested, the extended and nuclear family must be identified by the person doing the healing. The helper should know the Indigenous family structure and "work with the natural family helpers" that will be represented there (Cattarinich et al. 2001, p. 1477). The family will be able to offer support and relevant information when they are incorporated in the overall healing process (Carpenter et al. 2004 \& Kirmayer et al. 2003). 


\section{Healing with a Type of Psychoanalytic Theory}

When ethnologists examined the Iroquoian historical beliefs regarding healing, wellness and dreams they contended that the Iroquois dreams may have given birth to healing processes. In the seventeenth century the Jesuit missionaries reported the Iroquois were already sophisticated in the psychological aspects of the conscious and unconscious (Wallace, 1958). As early as the seventeenth century the dreams of a person were always considered important because the Iroquois believed when the dreams came, they came for a reason and the resulting visions would help the person (Mohawk, 1993; Porter - And Grandma Said, 2008). It was believed it was the person's unconscious soul asking for the help and seeking and answers to the pain or problems that came through in the dreams. It was not always clear what the interpretation was, but once the person was helped with the interpretation it was up to his/her community to assist the person in achieving what her/his subconsciously wanted; in a sense, fulfilling the desire of the dream so the mind would be clear of it. A kind of Freudian theory that the Jesuit fathers noted in 1649; and which the Iroquois had it two full centuries before "Sigmund Freud and his intellectual heirs in Western European culture tradition" did (ibid, p. 234).

The history and interpretation of dreams is still important today as it is a part of an Iroquois male youth's 'rite of passage' as well as useful for healing, he will be put out on the land for his visions to come to him. One of the techniques used with trauma participants in the Good Mind Model is to collectively link the history of the healing with a type of psychoanalytic theory so that the healer and client can explore the relevance together. 


\section{Trauma \& Memory}

According to the American Psychiatric Association post traumatic stress disorder "is a response, sometimes delayed, to an overwhelming event or events, which takes the form of repeated, intrusive hallucinations, dreams, thoughts or behaviour stemming from the event, along with numbing that may have begun during or after the experience, and possibly also increased arousal to (and avoidance of) stimuli recalling the event" (Caruth, 1995. p. 4). If a traumatic event is being "recalled" the way the memory is stored, the key would be to help the person integrate the horrors of the past with present day interpretations of reality (Van der Kolk, et al, 1995). The word recollection is not exactly accurate. According to Pally (2000) the flow of information travels through a memory system beginning with the sensory input flowing to the iconic memory, then travelling to the working memory and ending in the long-term memory. An iconic memory lasts less than a second, like a "visual image caused by a photochemical change(s) in the retina" (Ibid, p. 45). Working memory is short term memory like remembering a sequence of phone numbers or adding a small list of numbers in your head. Although the working memory is temporary memory, it is responsible for retrieving from long term memory and "long term memory is the permanent storage of information" (Ibid. p. 47).

Long term memory is then divided into two different areas; the explicit/declarative or the 'conscious' and the implicit/non-declarative or 'unconscious' (Zlodre, 2008). Explicit memory is remembering events and facts, and that too is divided into two types; semantic which is like recalling the Prime Minister's name and episodic is for special events like an anniversary celebration. Explicit memory relies on language for storage and retrieval and it can allow a person to place events in chronological order. Explicit memory begins to mature when the person is around three years old. Implicit memory on the other hand is processing information 
that is emotional rather than cognitive and prompts an automatic procedure, like driving to work. "Emotional memory is the conditioned learning of emotional responses to a situation..." (Pally, 2000, p. 59). Another difference between the two is the limbic structures used; explicit memory uses the hippocampus while the implicit uses the amygdale (ibid.). Implicit memory can be stored without our conscious knowledge and we are able to function on that material unconsciously. Implicit memory matures from birth (Zlordre, 2008).

The Diagnostic and Statistical Manual IV-TR recognizes Post Traumatic Stress Disorder symptoms where two of the following are present; involvement with a traumatic event where s/he was confronted with death, threatened death or injury or a serious physical threat to self or others and the person's response involved intense fear, helplessness or horror (APA, 2000). The traumatic event is re-experienced in one or more of the following ways; distressing recollections, dreams, an event that may cause a cue for the person to flashback to the original event or a physical response that was similar to the one experienced at the time of the original trauma.

Avoidance of the stimuli would be indicated by three or more symptoms such as; avoiding thoughts, feelings or conversations associated with the trauma or people, places and events associated with the trauma, or an inability to recall an important aspect of the trauma or a restricted range of affect. Symptoms causing arousal not present before the trauma such as; difficulty falling asleep, outbursts of anger, difficulty in concentration, hyper-vigilance or an exaggerated startle response are also generally evident in client affect. In order for a diagnosis of Post Traumatic Stress Disorder the re-experiencing, avoidance and arousal has to have lasted longer than a month. The impairment must also have caused significant distress in social, occupational or other areas of functioning (ibid). 


\section{Complex Post Traumatic Stress Disorder}

Although this term is not yet in the diagnostic and statistical manual it has merit and may be used as a blueprint because it speaks directly to the effects of what Indigenous people have had to endure specifically in relation to the effects of the residential school legacy on individuals and their families. The difference is that "complex" post traumatic stress disorder affects the health and well-being of an entire culture or community, not just the individuals who reside in it. According to Judith Herman (1997) the following seven criteria can be used as a diagnostic indicator for Complex Post Traumatic Stress Disorder, number one is: A history of subjugation to totalitarian control over a prolonged period [of time] (months to years). Examples include hostages, prisoners of war, concentration camp survivors and survivors of some religious cults. Examples also include those subjected to totalitarian systems in sexual and domestic life, including survivors of domestic battering, childhood physical or sexual abuse and organized sexual exploitation (1997, p. 121). The other six criteria are as follows; number two is alterations in affect regulation like chronic suicidal behavior, self injury, explosive or extremely inhibited anger and compulsive or uninhibited sexuality. Number three is alternations in consciousness including; amnesia or hyperamnesia for traumatic events, depersonalization/ derealization and reliving of experiences. Number four is alterations in self perception including sense of helplessness or paralysis of initiative, shame, guilt and self blame, sense of defilement or stigma and sense of complete indifference from others. Number five is alterations in perception of perpetrator including; a preoccupation with the relationship with perpetrator, unrealistic attribution of power to the perpetrator, idealization of paradoxical gratitude, sense of special or supernatural relationship and acceptance of belief system or rationalizations of perpetrator. Number six is alterations in relations with others including; isolation and 
withdrawal, disruption of total power, repeated search for a rescuer, persistent distrust and repeated failures of self-protection. The last, number seven, according to Herman is alterations in systems of meaning including; loss of sustaining faith and a sense of hopelessness and despair (1997).

Perceived failure compounded with real failure has resulted in what has been termed complex post traumatic stress disorder (ibid); fear, helplessness and horror are all extended components of what was experienced during painful historic and as yet unresolved events that occurred in the experience of an entire people (Wesley-Esquimaux, 2004). Some of the same criterion is recognized in the Diagnostic and Statistical Manual IV.

\section{Residential School Syndrome}

This term is not in the diagnostic and statistical manual either. Yet according to Dr. Brasfield (2001) he has seen many Aboriginal patients who attended residential school presenting with the same symptomology. Residential school syndrome is strikingly similar to post traumatic stress disorder. In both RS syndrome and PST disorder, the survivors had to endure a sometimes repeated experience (example, at residential school) that is intrusive, alien and frightening and their response to it was fear, helplessness and unexpressed anger (horror according to DSM). The avoidance stimuli are similar too, however symptoms peculiar to the residential school syndrome are "a significant cultural impact and a persistent tendency to abuse alcohol or other drugs that is particularly associated with violent outbursts of anger" (Ibid, p. 79) and an induced silence gripped with fear (Corrado \& Cohen, 2003). This silence is ignited by a fear of corporal punishment that was inflicted on them as children if they spoke their own native language (AHF A healing journey, 2006) and was a way to impose assimilation practices. One of the lingering effects from residential school syndrome, which again affects entire 
communities, is a deficiency of parenting abilities (Brasfield, 2001). The children were taken away at an early age; the parents could not act as parents, and the children learned different methods for discipline and communication at schools. Indigenous children traditionally learned via role modeling (Brant, 1990) and if positive parental role modeling was not present, how could they learn, or if the role modeling available was brutal and uncaring, what else would they learn?

\section{Attachment Theory}

When the children were apprehended from their parents or guardians at or before the age of six to attend residential schools (AHF, 2002), they rapidly lost secure attachments with their parents. In John Bowlby and Mary Ainsworth's attachment theory, Bowlby's theory changed the assumption about mother-baby attachment and the disruption caused after a separation, deprivation and bereavement. Bretherton writes that this remarkable theory helped to revolutionize and expand the significant relationship between mother and baby at an early stage (1992). Ainsworth identified an infant-mother attachment as based on an infant's cues and a positive attachment figure. Bowlby, along with two other psychoanalytic social workers believed that "actual family experiences were much more important, if not present, they became basic cause of emotional disturbance" (1992, p. 760). Ainsworth contends that infants and children need to develop a safe and secure dependence on their parents or guardians before going to unfamiliar places.

Both theories are especially important to Indigenous children who were abducted at an early age and forced to attend residential schools. The significance is based on the Indigenous family structure history and the importance of secure attachments with mother before leaving. Sometimes this happened, sometimes not, but the basic family relationship was always lost when 
the children were removed. Another significant finding according to Bowlby was the magnitude and importance of a loving, warm, intimate and continuous relationship between mother and child for a healthy and secure child. This loss of relationship between mother an child was another form of destruction that happened to the children of the residential schools; children were not hugged or loved in these schools and were left alone or beaten if they cried (Hodgson, 1990). Not only was capital punishment rampant, but unexplained deaths began to occur for many different reasons, including excessive physical punishment (AHF Series, The legacy of the residential school, 2008).

In ground breaking research Colin Parkes (1972) fused the theories of Bowlby and Ainsworth and identified similarities in the phases of child mourning and adult bereavement. In further research by Parkes his research revealed the best way to treat negative attitudes about death, dying and grief was to address it as a process rather than a state (Bretherton, 1992). This theory is a 'good fit' for the Indigenous community to begin to work on loss and grief issues because healing is best considered a "journey" that everyone must undertake, and not a state.

\section{Trauma or Bereavement}

The good mind model can address historic trauma, but it is not limited to that alone. Both trauma and bereavement are additional conditions that need to be addressed in different ways. The good mind model addresses both but a proper diagnosis must be identified from the start to develop a process correctly and effectively. There are basic assumptions; such as the helper being genuine, present and actively listening without judgment and allowing the participant to take the time that is necessary for full disclosure. Treatment for either condition requires the development of a degree of trust because this is the main ingredient in the helping relationship. 
Contrasts can be found between a traumatic reaction and a bereaved reaction in four major areas. According to Zlordre (2008) these reactions include: physical differences in the traumatized individual's eyes, wide and slack jawed, perhaps with a high pitch scream, while a bereaved reaction may be soft, dull eyes, constriction of the eye brows and depressed corners of the mouth with low guttural sounds. The thinking of the traumatized person at the time may include; focusing on the event or the scene that happened, while the thinking of the person who is bereaved is the loss of the person. The feelings of a traumatized person may include; distress and anxiety related to the scene, along with fear and helplessness, while the bereaved person may express feelings of anxiety. Finally the degree or nature of the avoidance of the event includes; in the traumatized person the triggers (a reminder of the event) are kept alive, and the anxiety level is high. On the other hand the bereaved person will react with avoidance by pretending the person is still alive, speaking of the future with the person present, and numbing out at the emotional loss. Their anxiety level will be aroused especially around episodic memories, like an anniversary. In general, the response for a traumatized person is fear, helplessness and horror while the bereaved person's response is yearning, 'lostness' and sadness (ibid). The event is not always the key piece; it is how the person perceives it. Another key is the "memory" of the person. In the traumatized person the memory is traumatic, maybe of suffering and the onlooker remembering s/he did not do 'enough' to help. In the bereaved person the memory may be of a last positive event that occurred before the incident.

\section{Treatment}

The first goal of treatment is to work toward empowering the survivor (Herman, 1997). It is important to understand and be aware of the distress, name the feelings correctly and 
differentiate between which area to address, whether it is trauma or bereavement for instance and proceed accordingly (Hill \& Antone, 1990, Zlordre, 2008).

Overall goals of treatment are to understand the symptoms related to the trauma, recognize the connections to the past and integrate present experiences in behavior, feelings and beliefs (Van der Kolk \& Van der Hart, 1995). Lift the participant's spirits to realize self empowerment, control and choice and endorse their authority over the memory process. To continue to strengthen self esteem and resilience, they are instructed to stay connected to positive people, to work to enhance their overall quality of life and to work consciously to prevent intergenerational transmission.

Healing from trauma denotes the ability and courage to work through established chronological development, and by fully maturing in each of the life cycles (see historic trauma). To be able to offer a program with techniques that work with the identified community population who are suffering is paramount for our people. What is also important in undertaking this work are the flexibility and pragmatic approaches used with the people, and the staff that offer, guide and support the healing work in the good mind model.

\section{The Good Mind}

This section will outline what it actually means to have ka'nikonhrì:io "a good mind" for the Haudenosaunee. There is no such phrase as "mental health" for the Haudenosaunee, the closest translation is ka'nikonhrì:io. The good mind is more than positive thoughts and ideas, it was given to the Haudenosaunee from the time of Deganawidah, therefore it is difficult to separate the meaning from the Great Law (Kayanere'kó:wa). For a richer understanding of this topic, the segment on the Great Law of Peace should be intertwined with this segment because this is all a part of the circle of thought, behavior, well-being and politics of the Haudenosaunee. 
To have a good mind means to live in balance and harmony with all of creation. It holistically encompasses the nature of being human, including the expression of all four quadrants of self; the mental, physical, spiritual and emotional. It means having a healthy relationship with other people and a profound respect for the environment (Nabigon \& Mawhiney, 1996). It means to strive to be well for self.

The four quadrants of self are all inter-connected and this is an important part of the worldview of the Haudenosaunee people. The main idea is that each quadrant affects the other parts of the person as a whole, and the totality of the person is fully engaged. When a person has a good mind, it means that person is healthy in all four quadrants. It means that the person has found profound peace and is at ease with the true spirit of self and everything in and around self. The true spirit of self is the inner most self, where we are honest about who we are and forgiving of ourselves for our faults, and where we express our loving of ourselves (Hill, 1995). It is the little voice in our selves, our intuition, and being comfortable with that voice. It is listening to the inner voice and knowing that it is content and in the right place, it means no harm and is patient with our learning and growing into maturity (Hill, 2007).

Since people use their human senses and balance in all four quadrants of self is required for a healthy equilibrium, it follows that each of the senses can have a role to play in creating that balance. To give an example of that interplay, the following senses are illustrated; they can and should interact with each other.

When a person has overall balance, that person will experience love, speak words that are kind, see the beauty around them and feel the joy in life. Those with a good mind are able to tell stories, hear stories, sing, laugh, visit, pray, have restful sleep and healthy elimination (Longboat, Aug. 2008). The good mind is developed from our senses (ibid) of hearing stories, teachings or 
kind words of encouragement. Our voice is also good medicine by way of singing our songs and laughter. The singing can be intertwined with dancing because those activities are spiritual, as is participating in ceremony and community events, all of which are good medicine too (Hodgson, 1990). Our sense of touch, drumming, gardening, participating in fun events and recreational games is good medicine (Hill, 2007). The point is that good medicine is found in many forms for the Haudenosaunee. It is all that is positive and provides a healthy outlook on life.

As the definition is made clearer, a difference is noted not only in language but in meaning. The phrase a good mind can be deceptive when read by a person who is not Haudenosaunee. It could be understood as some one who is smart or can figure out abstract thoughts, or refer only to the mental astuteness of a person, but for the Haudenosaunee it is much more. The idea is that each quadrant affects the other parts of the person as a whole.

Respected Haudenosaunee elders, John Mohawk, (1993), Jan Longboat (Jan. 2008), Freida Jacques (Simonelli, 1997) and Bruce Elijah (2008), teach us that people can find and experience a special form of love when they use their mind to its full potential. This means using the mind to express what is rational and moral and which results in what is socially beneficial.

To a person who is not Haudenosaunee it can be deceptive when they read that one quadrant is the "mental" aspect of a person. Why not just focus on that aspect of self? The answer lies with the way the people think and view the world. For the Haudenosaunee life is not linear, rather it is circular and all is connected; one can not separate one quadrant from another because one relies on the other which relies on the other and so on (Elijah, 2008). In order to illustrate this example Little Bear wrote about this distinction in Jagged worldviews colliding (2000). A couple of words he used to illustrate contrary thinking from an Indigenous world view 
were "linear" and "singular" (ibid, p.82). To explain "world view" he expressed time is seen as linear, it begins somewhere and progresses from $\mathrm{A}$ to $\mathrm{B}$ to $\mathrm{C}$ to $\mathrm{D}$ and singular means to specialize in one area only, like a plumber, a lawyer, or a doctor (ibid). Native people do not think like that, they are more likely to be generalists, good at many things, and using all of their faculties to get along in the world. This contrary thinking is not to emphasize that one value system is better than another, it really is about perspective, and should be kept in mind when discussing what is valid and what is not.

To have a good mind is not only about mental health; it is a state of being other than only thoughts and ideas, it can and does include the complete person. As far back as the early seventeenth century the Iroquois knew their existence depended on peace. Richer states "peace was primarily a matter of the mind" (1992, p. 40). Therefore an emphasis on good thoughts, words and an exchange of gifts between Nations were good not only for the people involved but also for the Clan and villages where they lived. Goodwill provided a positive emotional climate and acted as a deterrent for other people who may have wanted to cause wars with those Nations. The Peacemaker gave the League of the Five Nations those virtues that were held in esteem and allowed peace to prevail; patience, consensus, goodwill, harmony, selflessness and to stay away from criticism, harsh words, anger and greed. As the League of Nations already considered each other as family (Kayanerekowa; Parker, 1968) and believed in consensus, those like virtues were held in high esteem (Little Bear, 2000).

In fact, an historical record was made by way of a wampum belt to signify the importance of the family of the Great League. This wampum belt is known as the Hiawatha Belt (Tehanetorens, 1972). The symbols are four rectangular/square boxes and connecting the boxes in the centre is a tree. All of the symbols are horizontal to each other and all are connected by a 
line. At each end of the boxes the line extends out. The box on the left is slightly smaller than the one next to it and it represents the Mohawk Nation and its territory. The box next to the Mohawks represents the Oneida Nation and its territory. The next symbol is the tree, it represents the heart of the Nations and signifies unity within The Great Peace and signifies Onondaga Nation and its territory. The Onondaga Nation has the responsibility for the Council Fire to burn in their Nation. The box on the right of the tree is the bigger box of the two and represents the Cayuga Nation and its territory and the box to the extreme right of the Cayuga Nations represents the Seneca Nation and its territory (ibid). The line leading out of the Mohawk Nation and out of the Seneca Nation signifies the "Path of Peace by which other nations are welcomed to travel, and to come and take shelter beneath the Great Tree of Peace or join the Iroquois Confederacy" (ibid, p. 8). The symbols are outlined in white characterizing peace, love, equity and the Tree of Peace is completely white. The rest of it is purple. This symbol is recognized today among the Iroquois people.

Peace, harmony, consensus and tranquility are earmarks for cohesiveness. Family represents unity, loyalty and a responsibility to each other. Therefore, the rules and guidelines for acceptable behavior are born out of necessity. Elders used to say if a person does harm to self or others that person has not been given the teachings about proper behavior. If, however a person continues to do harm to self or others after the teachings then that person requires healing (Ross, 1996).

Dr. Clare Brant, a Mohawk from Tyendinaga wrote about Native ethics and rules of behaviour when he noticed the importance of cooperation that continues to this day (1990). Initially cooperation was essential to the survival of the group but it still continues in the behaviour of Indigenous people. Conflict suppression and overall harmony was most important, 
non interference was appreciated as a norm as any type of coercion in the group was considered bad manners. Non competitiveness was also a prized norm because it was considered bad form to make anyone feel they were any less than anyone else. In particular, the emotional expression of anger, rage or even extreme enthusiasm was suppressed (ibid). Restraint, emotional control, or even passivity were considered strong traits and held in esteem, and regarded as characteristics befitting a chief (Kayanerekowa).

The legends, values and customs of the Haudenosaunee provide the foundation for the good mind. Survival of the group meant that cohesiveness and unity in strength through cooperation was a necessity for fostering democracy, good governance and politics. There is talk today by elders that the Iroquois Confederacy gave rise to the thinking of the founding fathers of the United States and their democracy, right down to the Eagle on their flag and it forms the basis of the principles of the United Stated Constitution (Porter, 2004).

\section{A Crooked Mind/Not a Good Mind}

This section will explain what it means when people do not have a good mind. As noted it is complex to dissect what it means to 'not have a good mind', because it is not only the other half of 'to have a good mind'. It is not exactly a dichotomy like "good' versus "evil", as Mann has stated very eloquently "the equation of insanity with evil is a western notion" (1997, p. 428). In Haudenosaunee teachings, we are told that people basically are good; but because humans are such weak vulnerable creatures, Shonkwaya'tíhson (Creator) knew that we would stray from our original teachings and as a result gave us the Four Messengers to help straighten our minds (Porter And Grandma Said, 2008).

It is very difficult to dissect the notion of mind, body, spirit and emotion in harmony with the environment (Little Bear, 2000). With that limitation in mind, I will attempt to divide the 
good mind from the crooked mind. This endeavor is to illustrate the importance of connectedness as a process that does not contemplate one singular entity in and of its self; but contemplates the interconnectedness of all. This is about the relationship of connectedness to having a healthy existence, in this context; expressing the good mind and the crooked mind.

The worldview of the Haudenosaunee is circular, flux, in motion; it is continually moving as a process. Little Bear noted the seasons as a good example, there are four of them and while they run their course, over and over again, it still is spring, summer, fall and winter, only to begin again (2000). The Haudenosaunee know that, and have a ceremony to shake awake and to celebrate the renewal of seasons (Porter And Grandma Said, 2008). Because the Haudenosaunee worldview is circular and not linear it can not be cut off at a particular point and begin afresh. There is always some loss of meaning in the translation of concepts and worldviews (Mann, 1997). With that caveat I will attempt to explain the meaning of a crooked mind.

A crooked mind illustrates the lack of psychological peace or being in intense pain. The crooked mind exemplifies a true spirit injured by trauma or loss and generally a loss/ break of cultural teachings. A crooked mind is the reverse of a balanced or a good mind. All of the positive examples given will now be in the reverse. When a true self or spirit is referenced it means the genuine person inside, the true spirit of self, the reverse self is regarded as the false self. According to Jan Longboat the false self is the one that self doubts, and second guesses, and ignores self reflection and introspection (Jan., 2008). Self doubt and self reflection are two different concepts, self doubt refers to suspicion, distrust, or skepticism in self where self reflection is "the detailed mental examination of your own feelings, thought and motives" (Word, 2007, Thesaurus; Morrisseau, 1998). 
Self reflection is required to stay balanced but if it is ignored we will lose balance and become ill in some way. Self reflection reconnects us with our inner most self, because it is an honest examination of who we are, why we act like we do and how we honestly feel. All of these reflections are necessary for personal growth and healing (Nabigon \& Mawhiney, 1996; Hill, 1995). The opposite is true too, when self reflection is ignored, personal growth is stunted and the healing journey cannot start; the false self emerges, ergo the loss of balance. Self reflection goes hand in hand with the philosophy that Haudenosaunee and other Indigenous people must have personal agency in their healing. As mentioned before health is a person's responsibility and personal obligation (Shestowsky, 1992; Waldram, 2008).

For the Haudenosaunee having a "false self" can affect people collectively as well as individually. An individual may have a crooked mind for reasons unknown like Atotarho (see Glossary) or initially the person may have a good mind but grief has overwhelmed a person's life like Hiawatha. Collectively the "false self" can be unchecked; and this can prompt wars between Nations and make dis-ease among the people become a reality.

Haudenosaunee teachings tell us that where there is light there is also darkness and that this understanding is referred to as moving toward balance (Longboat, Jan. 2008; Little Bear, 2000; Nabigon \& Mawhiney, 1996). When a person acts only out of their darkness or focuses too much on their darkness there is violence, alcoholism, rage, abuse or dysfunction (Nabigon \& Mawhiney, 1996; Brant, 1990). They are out of balance with themselves and the world and this is regarded as a form of spiritual disease (Nabigon \& Mawhiney, 1996).

As a rule, if one aspect of a person is seriously out of balance, it will adversely affect the rest of the person. Being out of balance can include; being physically ill with an ailment; or spiritually lost with no connection to your true self or to the Creator. To be out of balance may 
result in a person feeling emotionally hollow. They might feel shame, fear or guilt. They may feel lost. They may be unable to tell stories or meditate or receive the value of teachings. This list is by no means exhaustive; it can mean many different kinds of reactions or emotions. When a person is out of balance, that person may think in a way that people normally do not and make themselves feel in a way that is negative. Then actions may follow that could be harmful to self or others, in turn, medicines may hide from them, and positive spirits may stay away.

The "mental" quadrant for the Haudenosaunee encompasses cognitive ability but that is only one fourth of it. Most Haudenosaunee people are taught to live a good life and have a good mind. To live a good life is not only about examining one quadrant of the mental aspect of a person's life, it is about the whole person and how that person should live their life with other people in their environment. This is one of the differences in Ka'nikonhrì:io because when there are teachings about a good mind it can be accompanied with an inspection of the dark side of the mind. It is not in isolation, it is part of the teachings of awareness and insight to stay in balance by recognizing signs and signals when the good mind is not engaged. The complete balance of love and good mind draws positive spirits, just as envy, jealousy, hatred, or unkind words will keep the positive spirits away (Longboat, Aug. 2008 ; Porter, 2004). They are not invited into that person; in fact the energy is opposite. We listen to the dark side of our good mind; because we can not ignore one without ignoring the other. The dark side is there to help keep us balanced. The dark side is always present. It is there to be listened to, and to learn from and to make us aware of negative thoughts. We can challenge it and in the end, make rational judgments (Jacques, 1997). 


\section{Legends as Example of the Good Mind and the Crooked Mind}

There is an individual example of a false self in the legend of Deganawidah. The Peacemaker challenges Atotarho when he does not have a good mind; Atotarho's body is crooked and he has snakes in his hair (Wallace, 1946). The legend does not detail why Atotarho has a crooked mind only that he is a malevolent and powerful man and feared by many. Deganawidah knew he needed Atotarho as an ally in order to accomplish his quest for peace. Deganawidah already had the other four Nations in agreement with the Great Law of Peace; Mohawks, Oneida, Cayuga, and Seneca and the other chiefs of the Onondagas were in agreement except Atotarho. By reciting the meaning of the Great Law of Peace, Deganawidah promised the title of Head of Chiefs to Atotarho if he joined the covenant. It worked, Atotarho was placed the Head of Chiefs of all the five Nations of the League and he accepted the message of peace. It is said that his mind went "smooth" his body unfurled and Hiawatha was able to comb the snakes from his hair. He was reformed (ibid).

Another example of a crooked mind, in relation to grief, is in the legend of Deganawidah; it outlines Hiawatha's inability to function after the death of his loved ones. He does not have a good mind for some time. It speaks about his inability to function in society and his attempts at isolation. The legend reads that Hiawatha gathered three shells of wampum suspended them between two sticks and wondered why no one came by to comfort him in his time of sorrow. Although he did cast himself away from communities he was not thinking rationally, his emotions, spirit and thoughts were clouded by grief.

Grief can become overwhelming to any person. When grief is ignored it builds up and can have an adverse effect on the mind, body and spirit. It becomes a heavy burden the person must carry and many negative emotions can emit from it like depression, anger, rage, silence or 
isolation. Hiawatha was walking around with unresolved grief. He was carrying depression and isolating himself, his mind was clouded by unresolved grief. To put this grief in context it is important to remember Indigenous people believe in the value of collectiveness, as Little Bear noted "The value of wholeness speaks to the totality of creation, the group as opposed to the individual, the forest as opposed to the individual trees" $(2000, \mathrm{p} .79)$. To be cast out of a community or Nation can mean death to that person even if it is self imposed. So for Hiawatha to isolate himself he was spinning into a darker side of his mind. In his mind he wanted someone to help him with his grief, he wanted someone to console him and speak words of sympathy but he chose to leave the villages, a stark contradiction.

Deganawidah went to Hiawatha and saw him in mourning and knew of his troubled mind. Deganawidah strung strings of shells together for Hiawatha and he picked up the wampum Hiawatha had made and he began to recite the Words of the Re-quickening Address. With the Address complete Deganawidah put his arms up and outward, Hiawatha's mind became clear and he was able to think rationally again (Wallace, 1994). It addressed the importance of ceremony in restoring peace in self and all around and with the good mind it strives to reclaim: the true beauty in spirit.

There had been death before Hiawatha and so the Iroquois people were given the Condolence Ceremony because death is a part of the circle (Porter And Grandma Said, 2008). The paradigm of death actually began with the Creation story. The legends have a connection to the ceremonies of today. The following is an example to that link. According to Porter it began when Sky Woman gave birth to the twins (ibid). As the story is told, Sky Woman died giving birth to her second son, Shawiskara and her mother was left in mourning. Her mother started to cover her daughter's body up with dirt; she did not dig a hole, rather she heaped dirt on the body. 
From where her head was buried the three sisters began to grow, corn, beans and squash. From where her heart was buried, the sacred tobacco grew. Gradually other kinds of food began to grow. The Creator gave the people these gifts through the mother. That is the reason why the Earth is called Mother, Mother Earth. Our Mother gives us food for sustenance and sacred tobacco to remember to be thankful. That is also why the Haudenosaunee consider tobacco sacred; it was given to bestow thanks and is used in ceremony (ibid).

There are times in history when the people forgot their ceremonies. According to prophecy when the people forget their ceremonies and no longer practice them, that will be the end of the Haudenosaunee people (Porter, 2004). The Great Law of Peace re-established the Condolence Ceremony and was used to end the grieving period for a chief that had passed away as well as 'launching' another chief. According to Tom Porter, violence and wars are happening to our people because we forgot our original teachings.

Creation, the land, animals and people are all symmetrical and according to prophecy if the people forget about the animals, the animals will forget about us (Sheridan \& Longboat, 2006). The animals follow their original instructions and provide guidance, and natural law, but when the circle is broken the people are unguided and disconnected to Creation. There is no identity, there is no connection and the people cannot go back to where they came from, there is chaos, uncertainty and imbalance (ibid). That is what happens collectively.

Brant noted traits and characteristics of suppression of emotion were regarded in high esteem (1990). In the Great Law traits such as passivity, patience, generosity "thick skin" and a genuine concern for the welfare of the group was noted as admirable. But times have changed and so have social circumstances, those traits while still admirable have shifted in the context of a modern life and living. 
Aboriginal people do not necessarily have higher rates of mental illness or are necessarily predisposed (Earle, 1998); rather they suffer a form of dis-ease that has resulted from colonization, the Indian Act, the residential school legacy, the sixties scoop and broken treaties (Out of the shadows at last, 2006). Feelings of powerlessness have manifested themselves into post traumatic stress disorder, complex post traumatic stress disorder, residential school syndrome, alcoholism, drug dependence, suicide, violence and living in poverty and despair (Report of the Royal Commission on Aboriginal People, v. 3, 1996; Stamm et al, 2003; Herman, 1997; Corrado \& Cohen; 2003).

This is the ethos of a crooked mind.

\section{Literature Review:}

A literature review was necessary to locate the body of knowledge already available about good mental health according to Indigenous peoples. In my native language, Mohawk, there is no such phrase as good "mental health". The closest translation to naming mental health is ka'nikonhrì:io which is translated as the good mind. "Available literature confirms that various physical illnesses or psychogenic illnesses cannot always be seen in a specific diagnostic light, in particular by those coming from what would constitute a foreign culture (WesleyEsquimaux, 2007, p. 63).

What really matters to Native practitioners are that the paradigm that best works with the person who is facing a mental health issue is fully addressed (Warry, 2007, Peacock \& Wisuri, 2002, Gideon, 2005). Therefore, what may sometimes look like an illness to an "outsider" may be accepted cultural behavior to the "insider" (Wesley-Esquimaux, 2007, p.63). The key for practitioners is to make distinctions between various behaviours and to identify states of 
unwellness as named by individuals or communities and then find out from them what they would like to do about it (Mander \& Tauli-Corpuz, 2006, Waldrum, 2008).

Linda Tuhiwai Smith (2000) takes research one step further in her account of methodologies. She notes that Indigenous activists take the position that they can tell their own stories and not be passive victims. This type of resistance research constitutes a valid process and it has been done successfully, even though it triggers attendant resistance from the dominant institutions. The kind of research I will be undertaking should be viewed as an opportunity to engage in "indigenist research" rather than a deviation from what is still considered normative research practice in the western academy (Rigney 1999, p.118; Walker, et al, 2006).

The thesis will outline a few legends of the Haudenosaunee including the Creation story the Thanksgiving Address and the Peacemaker legend. Those legends and prayers contain the teachings of how to live from the Creator. I will detail why the symbolism is important in these stories and how they relate to a people living with a good mind. All people have cultures, beliefs and language, these practices distinguishes people from each other. For the Haudenosaunee the Creation story, the Peacemaker legend and the Thanksgiving Address teaches many specific lessons; one of the most important of which is living in balance, in harmony, peace and tranquility. It is all about relationships or what we would refer to as ka'nikonhrìio, (a) good mind.

Although the Creation story sets the stage for Iroquoian cosmology (Blanchard, 1982) and the beginning of life for the Haudenosaunee; a comparative analysis will also set the stage to illustrate the gender differences between the Haudenosaunee and the people they met after contact. The Haudenosaunee Creation story introduces the symmetry of life and everything in it; it is about relationships. The intent of including these stories is to explain the duality of all of 
life, the circular inter-connectedness and how that can be expressed in relation to the good mind. The Haudenosaunee woman was regarded as the "centre of all things" (George-Kanentiio, 1993, p.1). Although the balance of man and woman is noted in the Haudenosaunee story; the woman is regarded as the giver of life and therefore extremely important (ibid). The Creation story introduces the balance of opposites, transition, and the cylindrical nature of everything, how crucial it is and how that relationship is tied very closely to having a good mind.

\section{The Mohawk Creation Story}

Today there are slightly different versions of the Creation story; the start of this version comes from John Mohawk (1993) who gave his account from J.N.B. Hewitt who wrote Myth of the Earth Grasper (1925-1926). Mohawk provided some interpretation and clearer language. This interpretation ends when Sky Woman falls from the sky. From there I will attempt to tell the story that is most familiar to my community of Tyendinaga. It will start when Sky Woman falls from the sky.

According to Mohawk the Creation story begins with The Ancient Man aka He tosses Skies About. He had a sister who was called Ancient Woman. According to legend it was believed if children were hid they could later become powerful so when Ancient Woman had two children a boy and a girl, he hid them from everyone. He had plans for the children. The Ancient Man foretold his pending death and instructed his sister and the children what to do with his body and that they could speak to him if they needed him and he would guide them. In time, he passed away and they took his body into the highest tree and left it there as instructed.

By and by the children started to grow and a messenger was sent to the Ancient Woman. She was told that their Chief wanted her family to come to his feast. She asked who had been to this feast and he said everyone except Wind, this meant; Sun, Moon, Star, Tree, Bush, grass, 
animals, birds, water, light, clouds, corn, beans, squash, tobacco plant, night, day light, Thunderers, Waters, Comet, blue sky and air. So Ancient Woman went to see this leader; his name was He-Earthholder and his other names were Hoda'he', He Has a Standing Tree, or Keeper of the Standing Tree. He-Earthholder said he wanted her family to come to his feast. She stated that her children were still young and He-Earthholder said he would wait.

In the meantime, the brother told his sister that their Uncle wanted to see her and it was good. So the young girl scaled the tree and listened to her Uncle, Ancient Man. He told her of He-Earthholder and that she is to go to his feast. He told her to tell him her name was Mature Blossoms and that she has come from the place where 'Stands the Standing Tree'. HeEarthholder will then ask you to prepare food for him and it will splatter all over you but you will not cry out. He will then call his "servants" which are dogs and they will lick off the splatter and you will remain silent. If you have this courage, you will pass the test. He will then tell you he had a dream where The Standing Tree of Fruits and Flowers was upturned and he and his wife were at that place. Her Uncle told her not to be afraid.

With that she scaled back down the tree to meet her brother. She told her brother that she was going to He-Earthholder's feast and her brother said it was good. Before she departed her brother said, it will come to pass that you will depart this world but before you do, remember me as He-Earthquake. Everything her Uncle had foretold had come to pass; He-Earthholder had a few other "tests" one that she failed that included silence of a different task and he was angry. He told Mature Blossoms to go back to her mother's lodge. He was angry that her mother had not given consent for her to marry him, so she did as she was instructed. Ancient Woman knew she had gone against custom and knew she was delaying the marriage, so she told her daughter to stay there and she would go and give her consent. He-Earthholder was pleased when the mother 
showed up and gave her consent to their marriage. He-Earthholder instructed the mother to go back to her daughter and tell her daughter not to talk to anyone and to come straight to his lodge. Ancient Woman did as she was instructed, the daughter left and was successful, He-Earthholder was pleased and they married.

Time passed on and Mature Blossoms became pregnant and He-Earthholder wanted everyone to come and guess his dream so his mind could be at rest. Everyone tried and finally Comet said you want us to uproot the Standing Tree and He-Earthholder said yes he was correct. He then finished the rest of his vision. He said he could see him and his wife sitting at the edge sharing food and he had seen everything that shall come to pass.

With that, all gathered around to make the dream come true, they all uprooted the tree and Mature Blossoms and He-Earthholder sat at the edge of the hole with their feet dangling into the dark hole. Mature Blossoms stated to her husband "your dream has come true".

At this juncture is where there are differing accounts of how Mature Blossoms or Sky Woman fell from Sky World. Tyendinaga's version usually starts when Sky Woman falls from the Other Side of the Sky (Sky World). Even in Mann's version of the Haudenosaunee Creation story it begins with the time of the Sky Woman and makes no mention of her before. She does say that Sky Woman fell but she does not say exactly how that came about. She writes that by the time the missionaries heard the Haudenosaunee's Creation story "they casually linked Sky Woman, the original Medicine Woman, to their Devil, even as they linked 'witches' to Satan in their own culture" (1997, p. 427). They cast Sky Woman as evil and say she was pushed from Sky World, as in the Christian story of Eve being cast from the Garden of Eden for luring Adam to eat the forbidden fruit. 
In Mohawk's version she was pushed into the hole by her husband for reasons which are still unclear; but Comet saw her coming down and promised to help her because He-Earthholder had accused him of the same deed and had cast him out too. By and by as she fell she heard other voices that had been cast out too and one voice reassured her that this new place would be the same as the one that she left.

In Tom Porter's (And Grandma Said, 2008) version he said that Sky Woman had instructed her husband to retrieve fruit from the tree but the husband knew they were instructed not to touch the tree or its contents. Sky Woman was angry when her husband returned empty handed and she went to get the fruit herself and fell in the hole, she got too curious and too close, slipped and fell into the hole. Porter stated that he had a hard time believing that a Haudenosaunee man could possibly hurt his wife, it was forbidden, especially if she was pregnant. It goes against all of our teachings (2004).

The story resumes when Sky Woman is descending with basically the same elements in all versions. As she was grasping for something to hold on to, and to stop her fall she accidentally grabbed some seeds before her descent. At that time the Earth was covered in water. The birds saw that she was falling and they noticed that she did not have webbed feet and would surely drown if they did nothing. They quickly had a meeting to decide what to do about it. The birds came together and with their wings caught Sky Woman in their feathers. They noticed that she had seeds clutched in her hands. She said she was trying to grab them to prevent her from falling but to no avail. The birds thought they were (the Three Sisters as the Mohawks would call them) corn, beans and squash seeds. They tried to take her back to the hole in the sky but found that it was impossible, they could not, it was too far and they grew too tired in their attempts. The birds were talking with the water animals and they tried to come up with a 
solution because they could not keep her suspended. The water animals talked amongst themselves and the turtle said she could sit upon his back. The birds sat Sky Woman on the turtles' back and decided they had to dive into the water to get some earth for her. Two different water animals tried but each one drowned trying to get some earth from beneath the water for the woman. The animals knew instinctually that Sky Woman needed earth so the last animal, a muskrat tried and after a prolonged period under water popped up; exhausted but successful. Clutched in his paws was earth.

The earth was placed upon the turtles' back and with the seeds she was able to start growing food for sustenance. It is said she walked on the turtles' back counter clock wise continually chanting and magically the earth started to expand, soon there was rolling hills and valleys. This is why the Mohawks refer to the world as Turtle Island because there is water surrounding the earth and the Turtle was there before humans.

Miraculously Sky Woman was pregnant when she fell or got pregnant and had a daughter. Time passed as they were the only humans on Turtle Island. The women were very close and wandered the earth naming the creatures they came upon because all could communicate with each other. The time came when a mystical presence showed up and the daughter got pregnant. Her daughter gave birth to twin boys but died giving birth leaving the grand mother to watch over the boys. The boys names were Tharonhyawá:kon "He Embraces the Sky" and Shawískara "Mischievous One" with obvious connotations to their personalities. While Tharonhyawá:kon made beautiful things like the rose, Shawiskara would put thorns on the stem. The boys were always vying for the Grandmother's attention and sibling rivalry continued. It is said Shawískara was jealous and his mind was wrinkled; he believed his Grandmother only loved Tharonhyawá:kon. Shawiskara thought his Grandmother blamed him 
for his mother's death which he thought made his Grandmother angry with him.

Tharonhyawá:kon believed he had to take care of his brother for all of humanity because his brother's mind would not become smooth. He sealed him under the great mountain because he could not kill him. There Shawískara lingers just on the outside of the community concealed under the mountain (Porter, 2006; Mann, 1997; Mohawk, 1993).

\section{The Analysis of the Creation Story}

The meaning of this Creation story is significant because it shows the importance of women from the very beginning. The Haudenosaunee have always believed since time immemorial that the women are very important to our survival (Kayanerekowa The Great Law, George-Kanentiio, 1993; Soloman, 1994; Tobe, 2000). The Haudenosaunee followed female matrilineage. The women are the givers of life as told by the Creation story and are a direct ancestor of the Five Nations, an originator of a line of descent (Kayanerekowa The Great Law). According to the Kayanerekowa Great Law the women are the original caretakers of the land and the soil and as such were at an economic advantage. The women provided the food supplies and owned the home. The women were very powerful politically (Richer, 1992). The women knew how to look after the men, the men knew how to look after the women and the men and women knew how to look after the children (Longboat, Aug. 2008). The women fed and nurtured the males until each male entered puberty and had a 'rite of passage' befitting his age. The ceremony distinguished the boy from a man and the man will begin to follow his father, uncles and the males of the village to learn his role and responsibilities.

According to tradition, the men are there to protect the women, children and Elders of the community. That was one of their original roles. The roles of men will be a significant factor when the Haudenosaunee come into this century. Due to colonization, the roles of men 
have changed dramatically. They no longer hunt, trap or fish to feed their families. The Indigenous people were herded on to reserves so they were not able to migrate to follow the animals for food (Indian Act, 1985). Furthermore, when the Government legislated that all six year olds and older of First Nations descent had to be taken away to residential school (AHF, 2002); the men could not stop it and therefore could not protect their children or their families, one of their original roles. The impact was devastating to the Indigenous family, the family structure, their political organization and their psyche (ibid; RCAP, v. 3 1996).

\section{Women and Men: The Different Genders}

It is no coincidence that the women or Clan Mothers choose the chiefs for the nation (Kayanerekowa, The Great Law; Parker, 1968). Practically it is sound as who would know a person better in character, trait, personality and heart than the people that help raise all of the children. The Clan Mothers will have known that person since the time of their birth. Typically the chiefs were/are males and it is the women that chose them and this has kept a balance of the genders in the past. The Haudenosaunee's history began with a matrilineal society and as such they followed the women's clan. The Mohawks have three major clans, Bear, Turtle and Wolf. A Haudenosaunee person can have cousins all over Turtle Island and throughout the Confederacy and it is believed they are not allowed to marry within the same Clans (Wallace, 1946; Kayanerekowa). The Clans are governed by the Clan Mothers, and they decide when to go to war, when there will be peace and they run the local government (Kayanerekowa The Great Law; Mann, 1997; Richer, 1992). It is said, that a man who wants to be chief, will never be chief, and the Clan Mothers ensure those who are chosen are suitable to lead.

The Creation story centers on the woman and her importance to life and continued life. However it is also inclusive of men, whether the way in which Sky Woman was pushed from 
Karoniake (where she came from) from her husband or the mystical way both her and her daughter got pregnant there is the mystery of the male presence. In Mohawk's version the daughter became pregnant by Wind; he wrote that Wind continued to change into beings that she could not resist (1993). It also lends support as to why Wind may not have attended the original feast of He-Earthholder. However there is nothing definitive about the father of the daughter's child of Sky Woman. It may not hold importance. The theme of the significance of women will be carried throughout the history of the Haudenosaunee people; the inter-generational key that will pass the value, tradition and cultural beliefs of the importance of family and relationships in harmony. This is further illustrated in the Thanksgiving Address, (the words that came before all else) a prayer to the Creator. It is about interconnectedness and relationships in harmony.

The introduction of balance is also important. In the Creation story, it centered on a Grandmother and a daughter. The daughter had twin boys therefore: balance. Yet later in the story one boy creates beauty while the other twin creates havoc: balance. There are humans in the story but the birds and animals were there first to save Sky Woman: balance and reciprocal respect. One animal was not more important than the other, one human was not more important than the other; all could talk and relate to each other: communication. One moved into action to help the other and all worked together to achieve a goal: cooperation.

The Creation story is also about relationships with and between the animals, birds, plant life, each other, the cosmos, water, earth, ka'nikonhrì:io the good mind, balance, spirituality, sken:nen, peace, tranquility, morality, rationality, sustenance, language, communication, identity, birth and death. All of these qualities and criteria outline Haudenosaunee tradition and culture. 


\section{Thanksgiving Address/ Opening Address or Ohen:ton, The words that come before all else}

The Words that come before all else was given to the Haudenosaunee by

Shonkwaya'tíhson (Creator). It is found within the Great Law and reminds the people to be thankful and send greetings to all in Creation. It is one of the first ceremonies to be given and is encouraged to be said every time there is a gathering of people for the first time; that is also why it can be called the Opening Address. The Address acknowledges and sends greetings and thanksgiving to all of the spirits on Mother Earth and in the cosmos. These things provide sustenance for health and well being and without it there would be no life. It is spiritual talk and reminds the people to stand united in thoughts, to be of one mind and to remember those people who are of ill health and to pray for them.

The Address is filled with symbolism and reminds the people they are not alone. It outlines many features in Creation and the people must remember to follow those natural laws and fulfill their responsibilities. The minute the people forget to follow those teachings is the moment they will begin to go astray. (Sheridan \& Longboat, 2006). It is said that the people will begin to fight amongst themselves because they strayed from their original instructions.

The Address shows the relationship of the extended family to the Original People. One of those relationships is to Mother Earth, because she gives sustenance and supports their feet. Mother Earth has never abandoned the people and she continues to follow the original instructions (Thanksgiving Address). Each extended family member also has a role and responsibility and must work together as this is the basis for natural law. The bodies of water are mentioned and thanked because it cleanses the earth and the people. The fruits and trees are mentioned, greeted and thanked because they give medicines, food for health and heat for human bodies. The Maple tree is given special thanks as it provides the maple water (wáhat ohses) 
during spring and is said to be a gift from the Creator. It is called maple water because it does not become syrup until after it has boiled down (Butcher, 2007). The strawberries have a sacred place in the Haudenosaunee's existence, it is said that it was one of the first fruit given to them. The animals and birds are acknowledged and thanked because they give humans food for sustenance and their coats of fur and feathers help to make clothing to protect the humans. The sustenance of the Three Sisters is corn, beans and squash all of which are basic to survival. Haudenosaunee can plant and harvest the sisters so they may feed the people and keep them strong. The Thunderers are the Grandfathers and they come from the west to assist with fresh water and assist with the growth of all things on Earth. The wind blows over the Earth to create moderate temperatures and assist the plant life by spreading the seeds. The Sun is the Elder Brother and his responsibility is to warm the land and air and assist in the growth of all things. The Sun works in harmony with Grand Mother Moon and gives the daytime light. The Grand Mother Moon provides light during nighttime and assists in all matters relating to females life on earth. The Stars are the relations that carry the knowledge of the early beginnings, and serve as markers of time and also provide nighttime light. The Four Beings or the Messengers are to give the people various messages about health and well-being. It is those beings that straighten the minds of the people and remind the people to stay balanced in spirit, emotions, mentally and physically. It is those energies that flow in all of the people (Elijah, Aug. 2008). The prophets are also given greetings and acknowledged because they have walked before the people and they were given the original instructions. Those spirits wanted the Haudenosaunee to give thanks and respect to all living creatures and to honor the way of the Creator. Then the Creator is acknowledged and thanked because the Creator lives on the other side of the sky and is the source of the life force. Although there is variation in the Thanksgiving Address it basically 
acknowledges all of Creation and shows the strength of the relationship to the people and outlines their responsibilities and the importance of working together.

The Thanksgiving Address at one time was the only ceremony given to the Haudenosaunee. It was a way to give thanks; it was oral and had to be memorized, but oral teachings were also educational (Friesen, 1999; Longboat, Aug. 2008) and the Thanksgiving Address is also considered sacred. The Thanksgiving Address is spiritual instruction and is the basis for connection to all spiritual forces. It was a reminder to the people to be thankful for everything they have and to show respect to all in creation and to the Creator.

The Address asks that everyone be "united in thought". With this concept in mind it is contrary to fight, to scheme, to be disrespectful, violent or jealous. It is about honesty, respect, and working toward a peaceful outcome, for the betterment of the family, and the Nation. One mind does not imply people can not have their own opinions, rather it means that opinions have been voiced, heard by the group, and there is consensus for a rational, civil, moral, tranquil and peaceful existence together.

An Elder once said we are all part of the same circle whether we are different colors or people from different places, our Elder Brother Sun does not only shine warmly on the Haudenosaunee, he shines on everyone. This means that even though the "Words that came before all else' were given to the Haudenosaunee originally, and continue to be used by Iroquois in Long House ceremonies to this day, they are words and concepts for everyone to share on Turtle Island.

\section{The Legend of Deganawidah- The Peace Maker}

The legend of Deganawidah is very important to the Haudenosaunee because it lays the foundation for the thought process of how the people should act and behave. Deganawidah is the 
Peace Maker and as such laid down the Great Law of Peace, or Kayanere'kó:wa (The Great Law, Porter And Grandma Said, 2008). Prior to Confederation there were many Indians fighting with each other (Richer, 1992; Wallace, 1946). There was no peace and people were afraid because they never knew when their neighbor would wage war against them, or just kill them (Simonelli, 1997). It was said to have been a savage time in which to live and Indians were said to have been cannibals because they did not know it was wrong (Mann, 1997).

\section{The Four Sacred Beings:}

According to our Creation story Shonkwaya'tíhson (He who Created Us, the Creator) knew the humans were the most needy of the creatures that were made (Porter, Oct. 2008). To make sure humans had help when they needed it, the Four Sacred Beings were summoned for this job. It was foretold that humans would go astray and away from their original teachings of the Creator and it was the job of one or all of the Four Sacred Beings to set right what had gone astray. By this time, cannibalism, civil war and death were surrounding the Haudenosaunee. Legend has it that one of the Four Sacred Beings was Deganawidah. Deganawidah was born Huron but was later adopted by the Iroquois (Shenandoah, 1994). From Porter (And Grandma Said, 2008) Wallace (1946) and Parker (1968) Deganawidah was born north of Ontario, not far from modern day Kingston, Ontario, at the Bay of Quinte, close to Deseronto (which is close to Tyendinaga). Further Parker writes that the people there have found where "the great Elm" is buried, the reputed Tree of Peace (1968, p. 13). Other versions of the Great Law report that the tree is white pine (Wallace, 1946).

It is said Deganawidah was born from the form of one of the Four Sacred Beings to help the Haudenosaunee restore order and peace. It is also said that he started with the Mohawks because out of all of the tribes they were the fiercest of the Tribes (Porter, Oct. 2008). After all 
if he could convince the Mohawks to restore peace and harmony, the rest of the Tribes would be easier to convince.

There are different versions of the Peacemaker according to the Iroquois legends. One is of Deganawidah and another is of Handsome Lake. It is important because both claim to be the "Peacemaker". The people of Tyendinaga have been taught about Deganawidah for many years and the majority of the people believe in the legend of Deganawidah over the Code of Handsome Lake (Porter, Oct. 2008). The Code of Handsome Lake originates from other Nations within the Iroquois like the Seneca and Onondaga Nations. It is significant that the Code of Handsome Lake brought "Indian religion" (Parker, 1968, Plate 9) while Deganawidah makes no such claim, he was to have brought peace, not religion. It is noteworthy to mention both to provide a more full account of different versions; it is not my intent to argue one way or the other possible reasons for it. In this particular segment the legend of Deganawidah will continue.

\section{The legend of Deganawidah- The Peace Maker continues}

Deganawidah's Grandmother was visited in her dreams by a Messenger from the Great Spirit Shonkwaya'tíhson. In the dream the Messenger told the old woman her daughter will have a son and he will have an important mission in life. When asked what that mission will be, the Messenger said he will pass the message on of peace, unity and respect among the people. Do not try to stop him in his quest as this is the wish of Shonkwaya'tíhson.

As time moved on the daughter became pregnant. The Grandmother was very disturbed because she wanted to know who the father was because she had kept a very sharp eye on her daughter and did not think it was possible for her to be with a man. The daughter was indeed pregnant and professed that she had been with no man but the Grandmother did not believe her daughter. When the child was born, the Grandmother thought she had to get rid of the child 
because it was not natural, because the daughter swore she was a virgin. Nonetheless, the daughter named the child Deganawidah. As the daughter was sleeping with the child the Grandmother stole the child and went down to the river. She made a hole in the ice and threw the child in the hole into the water. But when she returned to her settlement, she heard the child; she rushed into their home only to find the child snuggled deep in his mother's embrace.

The Grandmother was convinced this event was not natural so she tried to kill the child a second time. This time away from her settlement she built a huge fire and threw the child in the fire and walked back home. Once more, before she even got to her home, she saw in the distance the child playing with his mother comfortably and she was incredulous. The Grandmother knew she had to try again and once more she took the child out far into the woods and dug a huge hole very deep and covered the child up with the earth. Once more the child was home before the Grandmother, sleeping contentedly with his mother.

By this time the Grandmother was exhausted and confused so she went to her hut and fell into a deep sleep. There she was visited by a Messenger again and the Messenger reminded her of the last visit and advised her not to try to harm Deganawidah because he was given a great task. The Messenger said that Deganawidah will be a leader and to stop trying to harm him. The Grandmother finally understood and she did not try to harm the child again.

Time passed on and the child grew, one day as a young man he asked his Mother and Grandmother to come to the edge of the water with him. They were very curious and wanted to know what he was going to do. He showed them a spot by a great tree and said he had a mission to go into the world to spread peace. He said the warring must be stopped and he was going to try to stop it. The women were afraid for him and asked how he would do it but he asked them not to question him. For reassurance he told them from time to time to slice a little shock from 
the bark of the tree; if nothing happens to it he is successful, but if it bleeds then he is dead and his mission failed. He asked them to help him push his canoe out into the water but the Grandmother said to him it will not float because Deganawidah had made it out of stone. Once more he asked for their help and lo and behold he got into his canoe made of white stone and paddled away.

Deganawidah went to many villages and the people were originally afraid because they thought he came to fight. Just the opposite, he came to talk of peace and more specifically "righteousness, civil authority and peace - the three components of the Great Law" (Fenton, 1975 , p. 134). Deganawidah knew instinctively that he had to speak to a powerful woman, Tsikónhsase (pronounced Jigonsashe). The legend of Tsikónhsase is not written as prolifically as the account of Deganawidah. In Mann's article of Haudenosaunee's women's traditions and history (1997) she offers differing reasons as to why this could be so. She writes that the Haudenosaunee have had different titles for the same person throughout history. Tsikónhsase was also known as the Head League Clan Mother or the Mother of All Nations (ibid) for all chiefs except for Atotáhrho (Porter - And Grandma Said, 2008). She had several names and all refer to her but the title 'Clan Mother of the League' was the legacy title. It meant that all succeeding that position would hold that particular title (Mann, 1997). It can be confusing. Another reason she offers for the omission of Tsikónhsase's contribution is that the Haudenosaunee knew of her importance and sacredness and did not use her name often out of respect. Or possibly the people who wrote of accounts in journals and ledgers were males and did not believe in the importance of women's contributions even at that time. Whatever the reason, it is known that she made an important contribution to the continuing legend of the Peacemaker. It is important because it preserves the importance of women in Haudenosaunee 
culture but also illustrates the balance that is imperative in circular worldviews; that Tsikónhsase was a woman and Deganawidah was a man: the balance.

Circular worldviews play out time after time, with legend after legend and throughout history. As Tom Porter noted in his book, And Grandma said, (2008) the number "three" keeps coming up in our traditions, as confirmed by Mann who notes that "returning characters continue earlier plots so that the wounds inflicted in one era may be healed in the next" (1997, p. 435). Nonetheless, the story of Deganawidah continues when he went to Tsikónhsase's house. He knew she was powerful. She lived by a crossroads and would feed different tribes that passed by her house. She felt this was her responsibility. Deganawidah convinced Tsikónhsase that the Great Law of Peace was good and she embraced it. Legend has it that she was the first woman to embrace the Great Law of Peace and as a result she now carries the title Clan Mother of all Nations.

\section{Hiawatha}

Once more there are differing versions of the legend of Hiawatha and how he came to be involved in the story of Deganawidah. The version as told by Chief Leon Shenandoah is different as he notes in the forward of Wallace's account of Hiawatha's introduction (1946). Chief Shenandoah writes that Ayowenta (Hiawatha) was already exiled in the woods and Deganawidah went to him and he was converted and became his loyal companion. However in Wallace's version he writes that Deganawidah purposefully went to Hiawatha's home knowing that he was the notorious "man who eats humans" (1946, p. 42). He climbed on top of Hiawatha's lodge and looked down the chimney and just at that time Hiawatha had a kettle of water over his fire. Hiawatha looked in the kettle and saw a beautiful face in the reflection which he thought was his own, at that time he felt he was being transformed. He did not think 
such a beautiful face could do such atrocities as he had but he had to make sure so he went to the lake to look at his reflection again. He was transformed after seeing himself in the lake. He returned from the lake to find Deganawidah there and they entered his lodge. Hiawatha said he was miserable because he had caused so much suffering and Deganawidah suggested he help him make justice prevail to make right his past injustices. Hiawatha endorsed the message of peace and became a willing companion.

The version told by Porter (And Grandma Said, 2008) about Hiawatha is that Deganawidah already knew of Hiawatha and dreamed he would be able to help him spread the message of peace. He believed Hiawatha was a Mohawk married to an Onondaga woman with seven children, all girls. But there was a wicked man who was Onondaga who was a bad medicine man who practiced witchcraft. He was twisted and he was crooked in his mind. Porter writes that the Onondaga man was called Atotáhrho. Atotáhrho was in love with Hiawatha's wife. He tried every trick he could to seduce her but she rejected him, he even tried his bad medicine on her to sway her to him but she rejected him at every turn, so strong was her love for her husband. It is said he grew angry with her and began practicing his crooked medicine on her to kill her. Slowly she began to grow sick and eventually died. Hiawatha was lonely and sad but he knew he still had a responsibility to the rest of his family. But Atotáhrho was also attracted to his daughters and starting with the oldest tried to seduce each female. They too rejected him. In his rage, he slowly killed off the daughters too.

Hiawatha was devastated and sadness enveloped him. He felt he had nothing to live for and began walking aimlessly, his family gone. He was inconsolable. He walked and walked not caring if he lived or died. He walked until he came upon some water; he started walking right into it, not caring if he drowned. There were many birds on the water and when he headed 
toward the water they took flight and the water stuck on their feathers until there was only mud in the basin of the water hole. He still did not care, even if he met his fate by quicksand. He continued walking when he came upon a quahog shell. He had never seen one before and he picked it up. He continued walking and found more of the shells; they were either white or purple. He had sinew in his pockets so he strung them together and said if he ever came across anyone with his intense pain, loneliness, tearfulness, grief and no reason to live anymore, he would console him with this wampum. He would go to him and reach into the beautiful sky and pick an eagle's feather to wipe away death from the sad one's ears so that the person could hear the beautiful sounds of children's laughter and singing and talking. He would take from the sky a soft cotton swab like a deer skin and wipe away the tears that continue to fall. He would wipe away the sadness and loneliness so he could see the beauty of Mother Earth and the beauty of the children. He would then take from the sky some medicine water so he might drink away the sadness and grief so that he might talk without the heaviness and it would dislodge his grief. It would clear his throat so he may talk without stuttering and eat the food that would taste good once more. From the beautiful sky he would get a glass of water to help him drink so he will once more feel refreshed, to eat, drink, talk and be nourished again. He continued walking and continued gathering wampum and strung them together and once made put them in a pouch; and said if he ever came across anyone like that, that is what he would do for them.

Along the way Hiawatha met Deganawidah and they talked. Hiawatha was sure no one had ever felt his kind of pain; he could not see, he could not hear, he could not speak properly and could not think. Deganawidah did all the things that Hiawatha said he would do. Deganawidah slowly began to raise both hands over Hiawatha until they reached high out 
stretched. As he was rising his hands Hiawatha could feel the lump in his throat disappear and the fuzz in his ears disappeared and his eyes became clear and he was able to think again.

Deganawidah completed the Condolence Ceremony and recited the Requickening Address because people who are clouded by grief cannot fully comprehend anything (Porter, 1998), so with Hiawatha's mourning process completed he was once more fully functioning.

Deganawidah told Hiawatha of his plan to spread peace and unity among the people. Hiawatha too embraced the idea and helped Deganawidah. It is said Hiawatha was a gifted speaker and his gift allowed him to persuade many tribes.

Deganawidah had yet to face his nemesis Atotáhrho who was against any kind of peace and he was much feared by all who came close to him. It is said he was so wicked that he had a twisted body, his mind looked for trouble and he even had snakes in his hair. He looked to fight and continued to eat the flesh of humans. But Deganawidah knew he was strong and he and Hiawatha went to Atotáhrho.

Deganawidah entered the lodge after calling Atotáhrho. Atotáhrho tried to scare them but Deganawidah held fast and explained the importance of the Five Nations, peace and unity message. He said when the Five Nations speak in Council it shall be of one voice, united and strong, this will be the legacy of the people. With that it is said that Atotáhrho's mind became clear and he understood the message of peace and unity. He understood that it was integral to be united for their survival. Deganawidah touched him and his body straightened out and Hiawatha combed the snakes from his hair. Atotáhrho became the Spiritual Leader of the Grand Council of the Haudenosaunee (Wallace, 1946; Porter- And Grandma Said, 2008). The Iroquois were the first people to believe in the Great Law of Peace, they began to join the covenant and soon the Five Nations of the Iroquois was formed. The Five Nations are said to be of One Family. 
Once peace was embraced, the Nations realized they all had to stop the fighting especially among their own people. They dug a huge hole under the Tree of Peace and threw all of their weapons in the hole and covered it back up. They dug the hole under a great white pine and the tree became significant because it symbolized peace among the people. The roots spread in all four directions symbolizing peace in all directions; it is now referred to the Tree of Peace, one heart, one body and one mind.

\section{The Analysis of Deganawidah's Legend}

Deganawidah's legacy rests on the "the good word" of righteousness, civil authority and peace (Fenton, 1975). Peace, unity, cooperation and respect shall keep the League together and those who wish not to join in the Great Peace understand that they will be fighting many different tribes within the Iroquois Confederacy. This is the Iroquois' way of explaining the civic and social system as it was in the beginning.

The question is; how does the legend of Deganawidah affect the Ka'nikonhrìio of today's Haudenosaunee? Back during the Thanksgiving Address the people were given that one spiritual ceremony, but as time marched on, legend has it that the Address was too long to recite every time and the people tried to shorten it. As time went by the people stopped saying it and doing it and the people strayed from the original teaching. Havoc reigned and there was fighting and wars started all over again and the Creator was not happy about the situation. An era passed and there was also the re-implementation of the Clan system. It reinforced the importance of Haudenosaunee women's position. This system brought social structure into our life, but that did not stop the wars. The Creator sent in the Four Messengers to remind the people of their responsibilities and gave them the four sacred rituals; the Feather Dance, the Great Drum Dance, the Men's Dance and the Peach Stone game. It was later prophesized that only after all three 
connections to the Creator are restored will the people have the Great Law (Porter, 2004). Peace will be among all Nations that uphold and embrace The Great Law of Peace. The reader must remember this took thousands of years to accomplish. Peace, a sense of wellbeing, safety, identity, inclusion and working together for the same goal will lead to ka'nikonhrì:io.

In the legend of Deganawidah there is the mystical force that allowed his mother to become pregnant and kept him alive despite his Grandmother's attempts to kill him. Although it is a legend, there is the introduction that there are 'other worldly powers' in this realm that do exist. People may not see the Creator but they know of the existence. Getting power on the side of Deganawidah was important and he knew he had to spread his message of peace.

Deganawidah went to Tsikónhsase, a powerful woman in her own right. He was able to convince her of his message and she would become a powerful ally. The Iroquois acknowledged the importance of women and it is told that the Mohawks were the first people to embrace the Great Law of Peace and join the covenant. The Great Law of Peace is an outline of how people are to relate to each other in society. As the Nations began to embrace it, they all joined; Mohawk, Oneida, Onondaga, Cayuga and Seneca to form the league of the Five Nations, One Family. The League is spiritual in nature too; the aspect of relationships is reaffirmed in this legend. The characteristic of relationships is still an integral part of the Haudenosaunee today. The story of Deganawidah is important because it speaks of death when Hiawatha suffers the loss of his family. According to Jan Longboat, the concept of death was introduced with the death of Sky Woman's daughter in the Creation Story. It weaves its way into the legend of Deganawidah when Hiawatha suffers the loss of his family. According to Paul Wallace (1994) Deganawidah recites the Requickening Address used for many generations since the Condolence Ceremony. It is momentous because when people suffer from loss and grief and can not 
overcome their mourning, they need help. It means when people are suffering from loss they can not function, think, speak or hear clearly.

Throughout my years of living here on Tyendinaga I think Elder Jake Swamp from Akwesasne summed up the lifting of the burden of loss best when he described it as follows:

To remember those things that have been taught to us and that have supported us since the beginning of time. Symbolically we need to reach into Sky World to remove obstacles that prevent us from having our senses be clear. The first reaction we have is the tears and they cover the eyes. We need to reach for the dove because the dove has the softest feathers to wipe away the tears so we can see. We need to clear the obstacles from our ears because our hearing is lost so we reach to the Sky and get the Eagle feather to wipe away the dust from the person's ears so their hearing will be restored. The Eagle is representative of the people, the Eagle watches over us. Then we need to have a strong voice but when we suffer we get a lump in our throat and we can not communicate so we reach toward the Sky World for the freshest water to drink then we would be able to speak. When we are burdened by great loss we do not have full use of our senses and it causes detachment, the past can hold us back (Swamp, 2007).

The legend tells us for many centuries the Haudenosaunee have known loss.

Unfortunately it also tells us that we have strayed from the ways that we used to know to clear our senses and heal. The teaching tells us grief is layered; there is not only one sense that is affected negatively. All senses when relieved from the great loss are connected to form one rational clear minded person. The teachings tell us ceremonies are a way to connect and restore ourselves. Later in this thesis there will be more information about loss, trauma and healing. 
The final message in the legend is the opposites of Deganawidah and Atotáhrho; Deganawidah's mission to spread peace and unity and Atotáhrho whose mind was twisted, wrinkled and partook in cannibalism. By way of this dichotomy the property of balance is reinforced, even if only for a little while until the next era is played out because according to our teachings everything is circular.

\section{The Code of Handsome Lake}

Handsome Lake or Skanyatari:yo was born Turtle Clan of the Seneca Nation in 1735 and became known as a Chief or self proclaimed prophet among his people (Shimony, 1994). His story will be told as part of this thesis because it was during his lifetime that the people were seen to be shifting away from the old ways of spirituality. Since the beginning of time, the Mohawks were taught to be thankful for what the Creator gave them. They would pray, send greeting and thanks to those life forces that provided sustenance. (see Creation Story, Thanksgiving Address). The influence of European beliefs in Christianity and the interference of the missionaries and Jesuits in the expression of Haudenosaunee worldviews changed the spiritual practices of the people; this was because Christians believed the Natives were pagan (Porter, 2006; Hill, 1995).

Although it is believed that Handsome Lake was strongly influenced by Christian Bible teachings, he later converted those teachings into what is now known as Kariwiio (the Code of Handsome Lake) (Shimony, 1994; Parker, 1968). This is significant because although the Code of Handsome Lake resembles the Christian religion, spirituality has retained a different meaning for the Haudenosaunee. Spirituality is the overarching concept in the balance of the four quadrants of self; the Code of Handsome Lake and its Christian influences makes the lines of practice blurry. I mention this spiritual conflict because there are Iroquois people who strongly 
believe in the Code of Handsome Lake, however the Mohawks of the Bay of Quinte, who reside in Tyendinaga believe it was Deganawediah the peacemaker who brought peace and the Great Law to the people (Kayanere'kówa The Great Law; Parker, 1968; Porter - And Grandma Said, 2008).

\section{The Great Law of Peace or the Constitution of the Five Nations}

The reason this section is included in the Ka'nikonhrìio (good mind) is because it provides the foundation for the framework of the meaning for and binds the ideas of the Great Law and the good mind together. The meaning becomes transparent when the Great Law is presented. Little Bear noted in his article Jagged Worlds Colliding that most Aboriginal societies have an ideal impression of a person, that person is brave, suppresses disagreement with the group, thinks of the welfare of the group, is hardy, good natured, kind and has survivor skills (2000). Basically this section is to demonstrate that this idea is a shared value among other Indigenous societies, even though the way that those societies come to the same decision may be different from the Haudenosaunee perspective.

The Great Law of Peace is a covenant for people who want to join in the vision of peace. There are slightly different versions/translations of the Great Law but the overriding principle is that peace shall always reign (Kayanerekowa; Parker, 1968). This thesis will explain some basic ideas of it as it has been passed down to the people orally from generation to generation. It was introduced by the Peace Maker Deganawidah, embraced first by the Mohawk people and acts as a guideline to instructions to live a good life. Included in the Great Law are topics such as; governance, spirituality, the Clan system, the admittance of people in the Five Nations or the League, the people that wish to belong to the covenant, how events shall be conducted, and the 
continuance of the League (ibid). The Great Law endorses peace among the people and anyone who wishes to join the covenant must abide by these instructions.

In Haudenosaunee culture the Great Law of Peace was given to the people orally and later translated. As the original Great Law was orally presented it had to be memorized. Tom Porter stated that when recited properly it could take up to 4 days to perform and those speakers are very rare now (Oct. 2008). Since that time, the Great Law has been translated, transcribed into English, truncated and put into clauses, as a result it is not as clear as the Original Law and disagreements about these clauses interpretations and omissions exist today. At this point Seth Newhouse should be given credit. He was born of an Onondaga mother and a Mohawk father in Six Nations in 1842. His Indigenous name was Dayodekane (Fenton, 1998). He was able to write both English and Mohawk, but his first language was Mohawk. He listened to respected people such as John Buck and Smoke Johnson and was able to record the rituals recited for the Requickening Address and introducing of a new Chief. Fenton wrote that "...Arthur C. Parker afterward acquired, edited and published a Newhouse manuscript almost verbatim, setting off a considerable literacy controversy" $(1998$, p. 81$)$ and produced his version without credit to Newhouse which became the English version that has become "the standard" (ibid, p. 81). Symbolism was important in the Great Law because it was a method of communication. It was crucial since people of other Nations had to know the meaning of the communiqué. One form of translation was through the wampum, strings or belts. An early form of wampum bead was made of clam shells as outlined in the legend of Deganawidah (Wallace, 1946). In the beginning there were only two colors that were used and they were white and purple. Those colors were used because they were naturally occurring in the clam shell (Tehanetorens, 1972). 
The clam shells were strung together to form different symbols to translate into a visual form of communiqué. The strings and colors had different meaning and even the number of beads was known for important belts (ibid). When a person carried wampum belt, or held certain strings or strings of wampum it was to symbolize that the person had a title, like a Clan Mother, or represented a contract or Treaty or agreement between Nations like the Dutch and Iroquois. Wampum was used for sacred ceremonies and official purposes or for a declaration like the authorization of a runner from one community or Nation to another. If the runner did not possess the wampum string, the people were not obliged to listen (ibid). The wampum gave the person or holder legitimacy (Wallace, 1946). Each Nation had a Keeper of the Wampum; the Onondagas were the Keepers for the Haudenosaunee (Hill, 2007).

To understand the Great Law it is important to understand some essential concepts about it. The Great Law is about peace, unity and strength in numbers. It introduces the Tree of Peace, the Great White Pine. The symbolism is to reflect the continuous nature of peace, harmony and strength in the people with the long leaves and the Great White Roots stretching out in all four directions. It represents one heart, one body, one mind (Swamp, 2007). The Tree signified the Law (Wallace, 1946). If the people want to join in the covenant and obey the League they will be welcomed to sit under the Tree of Peace. It was not solely for the Haudenosaunee, other Nations could join (Tehanetorens, 1972). At the top of the tree is the Eagle because he is closest to the Creator and can fly the highest. He is between the people and the Creator. The eagle is representative of the people (ibid). He can watch over the people and warn the people of coming danger. The statesmen of the League have been given the responsibility to care for and watch over the Five Nations Council Fire. 
The Great Law sets out the governance of the league and how the League shall function. It sets in motion a democracy to settle matters of importance to the League. All members are equal and considered brethren. Whenever there is a gathering for council, the Onondaga statesmen will express their thanksgiving as an opening and the session can begin. Decisions are made by consensus. In the event there is a disagreement, he shall rule with the majority.

The Great Law of Peace is a guideline for how people behave toward each other but it is much more than that: it is spiritual. The Haudenosaunee people are spiritual beings and as spiritual beings we must abide by spiritual laws. It revolves around relationships to and with each other. Our relationships are connected to our health we must rebuild and reconnect to what is important. What is important is reconnecting with our language, ceremonies, teachings, songs and healthy activities. It is remembering our history, our clan (our family) our place in our community and our identity by our name. It is about active involvement in government, respecting our Mother Earth, the animals the medicines and maintaining a healthy lifestyle.

For the Haudenosaunee understanding and embracing the Great Law of Peace is equal to the possession of a good mind. It includes the balance of the mind, body, spirit and emotions. But what does a good mind mean and what does that 'balance' mean?

In order to understand The Great Law it must be put in context however by deconstructing it would only take apart the meaning of it. It is necessary for it to be taken as a whole and not de-compartmentalize because the meaning would become diluted. If one were given more substance than the other then the meaning is no longer clear. However an examination of the foundation of some of the concepts of the Great Law will lend clarity. According to Rick Hill in this foundation there are eight ideals that tie together (2007). Number one is to remember to be thankful every day; number two is to keep a good mind and treat it 
well. Number three is to respect and look after each other. Number four is to always be at peace: comprehend the values of our grandparents - and be content that you are in the right place. Number five is to follow the path of the Creator and number six is to respect life; support all the medicines that grow. The last two are to consider the future generations and our connection to the land and lastly know that people have an obligation to be healthy. Health is not just physical health, although that is a part of it, as stated at the beginning of this paragraph.

To be thankful is the first teaching. It was taught in the Thanksgiving Address to remember that everything humans need has already been provided. Everything put on this Earth deserves respect and in order to get respect it must be given, it is reciprocal. If people forget to be respectful, the Earth will not provide as she had done before. The number two foundation is to keep a good mind and treat it well. A good mind involves introspection and reflection on self. It means to be patient and to always think of the group as a whole. Number three is to respect and look after each other. That does not refer only to each other as the Creator made us but everything in creation. The group as a whole is always more important than the individual. According to Longboat (Aug. 2008) originally there was no such word as "why". Our Elders, parents, teachers, aunties and uncles told us that that was the way it was, there was no need to question it, and it was because they said so. Our Elders have given us the teachings of who we are and where we belong since the time of our naming ceremony and introduction into the Longhouse. You are here because you are supposed to be here. Number five is to follow the path of the Creator and respect life. The Creator wants people to be peaceful, loving, and thankful and work together for the goodness of the group. That cohesiveness is necessary for the Nation because when Haudenosaunee start fighting each other there will be no more Haudenosaunee. Number six is that life is a gift and needs to be treated with respect; there is no 
place for killing, murdering or harming. This includes all the medicines. Remember to be respectful and not take more than is necessary and showing thanks for what is taken. Number seven is to consider the future generations and our connection to the land. We must always think of the next seven generations, our children and the respect for the land. The term "seven generations" is not meant to be taken literally, it is never ending because when we give this teaching to our children and they give to their children and then the next, the "seven generations" continue on perpetually. Number eight is, people have an obligation to be healthy. That means that people must take an individual interest to strive for wellness and maintain their health. Remember health is not only physical health it encompasses all four quadrants of self. The Great Law extends beyond a code of conduct; interwoven are social, political and spiritual guidelines. It re-establishes some teachings that came before it, like the 'Words before all else' 'Ohénto Kariwentéhkwen'. In the Great Law of Peace there were originally fifteen Clans for the Five Nations. A person of the same Clan was recognized as family, and it is forbidden to marry within families (Porter, 1996). The Mohawk and Oneida Nations still have three dominant clans. Today the people who recognize their Clan in Tyendinaga identify with one of three Clans; Bear, Wolf or Turtle (Barbeau, 1917). That system brought the 'families' together regardless of where the people were across Turtle Island. Indeed, as mentioned earlier, in "family" the five nations considered each other as brothers.

The Five Nations followed a matriarch social system. As outlined in the Great Law both men and women would follow their mother's clan. The women were considered the direct ancestors of the nation. There were fifty women who were the Royaneh/ Otiianer/ Yotiyane or "Noble families". These women inherited the responsibility to be the heirs of the chieftainship titles of the League. It was designations like this that re-established the balance of power 
between the women and men, the women carried the right to bestow the title of Chief and usually the Chief would be a male. If decisions needed to be made the Clan mothers and women would hold council and advise the men of their decision before the men would deliberate. The females of the family would have a string of wampum to show authenticity and ownership in bestowing the chieftainship title for all time to come.

The ceremonies are also being restored and the Chiefs continue to be responsible for reciting the Thanksgiving Address to confirm their commitment to peace. No Chief could be a killer, even in war; it was directly against the Great Law. The condolence ceremony has been reestablished and is used to end the grieving period for a chief that has passed away and to 'launch' another chief. The Great Law outlines the moral and political structure for a peaceful existence.

The Great Law has values embedded in it. Ka'nikonhrìio (good mind) is not only about thinking good thoughts and ideas and saying kind words or words of encouragement; it is also about following up those thoughts with noble actions. Words by themselves are only half of the whole commitment; actions always speak louder than the words. Kind actions can be an exchange of gifts or it can be symbolic such as combing another person's hair while speaking kind words, or cooking a nice meal for someone while speaking words of encouragement. For example on June 11, 2008, Canadian Prime Minister Stephen Harper apologized to the residential school survivors for the government's role in implementing legislation that forced First Nation, Métis and Inuit people to send their children to schools against their will (Harsard, 2008). This was legislation that apprehended young First Nation, Métis and Inuit children from their homes took them to foreign places and tried to "kill the Indian" (AHF A healing journey, 2006, p. 11) in the child. Although some Native people may applaud the Prime Minister for making the apology, others have said that it was shallow. He failed to follow up in his speech 
with actions to solidify his commitment with money to resolve old land claims or a promise of equalizing the inadequate funding for aboriginal people in the present child welfare system.

In the Great Law the values of Ka'nikonhrìio, kind words and actions, are meant to spread unity. Fair and equal treatment and compassion for all is indicative of respect and an unwavering heed for self and others. Those values extend the strength of the chiefs and nations through a harmony that comes from an unconditional love for everything provided by the Creator. The balance that is creates mentally, physically, emotionally and spiritually empower the people to care for everything on Mother Earth, to remember the beauty of the natural world, and to walk in harmony with self and others. Through out the Great Law there are symbols of peace and unity; one is encoded in the wampum belt of the Dish with One Spoon. This wampum symbolizes that all have a right to dip into the proverbial dish, to eat together, or to have treaty and hunting rights together, but care must be taken vis-à-vis the spoon, no sharp utensils shall be used in the event blood is spilled accidentally. In the Great Law, all measures must be taken to prevent blood shed (Kayanerekowa The Great Law of Peace; Hill, 2007).

The natural world, the Haudenosaunee, and Mother Earth are inter-connected. The Haudenosaunee are to maintain that spiritual connection to Mother Earth and that spiritual connection is linked through the maintenance of a good mind. They are considered inseparable (Sheridan \& Longboat, 1996). The Great Law is not just text, at one time it was totally oral, and it was a way of living and a state of mind. The work that is being done through the Health Centre is restoring that way of life by restoring a good mind to the people who voluntarily choose to participate in the healing that is available to them through the good mind model we have developed. 


\section{The Elders' Voices}

This particular section is included because it is inclusive of the foundational belief system of the Haudenosaunee. Like many Indigenous people, the wisdom of the Elders is part of the teachings, values and customs of the people. "The persons who are most knowledgeable about physical and spiritual reality, the teaching and practice of ceremonies, and the nuances of meaning in Aboriginal languages, are Elders" (Brant Castellano, 2004 p.101). Our people recognize that, "they carry spiritual credentials that are recognizable within Aboriginal society, but invisible to those who assess expertise on the basis of formal education" (Ibid. p.101). There are unique expressions that have been chosen specifically to represent our youth and seven generations, our spirituality, our beliefs about women, our elder's knowledge, our politics, land or Mother Earth, our resilience, and our comprehension of social/health issues connection with colonization and oppression. The healing language we use speaks to our value of family, the clan we belong to, and the revitalization of our languages and culture.

Respected Haudenosaunee Elders, Tom Porter, Jan Longboat, Freida Jacques and Bruce Elijah, teach us that people can find and experience a special form of love when they use their mind to its full potential. This means using the mind to express what is rational and moral and which clearly results in socially beneficial actions. The Iroquoian people feel that all energy is spiritual and that the Haudenosaunee in turn are all spiritual beings (Elijah, 2008).

Below are some memorable quotes by Indigenous people reflecting on healing, health and mental wellness;

"The first story is about a number of Hopi Elders who were in ceremony in the mid 1850's. In that ceremony they were given the following prophecy: Our people are in our midnight and we will come into our daylight when the eagle lands on the moon. When the eagle lands on the 
moon we will become world leaders". In 1969 when the astronauts landed on the moon, the message they sent back to earth is: "THE EAGLE HAS LANDED"!

Maggie Hodgson: Impact of Residential Schools and Other Root Causes of Poor Mental Health Paper presented November 7, 1990 to Health \& Welfare Branch - Indian Health National Assistant Regional Directors/Zone Directors Meeting Toronto, Ontario November 6, 7, 8, 1990, p.1: "We have to heal ourselves, our communities, our Nation. We are the final teachers in this sacred land".

Art Solomon: "We need to respect and honour our women and they will in turn honour and respect us". Art speaks to us about women "to the men she is like the centre of the Universe and without her everything would come apart and disappear. She is the heartbeat of Mother Earth and without a heartbeat there is no life". Solomon has also spoken on Family Violence Manotsaywin Nanotoojig Inc. Za-geh-do-win, October 1994, pg.1, “As he (a respected Elder) spoke of the strength of our women and how the role of women was changing within the culture, I asked him what kind of medicine (sacred herbs used for healing and purifying) were for women. In his kindest and gentlest voice, he leaned over to me, and touching my shoulder said, 'young man, women are the medicine"'.

Calvin Morrisseau, Into the Daylight: A Wholistic Approach to Healing University of Toronto Press: Toronto Buffalo London 1998, p. 76 - The purpose of the workbook is to allow give people like Iris Heavy Runner who writes about residential schools, a voice; "Resilience is not a new concept to aboriginal peoples. It's an ancient principle in our philosophy of life. To persevere, to stand strong, to never give up hope. A culture's world view is the lens through which they learn how to nurture, protect, and dream for future generations." 
Lorraine Kenny also speaks in the workbook for residential school survivors and asks that they to recognize, create and share their own resiliency stories. Exercises for building healthy children, families and communities are included: November 2003 - Workshop Participant, "It's better to build children than to repair adults". September $17 \& 18,2008$ - Carmen R. Jones, Facilitator, Draft Chiefs of Ontario Dialogue Session Report "Strategic Action Plan for First Nations and Inuit Mental Wellness, September 17 \& 18, 2008, p.14 - "To accept a European interpretation of our old ways is foolhardy. Politics arises from law. To be without politics is to be lawless. To say our politics are in opposition to European politics would be correct. European law legalizes our oppression. Our law forbids it. But to say that we were lawless is to say indeed, we were savages."

Lee Maracle: "I expect that Europeans cannot define our societies with any accuracy or draw connections between our society and their own. Further, I hardly expect them to be able to look at our laws and see the traditions, values and body politics that arise out of our legal system. I expect them to interpret history so as to justify their genocide against us in the name of humanity and civilization" - Her book, I am woman - A Native perspective on sociology and feminism Press Gang Publishers Vancouver 1996, p.39.

"If we have been researched to death," he said, "maybe it's time we started researching ourselves back to life." Unknown Elder, recorded by Marlene Brant Castellano, Ethics of Aboriginal Research, Journal of Aboriginal Health, January 2004, p. 98, From RCAP v. 3 Chapter 31996. "In our experience, Aboriginal people have no doubt whatsoever that the destruction of their ways of life, including the multi-faceted rupture of their spiritual ties to the land, is a major factor" Robert Moore, Program manager, Six Nations of the Grand River Forestry program Brandford, Ontario, 13 May 1993 
From RCAP v. 3 Chapter 31996 - "These speakers and many others articulated a vision of health care in which each person is considered as a whole, with health and social problems that cannot be cured in isolation from one another, and with resources for achieving health that come not just from expert services but also from the understanding and strength of family, community, culture and spiritual beliefs. It is a vision quite different from that of mainstream health and social services, which tend to isolate problems and treat them separately".

Tom Erasmus, Alberta Mental Health Association, Lac La Biche, Alberta, 9 June 1992

The Elders voices and other community members, carry a type of knowledge that brings with it, lived experience. Indigenous people have always learned through modeling behavior (Brant, 1990) and they believe that there is more than one way to learn. That is why the experience they convey adds a richness that can not be copied exactly through the written word. Indeed, it is difficult to translate from Mohawk to English, and at times there is no exact way to carry the meaning forward. We have to remember to embrace this historic knowledge as a gift placed gently into in our hands, this can include both Indigenous and non indigenous knowledge so these teachings are not lost forever.

\section{Moving forward; Closing the gap of Knowledge}

It has taken far too many years for Indigenous knowledge to be recognized as credible by dominant mainstream people. It seems as if general knowledge is not translated according to the western model of treatment and medical diagnostics, it is seen as incorrect and without value (Tuhiwai Smith, 1999). If it is not demonstrated to fall under the rubric of "best practices" or "evidence based" data according to western criteria, it is labeled invalid and somehow designated a form of quackery (Widdowson, 2008). We have already spent several centuries on this continent with our cultures and understandings colliding (Little Bear, 2000), and seemingly 
unable to live side by side in relative harmony. The task of validating Indigenous knowledge, which includes the concept and practice of good mind continues to lag behind, but it is my hope that dissertations like this one can lessen the gap somehow and make our knowledge more accessible and understandable to readers outside of the Haudenosaunee community, as well as inside the community for those who for whatever reason, have not been exposed to their historic teachings.

\section{Methodologies:}

There are two methodologies I will be utilizing: one will be ethnographic in nature and the other will be secondary data analysis. The first methodology will entail examining and explicating a "portrait of a people" based on their culture, beliefs, and customs (Genzuk, M., 2003, p. 1). Ethnography takes into account the living and breathing account of the person doing the observing. But most research is no longer passive observation, rather active participation allows the researcher to see, feel and experience the recording of those activities. The second methodology is secondary data analysis; basically it is data that has already been generated through different sources by different people to answer my thesis question. This data does not involve interviewing new participants however I will be extracting data to answer a different set of questions to further the study of the good mind model. This research project will involve a reinterpretation of the Needs Assessment Survey and the Traditional Practitioner Program Evaluation.

The Haudenosaunee the concept of good mind is not exclusive to the Mohawk people, it was a concept taught to the entire Six Nations Confederacy (Simonelli, 1997). Six different Nations believed in the concept and way of life of the 'good mind'and continue to honour the ceremonies and traditional teachings of this model of wellness. In the early days, when it had 
been taught and implemented, history tells us it fostered one of the longest periods of peace for the Haudenosaunee. Therefore, we believe that it works well. For six different nations to believe in the concept, and utilize it for many generations, it must have demonstrated clarity, fairness and full transferability. Therefore, there is nothing to stop other nations from using this same framework for healing today.

Mohawks of the Bay of Quinte of Tyendinaga Territory Ontario, completed a needs survey in July 2000 entitled, “Tyendinaga Mohawk Territory's Needs Assessment: The legacy of the residential school system" to ask community members what type of services they wanted for health/healing for people who have been affected by the residential school system. The survey took approximately four months to complete, was funded by the Aboriginal Healing Foundation and data was collected via survey in the Tyendinaga community on a door to door basis. Surveyors went in the morning; afternoon and evening through the week and on the weekends to ensure the most surveys were completed. As a result, four hundred forty five (445) surveys were completed and there were eighteen people who declined to do the survey, out of a possible six hundred households on the Territory at that time. Based on the results of the survey Red Cedars Shelter determined that the community wanted the program to be based on traditional healing practices and a return to traditional ceremonies. That is exactly what the program offers today. On July 14, 2000 Chief R. Donald Maracle, the Chief of the Mohawks of the Bay of Quinte and portfolio holder for Red Cedars Shelter wrote a public "Thank you" to the community for their support in this endeavor and the thank you is included in the document (Red Cedars Shelter, 2000). This document was well publicized in our community and currently is in the Tyendinaga Kahniote Library as well as in the Aboriginal Healing Foundation's archives in Ottawa. 
Later in 2000 another proposal was submitted on behalf of the Mohawks of the Bay of Quinte in Tyendinaga Mohawk Territory, Ontario to the Aboriginal Healing Foundation for a Traditional Practitioner Program based on the outcome of the Needs Survey that was completed earlier. The proposal used key information from the survey to mold the program. The program was to address the legacy, including intergenerational impacts, left by the residential school system and Indigenous health and healing techniques.

In 2000, the Mohawks of the Bay of Quinte's Traditional Practitioner Program were granted funding by the Aboriginal Healing Foundation. It was chosen as one of sixty successful programs from a submission pool of approximately six hundred from across Canada that year. As the program was to sunset in 2004, a formal evaluation of the program began in September 2003 and was completed in April 2004.

I completed a formal evaluation of the program in 2004 with the assistance of Carleton University Professor Bessa Whitmore and Mr. Collin Stuart. This was accompanied by permission and approval of the Tyendinaga Council, Mohawk Council Resolution September 29, 2003, item number twenty eight, the Aboriginal Healing Foundation and the Ethics Committee of Carleton University. Data collection began early in 2004 using one of the evaluation tools from the Aboriginal Healing Foundation entitled "Your experience on the healing journey, 2002". The questionnaire also came with a guide entitled "Your guide to completing the questionnaire, your experience on the healing journey, 2002". As the questionnaire involved both qualitative and quantitative data, the evaluation was a mixed method of study. Fifteen people were chosen as the sample for the evaluation. The sample was chosen by asking every sixth person to participate voluntarily who had a file number with the Traditional Practitioner Program until there were fifteen participants. In the event the sixth person chose not to 
participate in the evaluation the next person would be asked to participate, for example participant number seven, if that person agreed to participate the six series would continue from six. In the sample, the self reported age ranged from thirteen years to fifty seven years young inclusive.

The outcome of the project demonstrated an overwhelming success. The community did not want the program to stop even though it was to sunset at a specific date; this was made clear to the Tyendinaga Mohawk Council. It is operating today in 2009 and statistics from the program are overwhelmingly positive. It is due to the success of this program that I have determined the need to take a closer look at the Ka'nikonhrì:io or The Good Mind Model and asses its value for revitalizing the future mental health of our own people, but also to offer it as an alternative treatment model to western society.

It was necessary to contact speakers of the language on our Territory at Tyendinaga to translate words and ideas generated through the data collection and questionnaire process. Although not an elder, my daughter Shannon was instrumental in helping me manage these translations. In addition, oral traditions and legends told to me while growing up in Tyendinaga from grandparents, parents, Elders and knowledgeable Aboriginal people have contributed to this proposal and fill out some of the research.

In addition, I have attended many workshops and conferences where I gained detailed information from knowledgeable people on topics related to the Haudenosaunee teachings and First Nation's health and wellbeing. Elder Tom Porter has been to our community many times and has passed along teachings specific to Haudenosaunee culture and tradition. Throughout my years at home I have been involved in various ceremonies that have helped me understand the teachings behind the activities. Two interviews were conducted with a respected Elder and 
teacher of Haudenosaunee culture, Jan Longboat. When I did not understand how to translate our ideas to paper she was instrumental in making these concepts come to life.

Lastly, but not least is my upbringing and the teachings and influence from my mother Elaine Brant. She taught me that rationality, civility, respect, non interference, peace, kind words, a yearning for knowledge, an ability "to rise above it all" and be proud of my family, clan, and who I am, along with contributing to community, are all Haudenosaunee teachings. She never sat me down and said "this is Haudenosaunee teachings" it was just the way it was, and that it was "born right into me". This paper is a culmination of all of those teachings, and the data collection exercises that informed the developmental nucleus and implementation of the programming at the Shelter.

All treatment models come from a foundation, and the ka'nikonhrì:io is no different. In order to understand the treatment model the Mohawks of the Bay of Quinte have been using in their Red Cedars Shelter it has been necessary to provide the full history of its formation though the legends, stories, and prayers of our people. We believe that it is imperative to know the history in order to understand and appreciate the underlying beliefs and traditions of the Haudenosaunee culture, because they explain the perspective of the people involved.

\section{Method for secondary data}

The task was to take a closer look at the data that had already been collected; specifically the data collection for the thesis was through the method of secondary data collection. The raw data was examined but through a different lens to determine how it may answer the question at hand: Can a Haudenosaunee historical paradigm of the "Good Mind" healing model be resurrected and reconstituted, to reflect a valid mental health healing and treatment model that revitalizes Haudenosaunee health and provide utility today? 
The information that was gathered was the number of those spoken and recorded responses in the survey and in the evaluation; specifically to do with mental health. Question Eleven in the survey read, "do you have any other comments or suggestions you feel would benefit the community in this process"? That data was further broken down into four categories. A scan of all of the "other" written comments in the surveys regarding mental health was recorded and counted. That data yielded ninety four "other" responses with a further breakdown of two categories.

The survey responses and the evaluation data was collected separately from each other. With this information at hand the search began to collate the information on mental health, Ka'nikonhrìio. As the answers were qualitative they were then grouped in "like" categories to ascertain the answers from the community survey and the respondents of the evaluation. After they were grouped in each category, the numbers of responses were counted in each category and a number was attached to that specific grouping. Percentages were assigned to the numbers to complete the analysis to answer the question. Each category was examined to determine how the question could best be answered with the data given.

\section{Results:}

Out of the 445 questionnaires completed in the survey, 274 had either no comments or suggestions or were blank. Out of the 171 other responses, 68 of those were about mental health and further break down into 3 categories included; traditional healing/techniques (39), communication/language (15) and community involvement/get together/socials (23).

In breaking down those responses some suggestions were connected with a conjunction therefore there may have been one respondent that noted that traditional healing and language were important. In that case traditional healing was in one category and language went in 
another. That will account why there was (77) responses about traditional healing/techniques (39), communication/language (15) and community involvement/get together/socials (23).

Twenty seven (27) additional responses were taken from the original Question Eleven that indicated the need for recreation in the community and requests for more activities for the youth for total of (104) suggestions. It is noteworthy that the category of recreation and youth was included in this section. The rationale for this inclusion was due to the remarks made in the survey regarding the significance of the youth re-learning the language, culture and traditions and the value of recreation as wholesome healthy activities. The link between a balanced life style in all four quadrants and the good mind is intrinsically intertwined across the life cycle.

The other 75 comments were; programs need to be advertised (18), people need to be qualified/equal treatment (12), confidentiality (7), politics (6), complaints in general (6), comments specific to seniors (5), compliments (4) and the need to have a doctor, nurse practitioner or hospital (4) in our Territory. Throughout the rest of the survey care was taken to look for all "other" responses that allude to mental health (94). "Other" means it was not extracted from Question 11 but from comments anywhere else in the rest of the survey about mental health. It is noteworthy that within those comments; (43) were made regarding traditional teachings/ ways and (34) were made regarding recreation/youth. The (17) other responses were too few to group, some of those statements were about; race, qualified native people in mental health positions, the mental health building itself, politics and mental health programs. Therefore the number that was used for "other" mental health comments was (77). To make sense of the raw data a percentage was allocated to bring the data together. 
- 77 responses about mental health

- $* * *$ Breakdown****

- 39 traditional healing/techniques

- 15 language

- 23 socials/get togethers

- 75 other

Plus

- 27 responses about recreation/youth

- Total 104 responses about mental health in Question 11

\section{Responses about mental health}

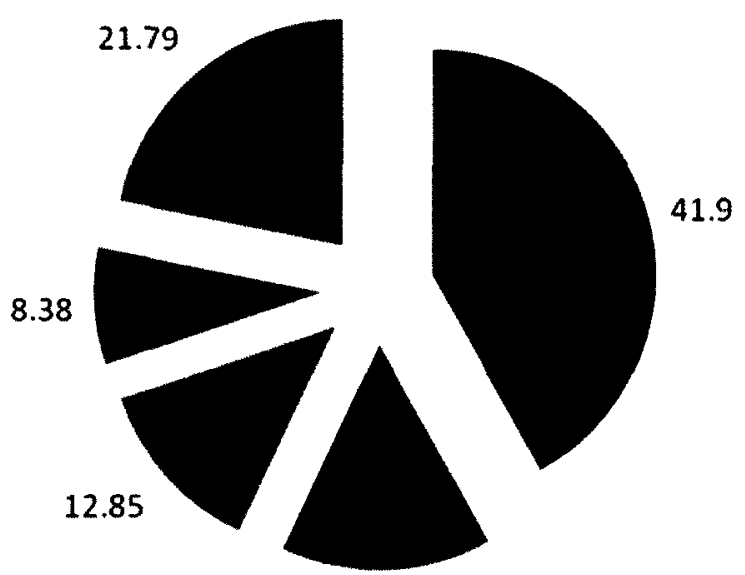

- other $42 \%$

- recreation/vouth $15 \%$

socials $13 \%$

- language $8 \%$

- traditional healing/ways/techniques $22 \%$

15.08 


\section{Other Responses Excluding Question 11 about mental health}

- 94 responses

- 43 traditional teachings/ways

- 17 other

The other data that was collected was from the Questionnaire from the Aboriginal Healing Foundation entitled, Your experience on the healing journey. Fifteen people were used as a sample; see above how this sample was achieved. Three key questions were used, asking respondents to answer about their Goals and Expectations, What was most helpful on your healing journey and new skills they had learned. These questions were examined for responses about mental health. Each response was qualitative and had to be grouped in like categories. Below is a synopsis of that data gathered along with a pie chart to illustrate percentages.

\section{Goals and Expectations:}

- Out of 62 responses

- 20 want to find inner peace/let go of anger/unburden

- 10 looking to reclaim identity/self

- 15 want to be happy, healthy, better for families

- 17 address feeling, (not anger) (not unburdening) 


\section{Goals and Expectations}

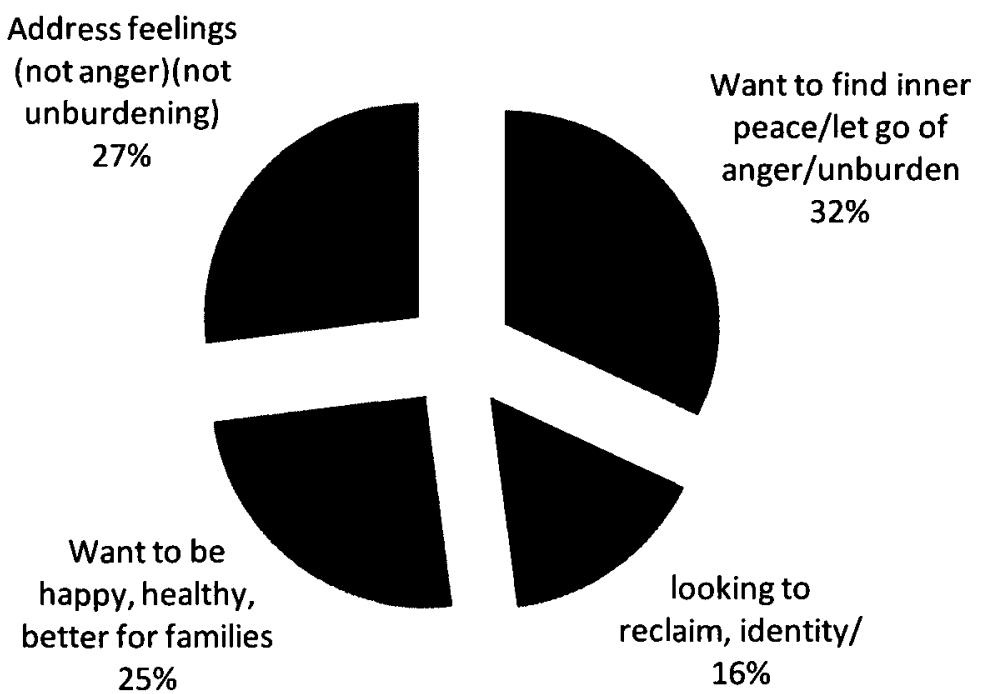

What was most helpful on your healing journey?

- Out of 63 responses

- 19 cultural safety

- 22 support and validation

- 22 talking about pain, experience, gaining insight 


\section{What was most helpful on your healing journey}

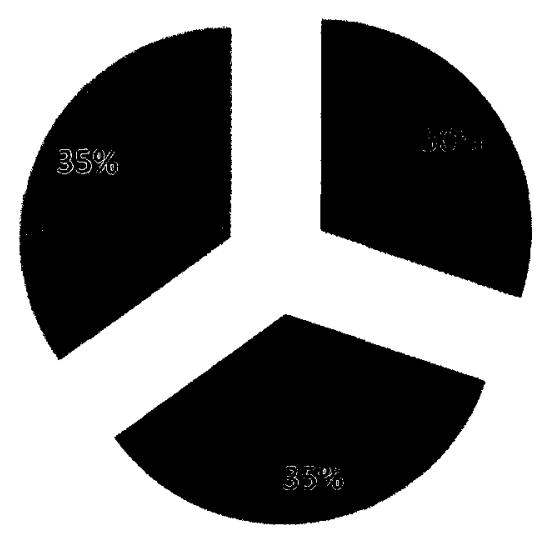

- cultural safety

- support \& validation

- talking about pain/gaining insight

What new skills did you learn?

- Out of 59 responses

- 17 traditional methods, healing ways

- Communicate

- Identify /own feeling

- 16 acceptance 


\section{What new skills did you learn}
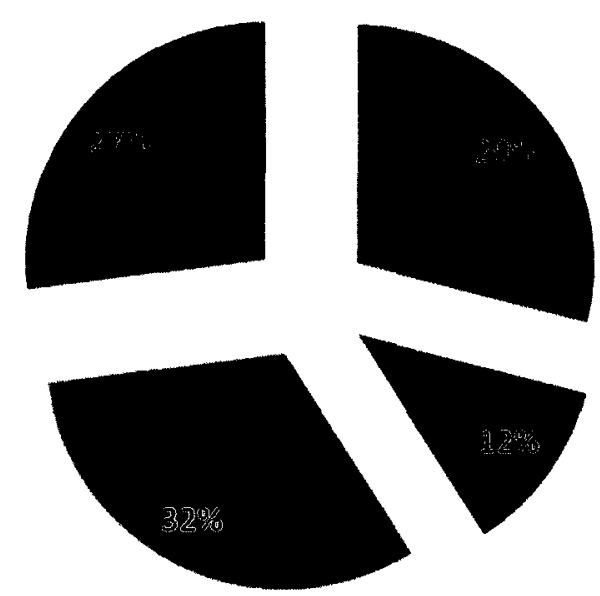

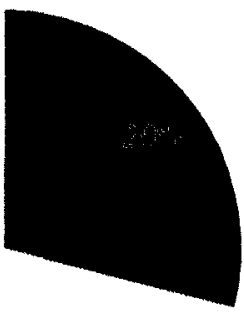

traditional methods, healing ways

- communicate

- identify/own feelings

- acceptance

\section{Analysis}

The above data illustrates the importance of traditional methods and healing ways for the Tyendinaga community, and the need to have them incorporated into any program that will deal with the issue of ka'nikonhrì:io, Indigenous mental health. It shows a clear resurgence in the traditional teachings as important in healing. Not surprisingly, the inclusion and the weight of the involvement of the youth in leading the next seven generations to wellness was also deemed very important and a necessary part of the healing model. The value of including the community in efforts of revitalization was made as a key point; it underscores the ethic of group participation and input as opposed to individual changes and healing alone. That is not to be confused with personal agency, is also very significant; however community healing is another step forward in continuing the wellness and re-fostering of a "good mind" for the entire Nation. 
The magnitude of colonialism and the impacts of inter-generational trauma as noted in the earlier text and some of the effects are demonstrated in the data. Participants wanted to find inner peace and let go of anger, centuries of pain, the feelings of oppression and the forced silence that has penetrated many generations of children and adults. However, the recognition/insight of that pain and the healing that needs to be done is amazing, as one Elder noted, this is a great example of the resilience that exists among the people. To be able to find new ways of communicating or re-learning the ways of communication is essential and helpful on setting positive healing journeys for those who come to the shelter. Validation, cultural safety and acceptance are criteria that are expected and preferred in the ka'nikonhrì:io Indigenous mental health model. In essence participants want a higher quality of life for themselves, their children, their community and their nation, consistent with other Nations on Mother Earth.

\section{Conclusion:}

The application of the Ka'nikonhrì:io or The Good Mind Model is being used today on Tyendinaga Mohawk Territory. The model itself is not new but it is influenced and shaped by our people, our culture, traditions and our belief that we can heal ourselves, we have the teachings and capacity. Mental health for us was not treating an illness from a western treatment paradigm; we always knew that did not work, and we still do not think within that frame of reference. We also knew that we had to ask the participants how they wanted to heal, what had wise practice utility and made sense to them. This final model is recognizing our past, uplifting our lived experiences and facing down the effects of colonization and oppression with dignity; and with a good mind. 


\section{References}

Aboriginal Healing Foundation. (2006). A healing journey final report summary points. Ottawa, Ontario: Aboriginal Healing Foundation.

Aboriginal Healing Foundation. (2006). Final report of the Aboriginal Healing Foundation, Vol. I A healing journey: Reclaiming wellness, Aboriginal Healing Foundation: Ottawa.

Aboriginal Healing Foundation. (2002, May). The healing has begun, An operational update from the Aboriginal Healing Foundation, Aboriginal Healing Foundation: Ottawa.

Aboriginal Healing Foundation. (2002). Individual Participants Questionnaire. Your experience on the healing journey. Aboriginal Healing Foundation: Ottawa.

Aboriginal Healing Foundation. (2002). Your guide to completing the questionnaire, Your experience on the healing journey. Aboriginal Healing Foundation: Ottawa.

American Psychiatric Association. (1987). Diagnostics and Statistical manual of mental disorders. 3rd ed. Rev. Washington, D.C.: APA.

American Psychiatric Association. (2000). Diagnostic criteria from Diagnostic and Statistical Manual - IV -TR. Arlington, VA.: American Psychiatric Association.

Antone, B., \& Hill, D. (1990). Traditional healing: Helping our people lift their burdens. Tribal Sovereignty Associates. London, Ontario.

Assembly of First Nations. (2008, Bulletin). National Chief praises decision regarding Human Rights Complaint on Child Welfare. Ottawa.

Barbeau, C.M. (1917). Iroquoian clans and phratries. American Anthropologist, new Series, 19(3), 392-402.

Baskin, C. (2003). Structural social work as seen from an Aboriginal perspective. In W. Shena, (Ed.), Emerging perspectives on anti-oppressive practice. (pp. 65-79). Canadian Scholars Press, Toronto.

Blanchard, D. (1982). Who or what's a witch? Iroquois persons of power. American Indian Quarterly, 6(3/4), 218-237.

Brant, C. (1990). Native ethics and rules of behaviour. Canadian Journal Psychiatry. 35(6). p.534-539.

Brant, H. (2004). An evaluation of Tyendinaga's Traditional Practitioner program. Unpublished undergraduate paper. Tyendinaga. $\mathrm{ON}$. 
Brant Castellano, M. (2004). Ethics of Aboriginal Research. Journal of Aboriginal Health. 1(1), 98- 113.

Brasfield, C.R. (2001). Residential school syndrome. BC Medical Journal. 43(2), 78-81.

Bretherton, I. (1992). The origins of attachment theory: John Bowlby and Mary Ainsworth. Development Psychology, 28(5), 759-775.

Bruyere, G. (2007). Making circles: Renewing First Nations ways of helping. (pp.259-272). In J. Coates, J.R. Graham \& B. Swartzentruber (Eds.), Spirituality and social work selected Canadian readings. Toronto: Canadian Scholars' Press Inc.

Butcher, S. (2007). Personal conversations, translations of Mohawk words. Tyendinaga.

Canadian Paediatric Society. (2007). Are we doing enough? A status report on Canadian public policy and child and youth health. Ottawa. Pp. 24, 25.

Carpender, J., Schneider, J., McNiven, F., Brandon, T.,Stevens, R. \& Wooff, D. (2004). Integration and targeting of community care for people with severe and enduring mental health problems: Users' experiences of the care programme approach and care management. British Journal of Social Work, 34, 313-333.

Caruth, C. (1995). Trauma: Explorations in memory. Johns Hopkins University Press.: Baltimore, Maryland.

Cattarinich, X., Gibson, N. \& Cave, A. (2001). Assessing mental capacity in Canadian Aboriginal seniors. Social Science \& Medicine. 53, pp. 1469-1479.

Chansonneuve, D. (2005). Reclaiming connections: Understanding residential school trauma among Aboriginal people. Ottawa :Aboriginal Healing Foundation. p. 10

Christ Church Her Majesty's Mohawk Chapel. Queen Ann Silver. RG10 Volume 2643 File No. 129,709-2A Reel C-11256. Microfilm archive.

Corrado, R. \& Cohen, I. (2003). Mental health problems and Aboriginal people. In Mental health profiles for a sample of British Columbia's Aboriginal survivors of the Canadian residential school system (pp.15-23). Ottawa: Aboriginal Healing Foundation Research Series.

Davin, N. (1879, March 14). Report on Industrial Schools for Indians and Half-Breeds. Confidential report to The Right Honourable The Minister of the Interior. Ottawa:

Diamond, J. (1999). Guns, germs, and steel; The fates of human societies. W.W. Norton \& Company: New York. Pp.195-214. 
Diamond, D. (2004). Attachment disorganization: The reunion of attachment theory and psychoanalysis. Psychoanalyic Psychology, 21(2), 276-299.

Duxamel, R. (1964). Copy of Treaty No. 6 between Her Majesty The Queen and the Plain and Wood Cree Indians and Other Tribes of Indians at Fort Carlton, Fort Pitt and Battle River with Adhesions.Cat. No. RJJ-0664. Land Publication No. QS-0574-000-EE-A-1. Ottawa: Queen's Printer and Controller of Stationery.

Earle, K. (1998). Cultural diversity and mental health: The Haudenosaunee of New York State. Social Work Research, 22(2), 89-99.

Elder speaks on family violence: In interview with elder Art Soloman. (1994, October). Za-GehDo-Win, Conversations. Manotsaywin Nanotoojig Inc.

Elijah, B. (2008, August). Teachings presented at a conference entitled: Recognizing our success; Building on our strength, native mental health conference, held in Sudbury Ontario by NMO Bimaadzwin.

Fenton, W.N. (1998). The Great Law and the Longhouse: A political history of the Iroquois Confederacy. Oklahoma: University of Oklahoma Press.

Fenton, W.N. (1975). The lore of the Longhouse: Myth, ritual and red power. Anthropological Quarterly, 48(3). 131-147.

First Nations Child \& Family Caring Society of Canada. (2009). Taken from i am a witness on August 10,2009@http//www.fncfcs.com/home.html Be A Witness

First Nations Technical Institute. (Oct. 2008). Hill R., MacDonald 1., Porter, T., Zammit, L.\& Conners, E. $2^{\text {nd }}$ Annual Restorative Justice Symposium. Healing in Restorative Justice. Tyendinaga, $\mathrm{ON}$.

Fletcher, C. \& Denham, A. (2008). Moving towards healing: A Nunavut case study. Aboriginal healing in Canada: Studies in therapeutic meaning and practice. Aboriginal Healing Foundation: Ottawa.

Fournier, S. \& Crey, E. (1997). Stolen from our embrace. Toronto, ON.: Douglas \& McIntyre Ltd.

Friesen, J.W. (1999). The function of legends as a teaching tool in pre-colonial First Nations' societies. Interchange, 30(3), 305-322.

Genzuk, M. (2003, Fall). A synthesis of ethnographic research. Occasional papers series. Center for Multilingual, Multicultural Research (Eds.). Center for Multilingual, Multicultural Research, Rossier School of Education, University of Southern California. Los Angeles. 
George-Kanentiio, D. (July 11, 1993). Women center of all things within Iroquois society. Syracuse Herald Tribune. Taken on 28, 1997 from

http://hanksville.phast.umass.edu/defs/independent/viola/newsl.html

Gideon, V. (2005). Kirby committee on mental health, Mental Illness and Addictions, Speaking Notes, June 21.

Graham, J.R., Coholic, D. \& Coates, J. (2007). Spirituality as a guiding construct in the development of Canadian social work: Past and present considerations. (pp. 23-46). In J. Coates, J.R. Graham \& B. Swartzentruber (Eds.), Spirituality and social work selected Canadian readings. Toronto: Canadian Scholars' Press Inc.

Hansard. (2008, June 11). House of Commons Debates. v. 142 , No. $110,2^{\text {nd }}$ Session, $39^{\text {th }}$ Parliament. pp. 6849 - 6857. Ottawa: Public Works and Government Services Canada.

Hart, M. (2002). Seeking Mino-Pimatisiwin: An Aboriginal approach to helping. Halifax:Fernwood Publishing.

Herman, J. (1997). Trauma and recovery: The aftermath of violence, from domestic abuse to political terror, New York: Basic Books.

Hill, B-H. (1995). Shaking the rattle: Healing the trauma of colonization. Six Nations of the Grand River:Shadyhat Books.

Hill, R., Thompson, T., Porter, T., Swamp, J., Hay, L., \& Burning, G. (2007, November). Indigenous approaches to restorative justice. In M.A. Spencer (Coordinator), Symposium conducted at the community Centre by First Nations Technical Institute, Tyendinaga Mohawk Territory, Ontario.

Hodgson, M. (1990, November). Impact of residential schools and other root causes of poor mental health. Paper presented at a Health \& Welfare Branch- Indian Health National Assistant Regional Directors/Zone Directors Meeting, Toronto, Ontario.

Indian Act: Office consolidation. R.S., 1985, c. 1 - 5. Ottawa, ON:

Indian Residential Schools Settlement - Official court website. (2009). Retrieved February 16, 2009, from http://www.residentialschools.ca the Official court website for the settlement for $r e$ Residential Schools Class Action Litigation.

Indian Treaties and Surrenders Volume 1. (1891). Queens Printer: Ottawa, ON.

Isaacs, H. (1976). Iroquois herbalism: The past 100 years. International Journal of Social Psychiatry, 22, 272-281. 
Janca, A. \& Bullen C. ( 2003). The Aboriginal concept of time and its mental health implications. Australasian Psychiatry, 11, s40-s44.

Johnson, J.L. \& Cameron, M.C. (2001). Barriers to providing effective mental health services to American Indians. Mental Health Services Research, 3(4), 215-223.

Johnson, P. (1983). Native children and the child welfare system. Toronto, ON: Canadian Council on Social Development in association with James Lorimer \& Company.

Jones, C. (2008 Sept.17 \& 18). Draft Chiefs of Ontario dialogue session on the draft Strategic Action plan for First Nations and Inuit mental wellness. Carmen R. Jones facilitator prepared report for Chiefs of Ontario on Oct. 14, 2008.

Kayanerekowa, The Great Law of Peace, Constitution of Hotinonsionne Iroquois League of Six Nations, The Council of Great Great Peace, The Great Binding Law. (Available from the Kahniote Library, Tyendinaga Mohawk Territory, Ontario, KOK 1XO).

Kenny, L. (Nov. 2003). Workbook for residential school survivors to recognize, create and share their own stories. Workbook for creating resiliency stories from research survivors. Exercises for building healthy children, families and communities. Project prepared for Sunset Women's Aboriginal Circles.

Kirmayer, L., Simpson, C., \& Cargo, M. (2003). Healing traditions: culture, community and mental health promotion with Canadian Aboriginal peoples. Australasian Psychiatry. 11, 15-23.

Kishk Anaquot Health Research. (2006). Final report of the Aboriginal Healing Foundation, Vol. II Measuring progress: Program evaluation, Aboriginal Healing Foundation: Ottawa.

Leslie, J. (1982). The Bagot Commission: Developing a corporate memory for the Indian Department. Historical Papers/Communications historiques, 17(1). Pp.31-52.

Little Bear, L. (2000). Jagged worldviews colliding. (pp. 77-85). In Marie Battiste (Ed.), Reclaiming Indigenous voice and vision. UBC Press: Toronto.

Longboat, J. (2008, August 19). Grief and Grieving. Conference conducted by MNO Bimaadzawin: Recognizing Our Success, Building On our Strengths. Sudbury Mental Health Conference.

Longboat, J. "Circle of Life" Healing Model Natural Doctors.

Longboat, J. (2008, Jan.). Personal Interview with Jan Longboat regarding true self versus the false self teachings. 
Mander, J. (2006). Paradigm wars: Indigenous peoples' resistance to globalization. (pp. 23 - 34). In Victoria Tauli-corpuz (Ed.). Aspects of traditional knowledge and worldview. San Francisco: Sierra Club Books.

Mann, B.A. (1997). The lynx in time: Haudenosaunee women's traditions and history. American Indian Quarterly, 21(3) 423-449.

Maracle, L. (1996). I am a woman - A Native perspective on sociology and feminism. Vancouver: Press Gang Publishers.

Maracle, L. (2009). Mohawks of the Bay of Quinte. (2009). Research Department. Tyendinaga Mohawk Territory. http://www.mbq-tmt.org.

Mercredi, O. (2008, June $1 \&$ 2). First Nations conference on reconciliation processes. Cohosted by the Queen's School of Policy Studies and the First Nations Technical Institute: Kingston, Ontario.

Mohawk, J. (1993). A view from Turtle Island: Chapters in Iroquois mythology, history and culture. Unpublished doctoral dissertation, University of New York at Buffalo.

Mohawks of the Bay of Quinte. (2009). Research Department. Tyendinaga Mohawk Territory. Tyendinaga Mohawk Territory 1784-1997. Queen Ann Silver. Document retrieved originally on 30/04/98 from http://tyendinaga.net.tyendin.htm

Morrisseau, C. (1998). Into the daylight: A wholistic approach to healing. Toronto: University of Toronto Press.

Morrissette, P. (1994). The holocaust of First Nations people: Residual effects on parenting and treatment implications. Contemporary Family Therapy, 16(5), 381-392.

Muller, K. (2007). The two "mystery" belts of Grand River; A biography of the Two Row Wampum and the Friendship Belt. American Indian Quarterly, 31(1) 129-164.

Nabigon, H. \& Mawhiney, A.M. (1996). Aboriginal theory a Cree medicine wheel guide for healing First Nations. In F.J. Turner (Ed.) Interlocking theoretical approaches social work approaches. $\left(4^{\text {th }}\right.$ ed., pp. $\left.18-68\right)$. New York: NY.

Norman, S., Tate, S., Anderson, K. \& Brown, S. (2007). Do trauma history and PTSD symptoms influence addiction relapse context? Drug and Alcohol Dependence. 90. 89 -96.

Ntum, K. (1998). Gifts from the Creator for man's use. Wind speaker - Guide to Indian country. Found in http:/www.ammsa.com/guide/WINDGIC98SMUDGE.html 
Out of the shadows at last; Transforming mental health, mental illness and addictions services in Canada. (2006, May). In M.J. Kirby (Chair). The Standing Senate Committee on Social Affairs, Science and Technology: Chapter 14, Aboriginal Peoples of Canada (361-408).

Ontario Ministry of Aboriginal Affairs. (2009). A statement to the Legislature by the honourable Brad Duguid on Jordan's Principle. Taken from website http://www.aboriginalaffairs.gov.on.ca/english/news/2009/042209st.asp

Parkes, C. (1972). Bereavement: Studies of grief in adult life. New York: International Universities Press.

Parker, A.C. (1916). The constitution of the Five Nations. New York State Museum Bulletin 184. Albany: University of the State of New York. Syracuse: Syracuse University Press, 1968.

Parker, A.C. (1968). Parker on the Iroquois. (William N. Fenton, Ed.). New York: Syracuse University Press.

Polanyi, K. (1957). The great transformation: the political and economic origins of our time. Boston: Beacon Press.

Porter, T. (2008). And Grandma Said...Iroquois Teachings as passed down through the oral tradition. U.S.A.: Xlibris Corporation.

Porter, T. (2006). Kanatsiohareke Traditional Mohawk Indians return to their ancestral homeland. New York: Bowman Books.

Porter, T. (2004, October). Teachings presented at A conference in Akwesasne, Ontario called Celebration of Life.

Porter, T. (2008). October). Teaching presented at A symposium in Tyendinaga, Ontario hosted by the Justice Circle. First Nations Technical Institute.

Publication Manual of the American Psychological Association Fifth Edition. (2001). Washington:D.C. American Psychological Association.

Red Cedars Shelter. (2000). Tyendinaga Mohawk Territory's needs assessment: The legacy of the residential school system. Tyendinaga Mohawk Territory, Ontario.

Report of the Standing Committee on Public Accounts. (2009 March). Chapter 4, First Nations child and family services program - Indian and Northern Affairs Canada of the May 2008 Report of the Auditor General. Hon. Shawn Murphy, MP, Chair. 404h Parliament, $2^{\text {nd }}$ Session. House of Commons Canada. 
Richer, D. (1992). The ordeal of the Longhouse: The peoples of the Iroquois League in the era of European colonization. Chapel Hill \& London: University of North Carolina Press.

Rigney, L. (1999). Internationalization of an Indigenous anticolonial cultural critique of research methodologies. A guide to Indigenist research methodology and its principles. Journal of Native American Studies. Wicazo: SA

Rogers, B. (2001). A path of healing and wellness for native families. American Behavioral Scientist, 44,(9), 1512-1514.

Ross, R. (1996). Returning to the teachings. Toronto: Penguin Books Canada Ltd.

Royal Commission on Aboriginal Peoples (RCAP). (1996). Report of the Royal Commission on Aboriginal Peoples, Vol. 1 Looking Forward, Looking Back. Ottawa: Canada Communications Group.

Royal Commission on Aboriginal Peoples (RCAP). (1996). Report of the Royal Commission on Aboriginal Peoples, Vol.3 Gathering Strength. Ottawa: Canada Communications Group.

Sale, K. (1990). The conquest of paradise, Christopher and the Columbian Legacy, Alfred Knopf, New York.

Saunders, B. \& Houghton, M. (1996). Relapse revisited: A critique of current concepts and clinical practice in the management of alcohol problems. Addictive Behaviors. 21(6). 843-855.

Shennandoah, L. (1994). Forward taken from P. Wallace's The Iroquois book of life: White roots of peace. Santa Fe.: Clear Light Publishers

Shestowsky, B. (1991-1992). Traditional medicine and primary health care among Canadian Aboriginal people. A discussion paper with annotated bibliography. Prepared for the Indian and Inuit Nurses of Canada.

Sheppard, M. (2002). Mental health and social justice: Gender, race and psychological consequences of unfairness. British Journal of social Work, 32, 779-797.

Sheridan, J. \& Longboat, R. (2006). The Haudenosaunee imagination and the ecology of the sacred, Space and Culture, 9(4), 365-381.

Shimony, A.A. (1994). Conservatism among the Iroquois at the Six Nations Reserve. (Laurence M. Hauptman, Ed.). New York: Syracuse University Press.

Simonelli, R. (1997, Spring). Use the good mind; an interview with Freida Jacques. American Indian Science and Engineering Society; 12(2) pp. 46-49. 
Soloman, A. (1994, October). Elder speaks on family violence. Conversations, Za-Geh-Do-Win Clearing House. Naughton, Ontario: Manotsaywin Nanotoojig Inc.

Stamm, B.H., Stamm IV, H.E., Hudnall, A.C., \& Higson-Smith, (2003). Considering a theory of cultural trauma and loss. Journal of Loss and Trauma, 9, 89-111.

Struthers, R., Eschiti, V., \& Patchell, B. (2004). Traditional indigenous healing: Part I. Complementary Therapies in Nursing \& Midwifery, 10, 141-149.

Swamp, J., Porter, T., Thompson, T., Hill, L., Burning, G. (2007). Indigenous approaches to restorative justice. First Nations Technical Institute. Tyendinaga, Ontario.

Tehanetorens. (1972). Iroquois reprints; Wampum belts. Six Nations Indian Museum: Onhiota, N.Y.

The Aboriginal Healing Foundation Research Series. (2008). From truth to reconciliation; Transforming the legacy of Residential Schools. Aboriginal Healing Foundation: Ottawa.

The Aboriginal Healing Foundation Research Series. (2003). Mental health profiles for a sample of British Columbia's Aboriginal survivors of the Canadian residential school system. Aboriginal Healing Foundation: Ottawa

Thompson, T., Porter, T., Swamp, J., Hay, L., Hill, J., \& Burning, G. (2007, November). Indigenous approaches to restorative justice. In M.A. Spencer (Coordinator), Symposium conducted at the Community Centre by First Nations Technical Institute, Tyendinaga Mohawk Territory, Ontario.

Thoms, M. (2007). Leading an extraordinary life: Wise practices for an HIV prevention campaign with Two Spirited men. (Report prepared for Two-Spirited People of the First Nations. Torongo: Watershed Writing \& Research).

Tobe, L. (2000). There is no word for feminism in my language. Wicazo Sa Review. 15(2), $103-$ 110.

Trask, H.K. (1993). From a native daughter. Common Courage Press, Maine, p. 7.

Tuhiwai Smith, L. (1999). Imperialism, history, writing and theory. Decolonizing methodologies: Research and Indigenous peoples. (pp. 19-41). London: Zed Books.

Tuhiwai Smith, L. (2000). On tricky ground - Researching the native in the age of uncertainly. In N.K. Denzin \& Y. S. Lincoln (Eds.), Handbook of qualitative research $\left(2^{\text {nd }}\right.$ ed. pp.85-107). Thousand Oakes, CA:Sage. 
Tyendinaga Mohawk Territory 1784- Mohawks of the Bay of Quinte, Kenhteke Kanienkeha. (2009). Retrieved from website http://www.mbq-tmt.org/ on 23/01/2009.

Van der Kolk, B. \& Van der Hart, O. (1995). The intrusive past: The flexibility of memory and the engraving of trauma. In Cathy Caruth (Ed.) Trauma: Explorations in Memory. Baltimore: The Johns Hopkins University Press.

Wagler-Martin. W. (2007). Listening to our stillness: Giving voice to our spirituality (Spirituality and clinical practice). (pp.135-142). In J. Coates, J.R. Graham \& B. Swartzentruber (Eds.), Spirituality and social work selected Canadian readings. Toronto: Canadian Scholars' Press Inc.

Waldram, J. (2008). Aboriginal healing in Canada: Studies in therapeutic meaning and practice. Prepared for National Network for Aboriginal Mental Health Research in partnership with Aboriginal Healing Foundation. The Aboriginal Healing Foundation Research Series. : Ottawa. Pp. 1-8.

Waldrum, J. (2004). Revenge of the windigo: The construction of the mind and mental health of the North American Aboriginal Peoples. Toronto: University of Toronto Press.

Walker, S., Eketon, A. \& Gibbs, A. (2006). An exploration of Kauppa Maori research, its principles, process and applications. International Journal Social Research Methodology. 9(4) 331-334.

Wallace, A.F.C. (1958). Dreams and the wishes of the soul: A type of psychoanalytic theory among the seventeenth century Iroquois. American Anthropologist, New Series, 60, 234-248.

Wallace, P. (1946). The Iroquois book of Iife; White roots of peace. Philadelphia: University of Pennsylvania Press.

Walton, M., Blow, F. \& Booth, B. (2000). A comparison of substance abuse patients' and counselors' perceptions of relapse risk: Relationship to actual relapse. Journal of Substance Abuse Treatment. 19. 161-169.

Warry, W. (2007). Being Aboriginal: Identity in ending denial: Understanding Aboriginal issues. (pp. 99-110). Toronto: Broadview Press.

Weaver, H.N. (2001). Indigenous Identity; What is it, and who really has it? American Indian Quarterly, 25(2), 240-255.

Wesley-Esquimaux, C. (2007, November).Inside looking out, outside looking in. First Peoples child and Family Review, 3(3/4), 62-71. 
Wesley-Esquimaux, C. (2007, November). The Impacts of historic trauma and intergenerational grief on Indigenous populations. Presented at the conference entitled Leaders for change; Aboriginal mental health and wellness conference, Toronto, Ontario.

Wesley-Esquimaux, C. \& Smoleswki, M. (2004). Historic trauma and Aboriginal healing. Ottawa: Aboriginal Healing Foundation.

Whitbeck, L.B., Adams, G.W., Hoyt, D.R., \& Chen, X. (2004). Conceptualizing and measuring historical trauma among American Indian people. American Journal of Community Psychology, 33(3/4), 119-130.

Widdowson, F. \& Howard, A. (2008). Disrobing the Aboriginal industry: The deception of Aboriginal cultural preservation. Kingston: McGill/Queen's Publishers.

Williams, R. (1998). Cultural safety - What does it mean for our work practice? Faculty of Aboriginal \& Torres Strait Islander Studies. Northern Territory University. Document retrieved from Http://www.ruralhealth.utas.edu.au/indigenous-health/RevisedCulturalSafetyPaper-pha.pdf. Darwin, NT, 0909.

Zlordre, N. (2008). Certificate in trauma counselling for front-line workers. At the Trauma \& Resiliency Centre. Hincks-Dellcrest Centre. Toronto: Canada. 